Check for updates

Cite this: RSC Adv., 2021, 11, 5958

Received 4th December 2020

Accepted 15th January 2021

DOI: 10.1039/dOra10229f

rsc.li/rsc-advances

\section{Review on carbonaceous materials and metal composites in deformable electrodes for flexible lithium-ion batteries}

\author{
Jahidul Islam, ${ }^{\text {a }}$ Faisal I. Chowdhury, (D) *a Join Uddin, (DD ${ }^{\mathrm{b}}$ Rifat Amin (D) ${ }^{\mathrm{b}}$ \\ and Jamal Uddin (iD ${ }^{c}$
}

\begin{abstract}
With the rapid propagation of flexible electronic devices, flexible lithium-ion batteries (FLIBs) are emerging as the most promising energy supplier among all of the energy storage devices owing to their high energy and power densities with good cycling stability. As a key component of FLIBs, to date, researchers have tried to develop newly designed high-performance electrochemically and mechanically stable pliable electrodes. To synthesize better quality flexible electrodes, based on high conductivity and mechanical strength of carbonaceous materials and metals, several research studies have been conducted. Despite both materials-based electrodes demonstrating excellent electrochemical and mechanical performances in the laboratory experimental process, they cannot meet the expected demands of stable flexible electrodes with high energy density. After all, various significant issues associated with them need to be overcome, for instance, poor electrochemical performance, the rapid decay of the electrode architecture during deformation, and complicated as well as costly production processes thus limiting their expansive applications. Herein, the recent progression in the exploration of carbonaceous materials and metals based flexible electrode materials are summarized and discussed, with special focus on determining their relative electrochemical performance and structural stability based on recent advancement. Major factors for the future advancement of FLIBs in this field are also discussed.
\end{abstract}

\section{Introduction}

The emergence and instantaneous increase of compact wearable electronic appliances, pliable smartcards, wireless sensors, electronic skin, flexible smartphones, roll-up displays, portable and implantable medical apparatus, etc. are receiving enormous attention in the field of flexible energy storage devices. ${ }^{1-5}$ The most typical challenge that is impeding the pragmatic implementation of flexible devices is the attainability of reliable and flexible energy sources with a high rate performance, desirable energy density, and long cycling stability. To be applicable, these electronic systems seek a flexible, small, and lightweight energy storage device that is robust under folding, twisting, bending, stretching, and compressing flexions without compromising their performance and functions. Among all the flexible energy storage systems, FLIBs are highly promising due to their greater power and energy density, longer cycle life, and environmental compatibility. ${ }^{5-7}$

Generally, almost all types of electrodes require conductive materials for the continuous electron flow through the electrodes

${ }^{a}$ Department of Chemistry, University of Chittagong, Chittagong 4331, Bangladesh. E-mail:faisal@cu.ac.bd; jahid.cu.ctg@gmail.com

${ }^{b}$ Department of Physics, University of Chittagong, Chittagong 4331, Bangladesh

${ }^{c}$ Center for Nanotechnology, Department of Natural Sciences, Coppin State University, Maryland, USA and maintaining the connection with the outer circuit. Over the past decade, carbonaceous materials (CMs) and metals have attracted researchers' attention due to their abundant sources, high conductivity, structural stability, and suitable mechanical strength. ${ }^{8-10}$ Also, CMs have a large specific surface area, a low rate of resistance rising, and greater energy density with good structural stability after mechanical flexion, and metals excellent electrical conductivity.

Typically, flexible electrodes still stay backward compared with their rigid analogues in terms of electrochemical performance. Moreover, under outer pressure and after long term electrochemical cycling, battery components especially electrode materials undergo permanent morphological distortions such as crack formation, delamination of active materials, or corrosion of conductive current collectors, which can severely affect the innate structure of the electrode materials along with electrolyte/electrode transportation. ${ }^{\mathbf{1 1 - 1 3}}$ Moreover, the challenges associated with CMs based flexible electrodes are low specific capacity, costly, not-enough energy density, aggregation of carbon nonmaterial. ${ }^{14}$ Metals undergo fast crack formation, corrosion, poor adhesion with active materials, overweight, low energy, and power densities. ${ }^{\mathbf{1 5}, \mathbf{1 6}}$ Additionally, challenges along with both materials based pliable current collectors are achieving excellent mechanical characteristics such as roughened surface, low density, and tunable thickness. ${ }^{17}$ Therefore, an attempt to morphological modifying of conductive materials 
and active particles can help to overcome some of these impediments to attaining some degrees of improved flexibility and electrochemical performance. ${ }^{18}$

In this review, we provide a general overview of CMs and metals based flexible electrodes for FLIBs. Also, based on recent works, we tried to find out their relative electrochemical and mechanical performances. Moreover, perspectives for upcoming advancement in this field are also provided.

\section{Carbonaceous materials supported flexible electrodes}

\subsection{Carbon nanotube (CNT) supported electrodes}

Recently, CNT and CNT-based composites draw great attention to use as electrode materials for flexible LIBs. Owing to excellent mechanical stiffness (Young's modulus of SWCNT and MWCNT are $1 \mathrm{TPa}$ and $0.9 \mathrm{TPa}$, respectively), ${ }^{19,20}$ remarkable mechanical resiliency, good current carrying capacity and electrical conductivity, $^{21}$ high theoretical capacity, good chemical stability, and improved electrochemical performance than metal current collectors. ${ }^{16}$ Thus, CNT has become the most attractive material for constructing flexible electrodes for LIBs. A variety of procedures have been designed to fabricate CNTbased flexible composite electrodes for LIBs (Fig. 1 and Table 1), including chemical vapor deposition (CVD), ${ }^{22}$ vacuum filtration, ${ }^{23}$ hydrothermal method, ${ }^{24}$ solvothermal, ${ }^{25}$ electrodeposition, ${ }^{26}$ and drop-casting. ${ }^{27}$ For example, by modifying a generally used CVD technique, CNTs are grown into the graphitic carbon layer (CL) that can be served as a flexible and free-standing anode material for LIBs. ${ }^{28}$ The 3D conductive network of CNT synergistically combined with the conductive carbon layer and provides stable electrical conductivity. The
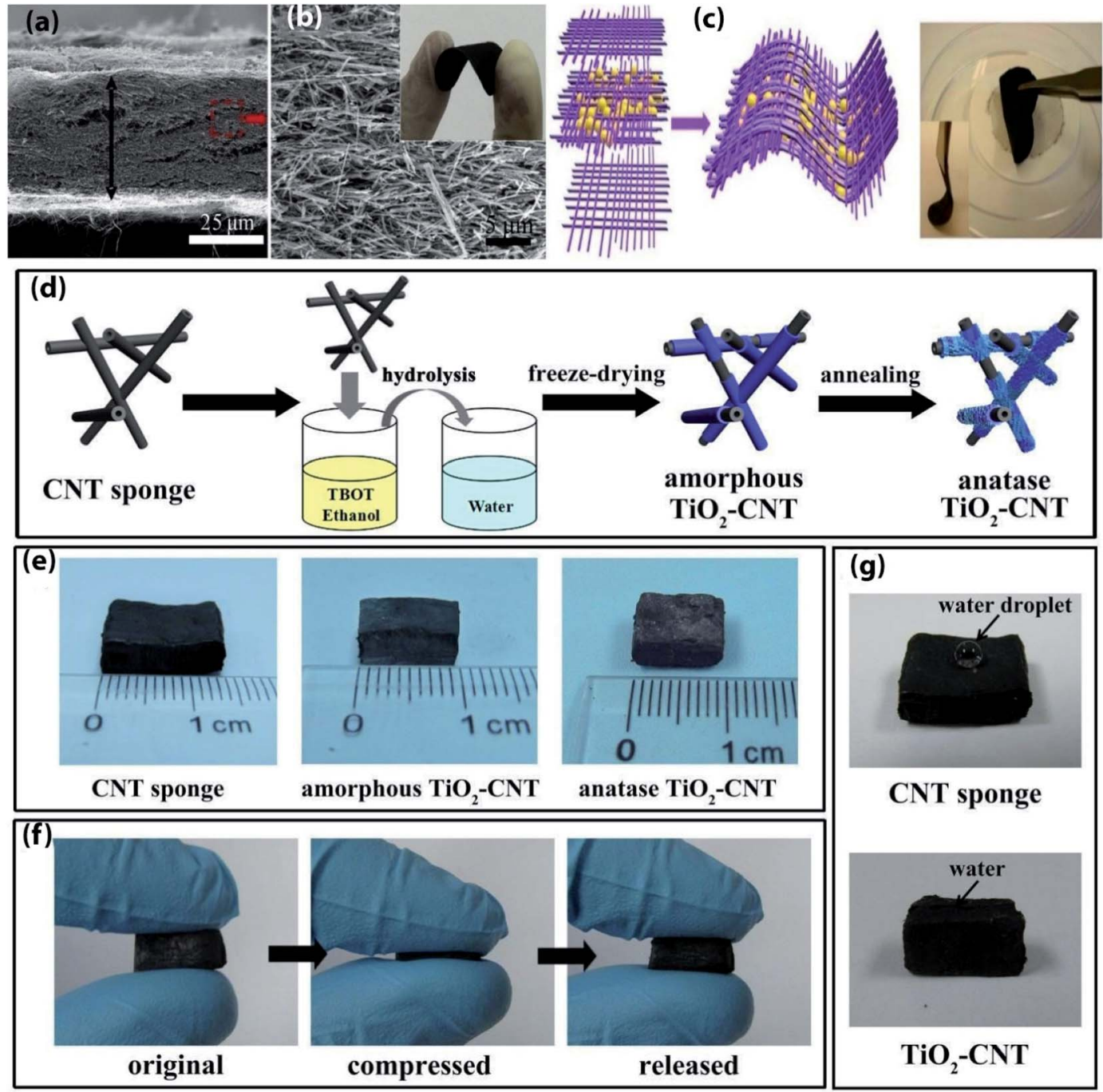

Fig. 1 (a) Side-view SEM image of the $\mathrm{V}_{2} \mathrm{O}_{3} \mathrm{aC}$ NWs film, (b) high-resolution side-view SEM image of the $\mathrm{V}_{2} \mathrm{O}_{3}\left(\mathrm{aC} \mathrm{NWs}_{\mathrm{S}}\right.$ film and corresponding digital picture. ( $a$ and b) Reprinted from ref. 24. (c) Schematic illustration of the fabrication process of the LiNi ${ }_{0.5} \mathrm{Mn}_{1.5} \mathrm{O}_{4} / \mathrm{MWCNT}$ electrodes and digital photo of the $\mathrm{LiNi}_{0.5} \mathrm{Mn}_{1.5} \mathrm{O}_{4} / \mathrm{MWCNT}$ network film to show the flexibility. Reprinted from ref. 45. (d) schematic of synthetic process of amorphous and anatase $\mathrm{TiO}_{2}-\mathrm{CNT}$ sponges, (e) photos of an original bulk CNT sponge, an amorphous and an anatase TiO 2 - CNT sponge, (f) compression and recovery process of an anatase $\mathrm{TiO}_{2}-\mathrm{CNT}$ sponge, $(\mathrm{g})$ water droplet staying on the surface of a CNT sponge and soaked into a $\mathrm{TiO}_{2}-\mathrm{CNT}$ sponge. (d-g) Reprinted from ref. 42. 
Table 1 CNT based flexible electrodes

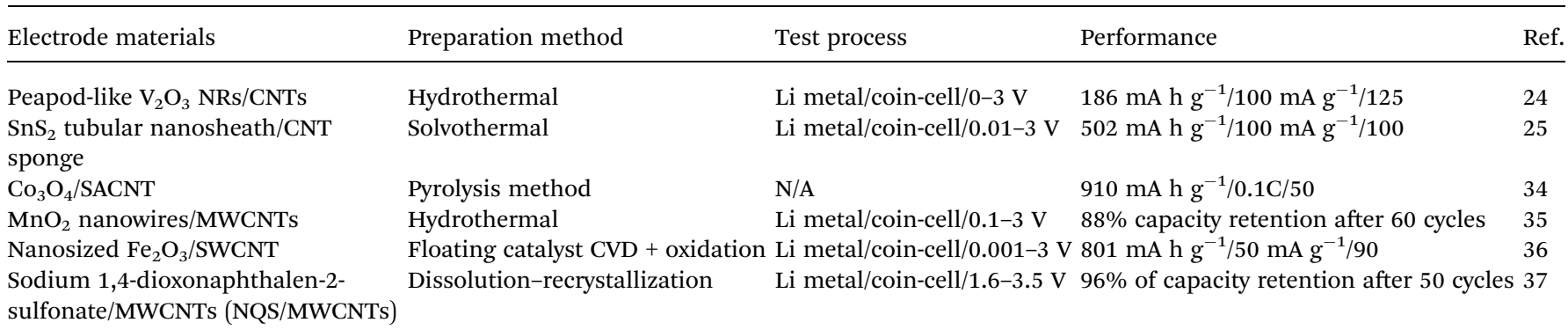

film showed no observable degradation even after the film rolled around a glass tube. Thus, the anode maintained a reversible capacity of $572 \mathrm{~mA} \mathrm{~h} \mathrm{~g}^{-1}$ after 100 cycles at a current density of $0.2 \mathrm{~mA} \mathrm{~cm}^{-2}$. Core-sheath structured nitrogen-doped CNT (NCNT) film anode materials are synthesized via CVD method using acetonitrile as a precursor of nitrogen and carbon under a high temperature of $1060{ }^{\circ} \mathrm{C}$, which has been demonstrated improved mechanical performance and capacity than bare CNT film with a superior electrical conductivity of $410 \mathrm{~S} \mathrm{~cm}^{-1} \cdot{ }^{29}$ As a result, $\mathrm{N}$-CNT films delivered a high capacity of $390 \mathrm{~mA} \mathrm{~h} \mathrm{~g}{ }^{-1}$ at a high rate of $4 \mathrm{C}$ and retained $320 \mathrm{~mA} \mathrm{~h} \mathrm{~g}^{-1}$ after 400 cycles. Also, the electrical resistance of this film is almost the same after 500 times of bending. Light-weight and self-standing pyridine modified boron-doped CNT (Py-B-CNT) film anode materials for flexible LIBs are synthesized through the floating catalyst chemical vapor deposition (FCCVD) method. ${ }^{30}$ The film can tolerate up to $50 \%$ strain without any fracture and can recover its initial state. Moreover, the anode exhibited a high initial discharge capacity (1182 $\mathrm{mA} \mathrm{h} \mathrm{g}^{-1}$ at $\left.100 \mathrm{~mA} \mathrm{~g}^{-1}\right)$, good rate performance (167 $\mathrm{mA} \mathrm{h} \mathrm{g}^{-1}$ at $2 \mathrm{~A} \mathrm{~g}^{-1}$ ), and excellent cyclic stability (548 $\mathrm{mA} \mathrm{h} \mathrm{g}^{-1}$ at $100 \mathrm{~mA} \mathrm{~g}^{-1}$ after 300 cycles). Freestanding Si nanoparticles/MWCNT (weight ratio $3: 2$ ) composite papers (high mass loading of $3 \mathrm{mg} \mathrm{cm}^{-2}$ ) are prepared by ultrasonication followed by filtration under positive pressure that can be employed as a flexible anode for high energy LIBs. ${ }^{31}$ The 3D network of MWCNT ensures high electrical conductivity and suppresses the volume change of $\mathrm{Si}$ particles. So, the composite anode maintained a high discharge capacity (2299 $\mathrm{mA} \mathrm{h} \mathrm{g}{ }^{-1}$ at $100 \mathrm{~mA} \mathrm{~g}^{-1}$ ), better rate capability (912 $\mathrm{mA} \mathrm{h} \mathrm{g}^{-1}$ at $1000 \mathrm{~mA} \mathrm{~g}^{-1}$ ), and good cycling performance (1300 $\mathrm{mA} \mathrm{h} \mathrm{g}^{-1}$ at $100 \mathrm{~mA} \mathrm{~g}^{-1}$ after 100 cycles). Si particles incorporated with CNTs (mass loading of about $1.5 \mathrm{mg} \mathrm{cm}^{-2}$ ) are also produced as ultrathin, paper-like, and free-standing anodes for flexible LIBs with high volumetric capacity via conformal electrodeposition of Si thin layer on CNTs films for 6 hours. ${ }^{32}$ The porous structure of CNTs film accommodating volume expansion of $\mathrm{Si}$ improving electrolyte infiltration simultaneously. The composite film shows the highest volumetric capacity of $\sim 1400 \mathrm{~mA} \mathrm{~h} \mathrm{~cm} \mathrm{~cm}^{-3}$ at a current density of $200 \mathrm{~mA} \mathrm{~g}^{-1}$ and that can be retained $567 \mathrm{~mA} \mathrm{~h} \mathrm{~cm}^{-3}$ at $800 \mathrm{~mA} \mathrm{~g}^{-1}$ after 50 cycles. One-step floating catalyst chemical vapor deposition (FCCVD) process in a vertical tube furnace at $1150{ }^{\circ} \mathrm{C}$ has been carried out to found free-standing and flexible $\mathrm{SiO}_{x} /$ few walled CNT composite film anodes for high capacity flexible LIBs. ${ }^{33}$ The synergistic effect between high capacity $\mathrm{SiO}_{x}$ and conductive CNT enables excellent flexibility and electrochemical performances such as exhibit a high reversible capacity (1600 $\mathrm{mA} \mathrm{h} \mathrm{g}^{-1}$ at $30 \mathrm{~mA} \mathrm{~g}^{-1}$ ) as well as outstanding rate performance with cycling retention $\left(400 \mathrm{~mA} \mathrm{~h} \mathrm{~g}^{-1}\right.$ at $3 \mathrm{~A} \mathrm{~g}^{-1}$ after 500 cycles). This composite film can withstand extreme structural distortion such as bent, fold, rolled, and even complex origami form without suffering from any configurational failure, makes it an effective electrode in next-generation flexible LIBs.

Thin and flexible 3D hierarchical core-shell $\mathrm{SnO}_{2} @ a-S i / C N T$ hybrid paper (mass loading of $5.9 \mathrm{mg} \mathrm{cm}^{-2}$ ) anodes are fabricated via two-step process; first, $\mathrm{SnO}_{2}$ nanowires (NWs) were grown on CNT paper by $\mathrm{Au}$ catalyzed thermal evaporation, subsequently thin layer of $\mathrm{Si}$ was deposited on $\mathrm{SnO}_{2} \mathrm{NWs}$ by using radio frequency plasma enhanced chemical vapor deposition (RF-PECVD) technique. ${ }^{38}$ In this unique core-shell nanostructure, CNT provides high conductivity and mechanical flexibility, Si served as a high capacity active material, and $\mathrm{SnO}_{2}$ NWs prevent Si layer from pulverization, which leads to high initial discharge capacity (3020 $\mathrm{mA} \mathrm{h} \mathrm{g}^{-1}$ at $250 \mathrm{~mA} \mathrm{~g}^{-1}$ ), large

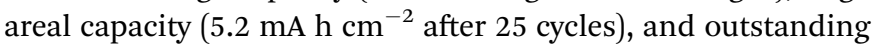
volumetric capacity ( $1750 \mathrm{~mA} \mathrm{~cm} \mathrm{~cm}^{-3}$ after 25 cycles). 2D layerbased $1 \mathrm{~T}-\mathrm{MoSe}_{2} / \mathrm{SWCNTs}$ hybridized films are prepared as high-performance anodes for flexible LIBs by solvothermal method..$^{39}$ The composite film possesses excellent mechanical characteristics such as, the maximum extension of $22.3 \%$ and breaking strength of $34 \mathrm{MPa}$ of the electrodes. Besides, Mo-O-C bond between $\mathrm{MoSe}_{2}$ and SWCNT enables great structural stability and stimulates high ions/electrons transportation, which leads to high discharge capacity $\left(1495 \mathrm{~mA} \mathrm{~h} \mathrm{~g}{ }^{-1}\right.$ at $\left.60 \mathrm{~mA} \mathrm{~g}^{-1}\right)$, excellent rate performance $\left(630 \mathrm{~mA} \mathrm{~h} \mathrm{~g} \mathrm{~g}^{-1}\right.$ at $\left.3000 \mathrm{~mA} \mathrm{~g}^{-1}\right)$ as well as good cycling durability $\left(971 \mathrm{~mA} \mathrm{~h} \mathrm{~g}^{-1}\right.$ at $300 \mathrm{~mA} \mathrm{~g}^{-1}$ after 100 cycles). A combination method based on ethylene glycol mediated solvothermal method and vacuum filtration has been proposed to prepared $\mathrm{Sb}_{2} \mathrm{~S}_{3}$ nanorods (NRs)/ MWCNT free-standing and flexible anodes for LIBs. ${ }^{40}$ The composite anode delivered a high discharge capacity of $930 \mathrm{~mA} \mathrm{~h} \mathrm{~g}^{-1}$ at a current density of $200 \mathrm{~mA} \mathrm{~g}^{-1}$ and after 100 cycles, at a current rate of $200 \mathrm{~mA} \mathrm{~g}^{-1}$ a capacity was stabilized at $443 \mathrm{~mA} \mathrm{~h} \mathrm{~g}{ }^{-1}$. NiS nanoparticles electrodeposited on CNT film was utilized in order to obtained NiS NPs/CNT paper-like high capacity flexible LIBs anode. ${ }^{26}$ The composite anode can tolerate the mechanical stress without any structural failure 
when the film is bent at nearly a $180^{\circ}$ angle. This paper-like composite anode delivered a high specific capacity of $\sim 845 \mathrm{~mA} \mathrm{~h} \mathrm{~g}^{-1}$ at $60 \mathrm{~mA} \mathrm{~g}^{-1}$ and retained $\sim 644 \mathrm{~mA} \mathrm{~h} \mathrm{~g}^{-1}$ after 100 cycles at $300 \mathrm{~mA} \mathrm{~g}^{-1}$ rate. 3D 'honeycomb-like' CNT/ transition metal oxides (TMOs) (i.e. $\mathrm{MnO}_{2}, \mathrm{NiO}, \mathrm{Fe}_{2} \mathrm{O}_{3}$, and $\mathrm{Co}_{3} \mathrm{O}_{4}$ ) porous microstructured sponges as composite anodes were fabricated via freeze-drying and subsequent thermal calcination at $250{ }^{\circ} \mathrm{C}$ for $5 \mathrm{~h}$ followed by mechanical pressing to decrease the thickness of sponges. ${ }^{41}$ Ultrahigh electrochemical performances can be attributed to the high porosity of electrodes, the large active surface area of CNT sponges, and more open spaces for volume expansion of active particles. Furthermore, a continuous CNT network in 3D architecture can effectively enhance the electron-transfer kinetics, which leads high reversible capacities with good rate performance, for instance, 1104, 1536, $1287 \mathrm{~mA} \mathrm{~h} \mathrm{~g}^{-1}$ of reversible capacities were delivered by $\mathrm{CNT} / \mathrm{NiO}, \mathrm{CNT} / \mathrm{Co}_{3} \mathrm{O}_{4}$, and $\mathrm{CNT} / \mathrm{MnO}_{2}$, respectively at the rate of $0.2 \mathrm{~A} \mathrm{~g}^{-1}$. On the other hand, CNT/TMO sponges can recover their initial state after releasing from $70 \%$ compressive strain, demonstrating their future demand in special deformable LIBs. A compressible anode, coaxial $\mathrm{TiO}_{2}$-CNT sponges were prepared by depositing $\mathrm{TiO}_{2}$ onto CVD grown CNT sponges via a simple in situ hydrolysis method, then freeze-drying followed by annealing at $500{ }^{\circ} \mathrm{C} .{ }^{42}$ The highly porous nature of this electrode helps to sufficient amount of electrolyte infiltration and buffer the volume change of $\mathrm{TiO}_{2}$, which leads to a high specific capacity of $234 \mathrm{~mA} \mathrm{~h} \mathrm{~g}^{-1}$ at $50 \mathrm{~mA} \mathrm{~g}^{-1}$, excellent rate performance (149 $\mathrm{mA} \mathrm{h} \mathrm{g}^{-1}$ at $2000 \mathrm{~mA} \mathrm{~h} \mathrm{~g}^{-1}$ ), and remarkable cycling stability ( $210 \mathrm{~mA} \mathrm{~h} \mathrm{~g}^{-1}$ at $100 \mathrm{~mA} \mathrm{~g}^{-1}$ at the $100^{\text {th }}$ cycles). Moreover, at $91 \%$ compressible strain, the anode can be able to sustain structural intactness after releasing from 10 times of volumetric compressed state. The in situ synthetic route using rhodanine acetic acid-pyrene (RAAP)-directed growth method has been adopted to prepare a self-weaving $\mathrm{CNT}^{-\mathrm{LiNbO}_{3}}$ nanoplates system, then decorated with polypyrrole (PPy) layer. ${ }^{43}$ Interwoven highly conductive and porous structure of SWCNT with additional conductive ppy coating synergistically enables high electrochemical kinetics and also helps to maintain structural integrity while retaining almost stable conductivity. Consequently, the electrode can maintain structural integrity with stable conductivity even after 800 repeated bending cycles, and exhibits a high rate performance (175 $\mathrm{mA} \mathrm{h} \mathrm{g}^{-1}$ at $2 \mathrm{~A} \mathrm{~g}^{-1}$ ) as well as outstanding cycling durability ( $\sim 220 \mathrm{~mA} \mathrm{~h} \mathrm{~g}^{-1}$ at $0.4 \mathrm{~A} \mathrm{~g}^{-1}$ after 500 cycles). $\mathrm{V}_{2} \mathrm{O}_{5}$ nanosheets encapsulated in hollow CNT via using electrospinning with CVD process formed nanocables-like structure which is further interwoven in a flexible free-standing and mechanically robust cathode films for high-performance LIBs. ${ }^{44}$ The cathode delivered a high reversible capacity of $224 \mathrm{~mA} \mathrm{~h} \mathrm{~g}^{-1}$ at $0.15 \mathrm{~A} \mathrm{~g}^{-1}$, surprising rate capability $\left(90 \mathrm{~mA} \mathrm{~h} \mathrm{~g}{ }^{-1}\right.$ at $\left.30 \mathrm{Ag}^{-1}\right)$, and retained $91.7 \%\left(211 \mathrm{~mA} \mathrm{~h} \mathrm{~g}^{-1}\right)$ capacity after 200 cycles at a current density of $0.15 \mathrm{~A} \mathrm{~g}^{-1}$. Light-weight, flexible, and high capacity $\mathrm{LiNi}_{0.5} \mathrm{Mn}_{1.5} \mathrm{O}_{4} / \mathrm{MWCNT}$ cathodes for high-power LIBs are synthesized by vacuum filtration, ${ }^{\mathbf{4 5}}$ which can retain $80 \%$ capacity at a high current density of up to $2800 \mathrm{~mA} \mathrm{~g}^{-1}$, and until 100 cycles the capacity remaining of $118 \mathrm{~mA} \mathrm{~h} \mathrm{~g}^{-1}$ at the rate of $1400 \mathrm{~mA} \mathrm{~g}^{-1}$. Impressively, these cathodes provide almost two times higher power density than that of a conventional one. An organic sulfur-linked carbonyl-based poly(2,5dihydroxyl-1,4-benzoquinoyl sulfide) (PDHBQS)/SWCNT have been proposed as high rate cathodes for flexible LIBs are prepared by vacuum filtration. ${ }^{46}$ This composite cathode exhibits an excellent rate performance of $75 \mathrm{~mA} \mathrm{~h} \mathrm{~g}{ }^{-1}$ at $5000 \mathrm{~mA} \mathrm{~g}^{-1}$ with retaining $89 \%$ of its initial capacity at a current density of $250 \mathrm{~mA} \mathrm{~g}^{-1}$ after 500 cycles. Moreover, a large area $\left(28 \mathrm{~cm}^{2}\right)$ flexible LIB based on this cathode and lithium foils anodes are assembled, which maintained $88 \%$ of its initial capacity even after 2000 repeated bending cycles while continuously illuminating 14 LEDs simultaneously. An acidassisted vacuum filtration method has been adopted to prepare perylene-3,4,9,10-tetracarboxylic diimide (PDI)/SWCNT cathodes for highly stable organic LIBs using $\mathrm{H}_{2} \mathrm{SO}_{4}$ as a solvent. ${ }^{47}$ The composite cathode only decays $0.014 \%$ capacity per cycle at $500 \mathrm{~mA} \mathrm{~g}^{-1}$ over 2000 cycles and also reserved $93 \mathrm{~mA} \mathrm{~h} \mathrm{~g}^{-1}$ at a high current density of $1000 \mathrm{~mA} \mathrm{~g}^{-1}$. Sandwichlike $\mathrm{Li}_{2} \mathrm{ZnTi}_{3} \mathrm{O}_{8} @ M W C N T$ high rate anodes for flexible LIBs are prepared by vacuum filtration with top and down layer consist of MWCNT. ${ }^{48}$ MWCNT formed a 3D porous and conductive network, which enables stereoscopic electron transportation and facilitate more electrolyte infiltration. As a result, the composite anodes delivered a high reversible capacity at a very current rate of $95.2 \mathrm{~mA} \mathrm{~h} \mathrm{~g}^{-1}$ at $7000 \mathrm{~mA} \mathrm{~g}^{-1}$ after 1000 cycles, demonstrating its great promise to developed flexible and high energy LIBs.

\subsection{Carbon nanofibers (CNFs)-supported electrodes}

Owing to the large surface area, sufficient electrical conductivity, excellent mechanical strength, 1D configuration with lightweight properties of CNFs have been employed to flexible electrode fabrication. ${ }^{\mathbf{4 9}, 50}$ Typically, polyacrylonitrile (PAN) is used as the precursor of CNFs. Generally, one of the most efficient synthesizing techniques involving three steps: electrospinning, stabilization in air, and subsequently hightemperature carbonization has been a widely applied strategy for producing CNFs. ${ }^{51}$ As pristine CNFs demonstrated poor electrochemical performance, in order to improve electrochemical performance several structural modified CNFs and CNFs based composite electrodes have been explored (Fig. 2 and Table 2). For instance, Self-supported and highly porous CNFs (HPCNFs) as flexible anodes for high-performance LIBs are fabricated via electrospinning followed by a post-two-step carbonization process, during carbonization of PAN at $1000{ }^{\circ} \mathrm{C}$ under Ar atmosphere, a certain amount of air introduced in Ar flow so that CNFs can partially burnt-off and produced a highly porous structure with numerous micropores and mesopores. ${ }^{52}$ The highly porous and 3D interconnected structure of this anode facilitates fast ion diffusion while improving flexibility. As a result, the flexible anode exhibited high reversible capacity $\left(1780 \mathrm{~mA} \mathrm{~h} \mathrm{~g}^{-1}\right.$ at $50 \mathrm{~mA} \mathrm{~g}^{-1}$ after 40 cycles), superior rate performance (200 $\mathrm{mA} \mathrm{h} \mathrm{g} \mathrm{g}^{-1}$ at $\left.25 \mathrm{~A} \mathrm{~g}^{-1}\right)$, and ultra long cycle life $\left(1550 \mathrm{~mA} \mathrm{~h} \mathrm{~g}^{-1}\right.$ at $500 \mathrm{~mA} \mathrm{~g}^{-1}$ after 600 cycles). Ge NPs encapsulated CNFs have been fabricated by electrospinning then stabilized in the air followed by 

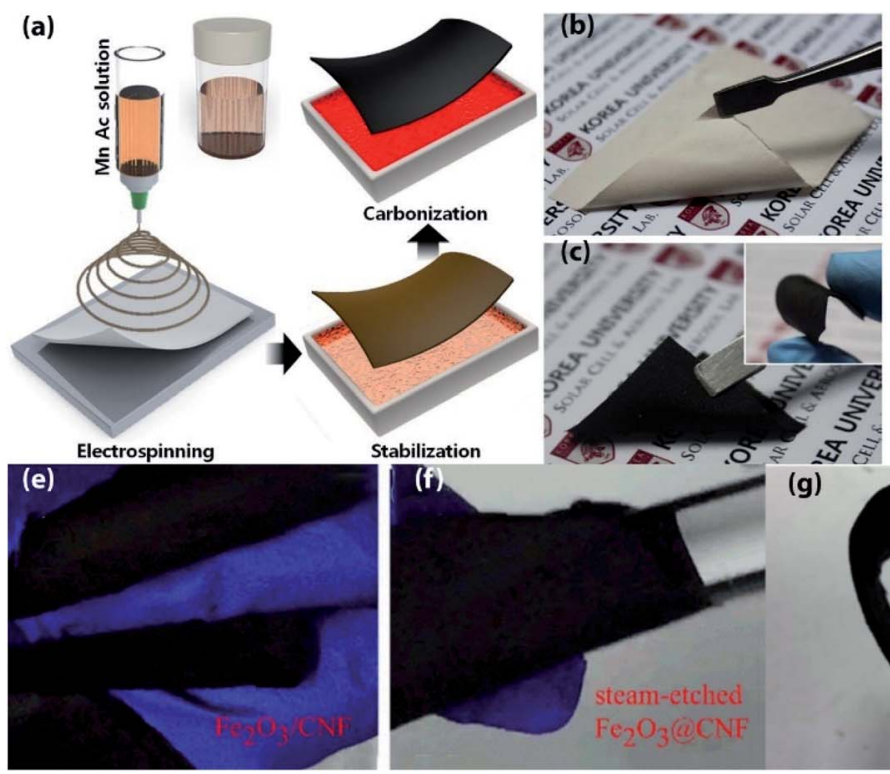

(d)

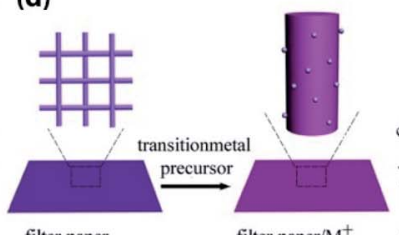

filter paper

- $\mathrm{M}^{+}(\mathrm{M}: \mathrm{Fe}, \mathrm{Mo}, \mathrm{Sn}$ or $\mathrm{V})$ TMOs I water steam
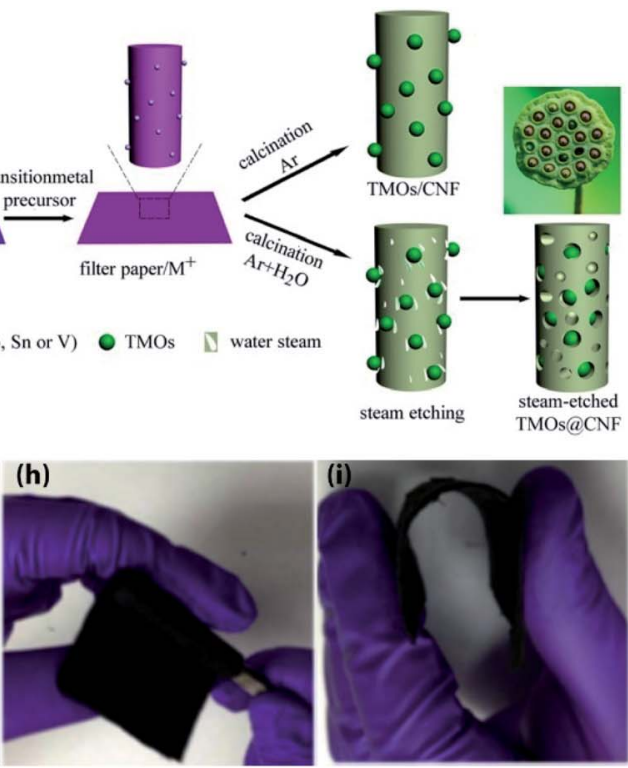

Fig. 2 (a) Electrospinning process of preparing CNFs mat, (b) photographs of as-deposited pale orange-colored mat, (c) carbonized freestanding mat with good flexibility. (a-c) Reprinted from ref. 60. (d) Schematic diagram of the fabrication processes of steam-etched TMOs@CNF and TMOs/CNF, (e) broken photographs of $\mathrm{Fe}_{2} \mathrm{O}_{3} / C N F$ after bending, (f) photographs of steam-etched $\mathrm{Fe}_{2} \mathrm{O}_{3} \mathrm{OCNF}$ wrapped around the glass rod. (d-f) Reprinted from ref. 79. (g-i) Photographs of a flexible $\mathrm{Si} / \mathrm{SiO}_{2} / \mathrm{C}$ nanofiber mat. Free-standing, flexible $\mathrm{Si} / \mathrm{SiO}_{2} / \mathrm{C}$ nanofibers can be folded without any structural damage. Reprinted from ref. 62.

carbonization at $6500^{\circ} \mathrm{C}$ under $\mathrm{Ar} / \mathrm{H}_{2}$ atmosphere, which can be served as self-supported flexible anodes for high-performance LIBs. $^{53}$ 3D porous interconnected structure of this hybrid anode facilitates high electrons and ions transportation and enhances electrolyte access toward active materials, which leads to high reversible capacity $\left(\sim 1420 \mathrm{~mA} \mathrm{~h} \mathrm{~g}^{-1}\right.$ at $0.15 \mathrm{C}$ after 100 cycles), and superior cycle life ( $829 \mathrm{~mA} \mathrm{~h} \mathrm{~g}^{-1}$ after 2500 cycles at 1C). 3D flexible core (Si)-shell $\left(\mathrm{Si}_{3} \mathrm{~N}_{4}\right) \quad\left(\mathrm{Si} @ \mathrm{Si}_{3} \mathrm{~N}_{4}\right) / \mathrm{CNFs}$ composite anodes are prepared by electrospinning subsequently stabilized in the air followed by heat treatment at $1200{ }^{\circ} \mathrm{C}$ for $3 \mathrm{~h}$ under $\mathrm{N}_{2}$ atmosphere..$^{54} \mathrm{In}$ this $3 \mathrm{D}$ configuration, highly conductive CNFs are cross-linked with each other and created numerous void spaces which facilitate fast Li-ion transfer and buffer the volume changes during cycling, results in high discharge capacity $\left(661 \mathrm{~mA} \mathrm{~h} \mathrm{~g}{ }^{-1}\right.$ at $\left.10 \mathrm{~A} \mathrm{~g}^{-1}\right)$, outstanding rate performance $\left(145 \mathrm{~mA} \mathrm{~h} \mathrm{~g}^{-1}\right.$ at $\left.80 \mathrm{~A} \mathrm{~g}^{-1}\right)$ and ultra long cycle life ( $369 \mathrm{~mA} \mathrm{~h} \mathrm{~g}^{-1}$ at $10 \mathrm{~A} \mathrm{~g}^{-1}$ after 2000 cycles). Free-standing $\mathrm{Fe}_{2} \mathrm{O}_{3}-\mathrm{SnO}_{x} / \mathrm{CNFs} \quad(\mathrm{Fe}: \mathrm{Sn}$ ratio of $3: 1$ ) composite anodes are prepared by electrospinning, then stabilized in the air followed by annealing at $700{ }^{\circ} \mathrm{C}$ for $2 \mathrm{~h}$ under $\mathrm{Ar}$ atmosphere,$^{55}$ in which CNFs are relaxing the volume expansion and shortening the Li-ion diffusion distance while $\mathrm{SnO}_{x}$ prevents the aggregation of $\mathrm{Fe}_{2} \mathrm{O}_{3}$. As a result, the composite anode delivered a high reversible capacity of $756 \mathrm{~mA} \mathrm{~h} \mathrm{~g}^{-1}$ after 55 cycles at $100 \mathrm{~mA} \mathrm{~g}^{-1}$. Flexible $\mathrm{TiO}_{2} / \mathrm{SiO}_{2} / \mathrm{CNFs}$ composite anodes are synthesized through one-spinneret electrospinning followed by calcination at $900{ }^{\circ} \mathrm{C} .{ }^{56} \mathrm{In}$ this architecture, $\mathrm{SiO}_{2}$ improves capacity and $\mathrm{TiO}_{2}$ helps to maintain structural integrity and carbon ensures high conductivity and mechanical flexibility. Thus, the composite anode delivers a high rate capability (115.5 $\mathrm{mA} \mathrm{h} \mathrm{g}^{-1}$ at $8 \mathrm{~A} \mathrm{~g}^{-1}$ ), and superior cycling stability (380.1 $\mathrm{mA} \mathrm{h} \mathrm{g}^{-1}$ at $200 \mathrm{~mA} \mathrm{~h} \mathrm{~g}^{-1}$ after 700 cycles). In situ assembly of 3D $\mathrm{MoS}_{2}$ nanoleaves/bacterial cellulose (BC) derived $\mathrm{CNF}$ composites are produced through hydrothermal reaction followed by carbonization at $350{ }^{\circ} \mathrm{C}$ for $1 \mathrm{~h}$ then increased to $800{ }^{\circ} \mathrm{C}$ for $1 \mathrm{~h}^{.57}$ In this $3 \mathrm{D}$ hierarchical architecture, CNFs formed interweaved porous structure which provides highly conductive channels for electrons and $\mathrm{Li}^{+}$diffusion, and $\mathrm{MoS}_{2}$ nanoleaves offer more active sites for $\mathrm{Li}^{+}$storage. Consequently, this composite anode exhibits a high discharge capacity (1313 $\mathrm{mA} \mathrm{h} \mathrm{g}^{-1}$ at $0.1 \mathrm{~A} \mathrm{~g}^{-1}$ ), and ultrahigh cycling durability (581 $\mathrm{mA} \mathrm{h} \mathrm{g}^{-1}$ after 1000 cycles even at a high rate of $1 \mathrm{~A} \mathrm{~g}^{-1}$ ). On account of, improve the capacity of $\mathrm{MoS}_{2}$ based electrode, a hierarchical self-supported core-shell $\mathrm{TiO}_{2}-\mathrm{MoS}_{2} /$ $\mathrm{CNF}$ mats as flexible anodes has been produced by using a combination of electrospinning, carbonization, and hydrothermal method.$^{58}$ So, the composite anode shows enhanced specific reversible capacity $\left(\sim 1460 \mathrm{~mA} \mathrm{~h} \mathrm{~g}^{-1}\right.$ at $\left.100 \mathrm{~mA} \mathrm{~g}^{-1}\right)$, better rate performance ( $928 \mathrm{~mA} \mathrm{~h} \mathrm{~g}^{-1}$ at $\left.2 \mathrm{~A} \mathrm{~g}^{-1}\right)$, and long-life cycle duration (1072 $\mathrm{mA} \mathrm{h} \mathrm{g}^{-1}$ over 1000 cycles at $1 \mathrm{~A} \mathrm{~g}^{-1}$ ), makes it a potential anode materials for the application in advanced flexible LIBs. A novel SnSe/CNFs membrane as a flexible anode has been successfully prepared by electrospinning and subsequent thermal annealing, which can tolerate bending stress when the bending angle is $180^{\circ} .^{71}$ The $3 \mathrm{D}$ porous and conductive structure is consisted of CNFs, which facilitates high electronic and ionic transportation, and lead to excellent rate performance (384 $\mathrm{mA} \mathrm{h} \mathrm{g}^{-1}$ at $4000 \mathrm{~mA} \mathrm{~g}^{-1}$ ), and superior cycle life ( $405 \mathrm{~mA} \mathrm{~h} \mathrm{~g}^{-1}$ at $1000 \mathrm{~mA} \mathrm{~g}^{-1}$ after 500 cycles). $\mathrm{Fe}_{3} \mathrm{O}_{4} / \mathrm{CNFs}$ as flexible anodes for LIBs are synthesized via using electrospinning, then stabilized in the air followed by heat treatment at $600{ }^{\circ} \mathrm{C}$ in $\mathrm{N}_{2}$ atmosphere, ${ }^{72}$ in which CNFs successfully buffer the volume expansion of active particles while providing a conducive and flexible scaffold for this composite electrode, 
results in better discharge capacity (1161 $\mathrm{mA} \mathrm{h} \mathrm{g}^{-1}$ at $0.5 \mathrm{~A} \mathrm{~g}^{-1}$ ), excellent cycling retention $\left(762 \mathrm{~mA} \mathrm{~h} \mathrm{~g}^{-1}\right.$ at $0.5 \mathrm{~A} \mathrm{~g}^{-1}$ and $611 \mathrm{~mA} \mathrm{~h} \mathrm{~g}^{-1}$ even at $1 \mathrm{~A} \mathrm{~g}^{-1}$, over 300 cycles). Flexible ultralong, aligned CNFs embedded with $\operatorname{In}_{2} \mathrm{O}_{3}$ nanocrystals has been prepared by electrospinning, subsequent air stabilization followed by calcined at $550{ }^{\circ} \mathrm{C}$ for $5 \mathrm{~h}$ under $\mathrm{N}_{2}$ atmosphere, which can be used as a flexible anode material for thin and high-performance LIBs. ${ }^{73}$ Ultrafine $\operatorname{In}_{2} \mathrm{O}_{3}$ particles can shorten the diffusion distance of Li-ion, and encapsulation of $\operatorname{In}_{2} \mathrm{O}_{3}$ in CNFs matrix helps to direct exposure of active particles in the electrolyte and formed a stable and uniform SEI layer and also reduce pulverization lead to a high electrochemical performance and cycling stability. As a result, the composite anode demonstrated a high discharge capacity of $282.2 \mathrm{~mA} \mathrm{~h} \mathrm{~g}^{-1}$ at $1000 \mathrm{~mA} \mathrm{~g}^{-1}$ after 1000 cycles, and a capacity of $183.7 \mathrm{~mA} \mathrm{~h} \mathrm{~g}^{-1}$ at a high current rate of $10000 \mathrm{~mA} \mathrm{~g}^{-1}$ even after 2900 cycles. Since, the improvement in conductivity, flexibility, and $\mathrm{Li}^{+}$ storage sites of CNFs, nitrogen doping has been proposed as an effective strategy. For instance, polyimide (PI) derived N-CNFs membranes as flexible anode materials for high-performance LIBs are prepared by electrospinning, then imidization, and subsequent carbonization at various temperatures $550-950{ }^{\circ} \mathrm{C}$ for $0.5-10 \mathrm{~h} .{ }^{74}$ The film which carbonized at $650{ }^{\circ} \mathrm{C}$ for $3 \mathrm{~h}$ demonstrated the highest reversible specific capacity $\left(695 \mathrm{~mA} \mathrm{~h} \mathrm{~g}^{-1}\right.$ at $0.1 \mathrm{~A} \mathrm{~g}^{-1}$ ), and better cycling stability $\left(245 \mathrm{~mA} \mathrm{~h} \mathrm{~g}^{-1}\right.$ after 300 cycles even at $1.5 \mathrm{~A} \mathrm{~g}^{-1}$ ). Robust $\mathrm{N}$ doped CNF film uniformly encapsulated amorphous $\mathrm{SiO}_{2} \mathrm{NPs}$ as free-standing and flexible anodes for LIBs are prepared by electrospinning, air stabilization followed by carbonization at $800{ }^{\circ} \mathrm{C}$ for $2 \mathrm{~h}$ under $\mathrm{Ar} / \mathrm{H}_{2}$ (95:5; v/v) atmosphere. ${ }^{75}$ Due to the encapsulation of active particles, CNFs can prevent the aggregation and pulverization and also suppress the volume expansion of active particles. So, the anode exhibits a high reversible capacity of $405 \mathrm{~mA} \mathrm{~h} \mathrm{~g}^{-1}$ at $500 \mathrm{~mA} \mathrm{~g}^{-1}$ after 1000 cycles and maintained structural integrity during the bending with a highest bending angle of $180^{\circ}$. In order to improve self-volume buffering properties and mechanical stability under long term flexion, porous $\mathrm{SiO}_{2}$ nanoclusters have been suggested as the active material. So, porous-SiO ${ }_{2}$ within N-CNFs as flexible anodes are prepared by electrospinning, and subsequently stabilized in the air followed by carbonization at $800{ }^{\circ} \mathrm{C}$ under $\mathrm{N}_{2}$ atmosphere for $2 \mathrm{~h},{ }^{76}$ in which porous-SiO ${ }_{2}$ buffer the volume expansion by itself and the deformable anode can maintain its favorable electrochemical performance after 1000 times of bending with the largest bending angle of $180^{\circ}$. Furthermore, after 1000 times of charge-discharge cycles, the charge transfer resistance surprisingly decreased significantly, indicates the long-term stability of SEI layer and fast diffusion kinetics of $\mathrm{Li}$ ions. Therefore, this could be an effective route to develop $\mathrm{SiO}_{2}$ based flexible and highly stable anode materials for LIBs. Flexible $\mathrm{Fe}_{3} \mathrm{O}_{4}$ NPs/N-doped CNFs as hybrid anodes for LIBs are synthesized via electrospinning, then air stabilization followed by carbonization at $600{ }^{\circ} \mathrm{C}$ for $2 \mathrm{~h}$ in $\mathrm{N}_{2}$ atmosphere. ${ }^{77}$ The synergistic effect between $\mathrm{Fe}_{3} \mathrm{O}_{4}$ and CNFs with a 3D interlinked conductive network of CNFs can ascribe the high electrochemical performance of this hybrid anode. Thus, the anode delivered a capacity of $522 \mathrm{~mA} \mathrm{~h} \mathrm{~g}^{-1}$ at $0.1 \mathrm{~A} \mathrm{~g}^{-1}$ after 200 cycles, and superior rate performance $\left(407 \mathrm{~mA} \mathrm{~h} \mathrm{~g}{ }^{-1}\right.$ at $\left.5 \mathrm{~A} \mathrm{~g}^{-1}\right)$. Hierarchical $\mathrm{CuO}_{x}-\mathrm{Co}_{3} \mathrm{O}_{4}$ heterostructure nanowires decorated on porous N-CNFs as free-standing anodes for highperformance flexible LIBs are fabricated by using electrospinning, solvothermal method, and heat treatment at $400{ }^{\circ} \mathrm{C}$ for $2 \mathrm{~h}$ in $\mathrm{N}_{2}$ atmosphere then annealing at $180^{\circ} \mathrm{C}$ for $6 \mathrm{~h}$ in air. $^{78}$ The impressive electrochemical performance can be attributed to the rational modeling of electrode configuration and the noticeable contributions from $\mathrm{CuO}_{x}-\mathrm{Co}_{3} \mathrm{O}_{4}$ heterostructure nanowires as well as the $3 \mathrm{D}$ conductive CNFs scaffold, which can enhance the interfacial contact, shorten the $\mathrm{Li}^{+}$ diffusion distance, and improve the active sites for Li storage. As a result, the hybrid anode exhibits a high discharge capacity of $1122 \mathrm{~mA} \mathrm{~h} \mathrm{~g}^{-1}$ at $200 \mathrm{~mA} \mathrm{~g}^{-1}$ after 100 cycles and, an excellent reversible capacity of $668 \mathrm{~mA} \mathrm{~h} \mathrm{~g}{ }^{-1}$ after 1000 cycles at $2 \mathrm{~A} \mathrm{~g}^{-1}$. An effective steam etching strategy has been developed to improve flexibility and capacity of CNFs based electrodes, such as a series of TMOs $\left(\mathrm{V}_{2} \mathrm{O}_{3}, \mathrm{Fe}_{2} \mathrm{O}_{3}, \mathrm{MoO}_{2}\right.$, and $\left.\mathrm{SnO}_{2}\right)$ are used to record their performances, all of them are fabricated by the same process. ${ }^{79}$ First, filter papers are soaked with TMO precursors then drying, finally, calcined for $3 \mathrm{~h}$, during calcination water streams are introduced for $0.5 \mathrm{~h}$ after $1 \mathrm{~h}$ of calcination for the sake of creates numerous holes in filter paper derived CNFs skeleton. In this system, steam-etched TMOs@CNFs demonstrated lotus seed-pod like structure which is beneficial for mitigating volume change and pulverization, and numerous holes in CNFs skeleton facilitates high $\mathrm{Li}^{+}$access towards active particles also absorbed the stressinduced from mechanical deformation results the films are successfully wrapped around a glass rod without any structural failure. Consequently, all of them retained over $100 \%$ of their initial capacity after 1500 cycles even at a high rate of $2 \mathrm{~A} \mathrm{~g}^{-1}$, indicates the high effectiveness of this unique strategy.

\subsection{Graphene-supported based electrodes}

Graphene is a $2 \mathrm{D} \mathrm{sp}{ }^{2}$-bonded single layer of carbon sheet has excellent charge carrier mobilities (about $10000 \mathrm{~cm}^{2} \mathrm{~V}^{-1} \mathrm{~s}^{-1}$ ) at a room temperature, high electrical conductivity $(4.8 \times$ $\left.10^{2} \mathrm{~S} \mathrm{~cm}^{-1}\right)$, large surface area $\left(2630 \mathrm{~m}^{2} \mathrm{~g}^{-1}\right)$, intrinsic mechanical flexibility, has zero effective mass, good chemical robustness, and light-weight in properties. ${ }^{80-83}$ Based on those useful properties many efforts have been devoted to the fabrication of graphene-based flexible electrodes (Fig. 3 and Table 3). However, graphene-based electrodes possess the low theoretical capacity and suffer high initial irreversible capacity as well as serious capacity fading. So, it is necessary to incorporating high capacitance active materials on the surface of graphene or intercalation between graphene sheets. This section will highlight the recent developments of graphene-based electrodes. For example, a flexible holey reduced graphene oxide (rGO) paper has been suggested for improving rate performance and prepared by a multiple-step process; first, pores forming into the basal plane of GO via a wet chemical method combined with ultrasonic vibration and mild acid oxidation, then simple filtration, and subsequent air drying followed by calcination at $700{ }^{\circ} \mathrm{C}$ in $\mathrm{Ar}$ or $\mathrm{H}_{2}(10 \%) / \mathrm{Ar}(90 \%)$ flow. ${ }^{84}$ The film with a thermal 
Table 2 CNFs based flexible electrodes

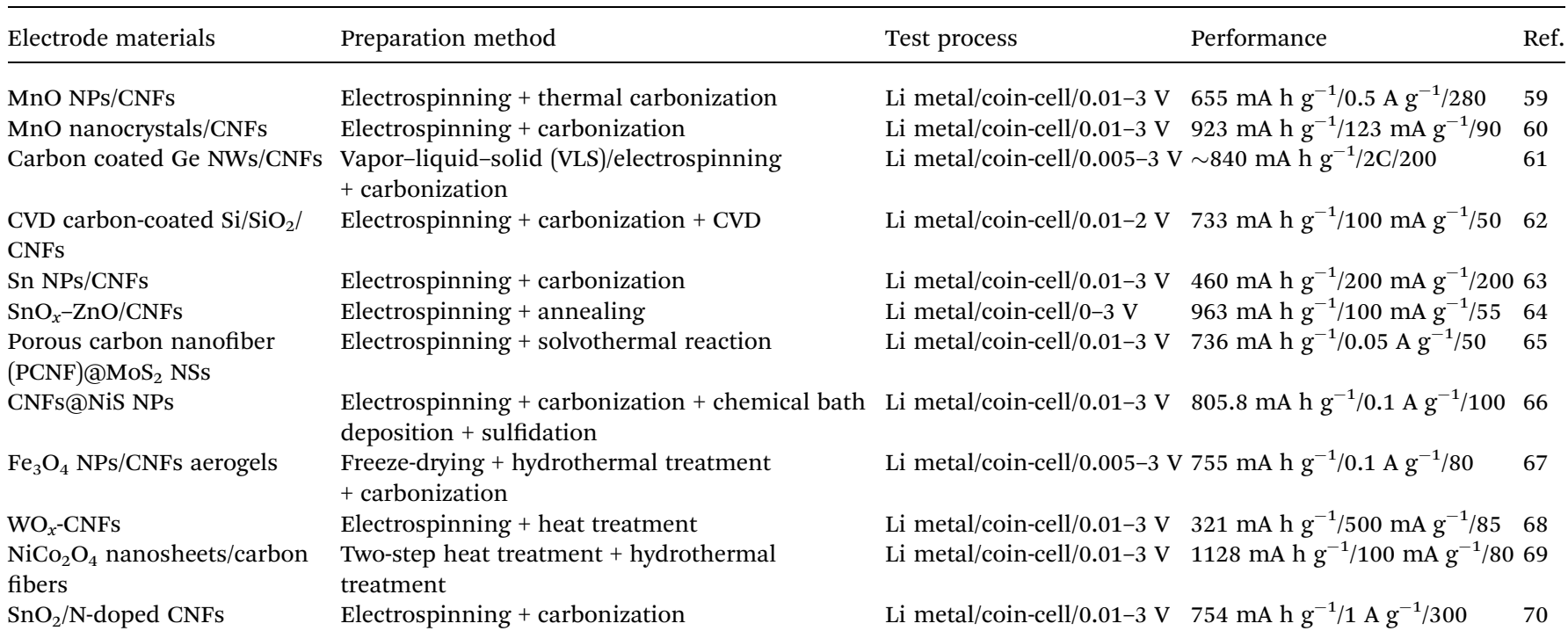

reduction in Ar flow shows a larger pore size than that of $\mathrm{Ar} / \mathrm{H}_{2}$ flow. Moreover, numerous pores in rGO enable high ion diffusion kinetics, abundant Li storage site, and much more accessible interior space which lead to almost no capacity fading after 1000 cycles at a very high current of $5 \mathrm{~A} \mathrm{~g}^{-1}$ and $10 \mathrm{~A} \mathrm{~g}^{-1}$. An interfacially modified Si NPs/graphene foam (GF) monolith as high performance flexible composite anodes are produced by ultrasonication, then freeze-drying followed by calcination at $350{ }^{\circ} \mathrm{C} .{ }^{85}$ Highly conductive $3 \mathrm{D}$ interconnected graphene foam facilitates rapid ion/electrons transportation, and the confining of Si NPs in GF reduces direct exposure of active particles in the electrolyte which leads to a stable SEI layer. As a consequence,

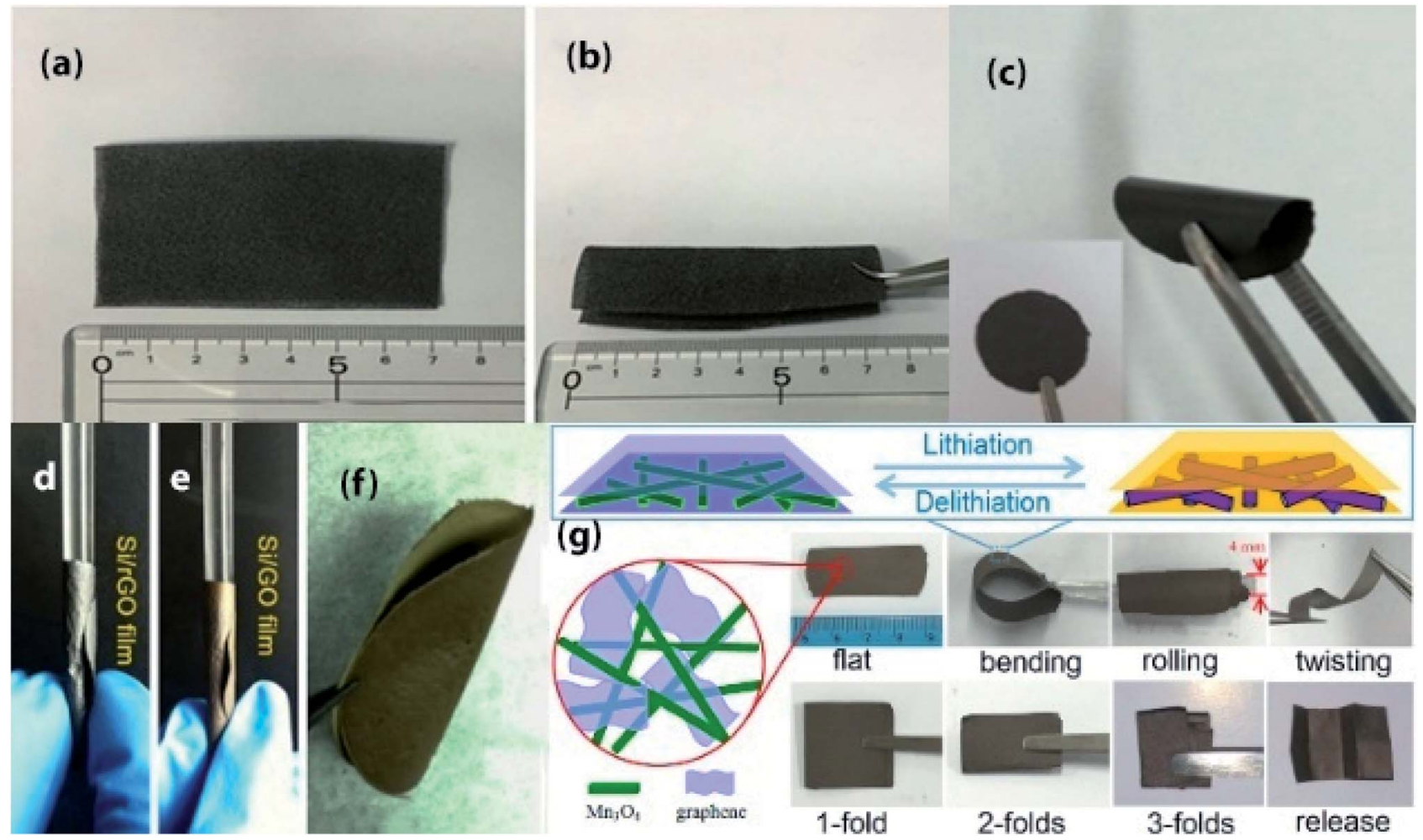

Fig. 3 ( $a$ and b) Photographs of a flexible Ge-QDaNG/NGF yolk-shell electrode. Reprinted from ref. 87. (c) Photograph of the flexible Bi $2 \mathrm{Se}_{3} /$ graphene film. Reprinted from ref. 97. (d-f) Exhibition of Si/rGO flexible films in different states. Reprinted from ref. 90. (g) Schematic diagram (top view and cross-sectional view) of the $\mathrm{rGO} / \mathrm{Mn}_{3} \mathrm{O}_{4}$ membrane and its digital photos illustrating the flexibility (bending, rolling, twisting) and foldability (1-, 2-, 3-fold) states. Reprinted from ref. 96. 
Table 3 Graphene based flexible electrodes

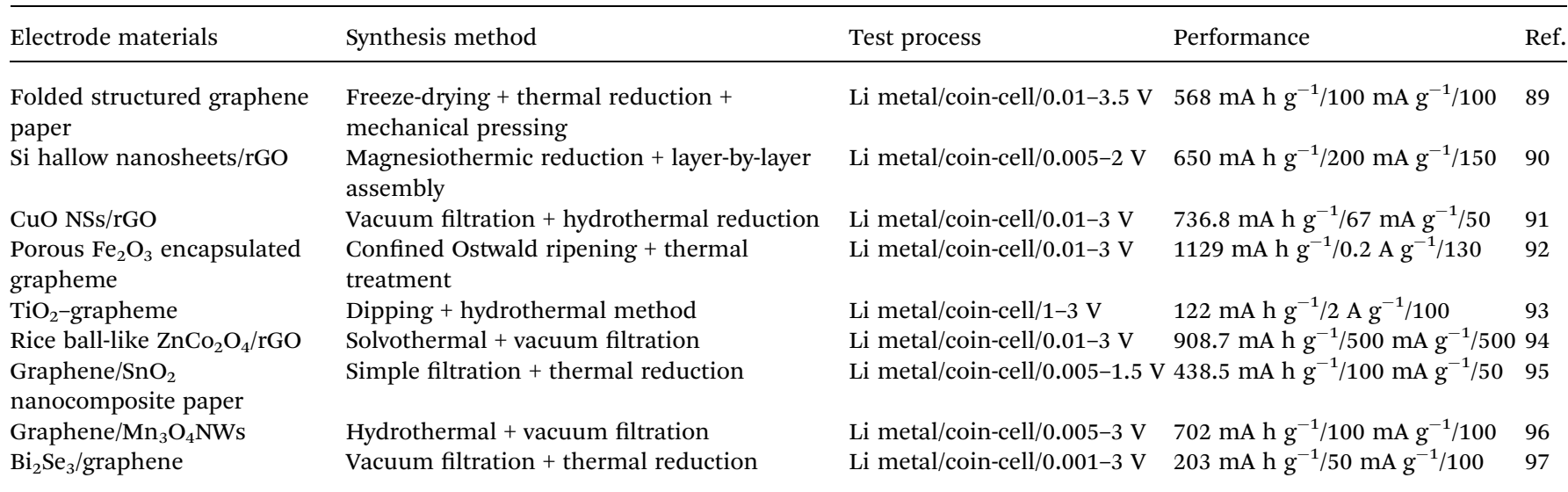

the composite anode exhibited surprisingly high reversible capacity and cycling stability $\left(1198 \mathrm{~mA} \mathrm{~h} \mathrm{~g}^{-1}\right.$ at $1 \mathrm{~A} \mathrm{~g}^{-1}$ and retained $1170 \mathrm{~mA} \mathrm{~h} \mathrm{~g}{ }^{-1}$ even after 1200 cycles), and superior rate performance $\left(609 \mathrm{~mA} \mathrm{~h} \mathrm{~g}^{-1}\right.$ at $\left.8 \mathrm{~A} \mathrm{~g}^{-1}\right)$. Self-standing flexible silicon oxycarbide (SiOC)/graphene composite paper anodes are fabricated by polymer pyrolysis process at $1000{ }^{\circ} \mathrm{C}$ followed by vacuum filtration, ${ }^{86}$ which demonstrated high rate performance $\left(\sim 175 \mathrm{~mA} \mathrm{~h} \mathrm{~g}^{-1}\right.$ at $\left.2400 \mathrm{~mA} \mathrm{~g}^{-1}\right)$, and ultra-long cycle durability $\left(588 \mathrm{~mA} \mathrm{~h} \mathrm{~g}^{-1}\right.$ at $1600 \mathrm{~mA} \mathrm{~g}^{-1}$ after 1020 cycles). A 3D interconnected porous nitrogen-doped graphene foam with encapsulated Ge quantum dot/nitrogen-doped yolkshell nanoarchitecture (Ge-QD@NG/NGF), synthesized by the step-by-step process; which can be used as a high-performance anode for flexible LIBs. ${ }^{87}$ First, N-doped graphene foams are produced by the CVD technique using porous $\mathrm{Ni}$ foam as a template. Then, Ge precursor placed in N-doped graphene foam by hydrothermal method followed by annealing at $650{ }^{\circ} \mathrm{C}$ in $\mathrm{Ar} / \mathrm{H}_{2}$ atmosphere for $6 \mathrm{~h}$, finally, acid $(1 \mathrm{M} \mathrm{HCl})$ etching to remove Ni template. In this architecture, 3D interconnected unique yolk-shell structure provides numerous open channels for fast Li-ion diffusion and accommodates the volume expansion of Ge by internal void space. As a result, this anode exhibits long-term cycle life $\left(1220 \mathrm{~mA} \mathrm{~h} \mathrm{~g}^{-1}\right.$ at $1600 \mathrm{~mA} \mathrm{~g}^{-1}$ after 1000 cycles), and exceptional rate performance $\left(792 \mathrm{~mA} \mathrm{~h} \mathrm{~g}^{-1}\right.$ at a high rate of $40 \mathrm{C}$ even after 200 cycles). Also, this hybrid anode can retain $\sim 95.2 \%$ capacity after 20 bending cycles. Pliable high-rate hollow metal oxides $\left(\mathrm{Fe}_{2} \mathrm{O}_{3}\right.$ and $\left.\mathrm{CuO}\right)$ nanoparticles/ porous graphene composite anodes are fabricated through simple filtration followed by a controlled oxidation process. ${ }^{88} \mathrm{In}$ this system, hollow metal oxide NPs placed in the pores of graphene sheets and formed $\mathrm{Cu} / \mathrm{Fe}-\mathrm{O}-\mathrm{C}$ chemical bond between $\mathrm{CuO} / \mathrm{Fe}_{2} \mathrm{O}_{3}$ NPs and graphene generates strong interfacial interaction. On the other side, hollow NPs and porous graphene effectively shorten the diffusion path for Li-ion lead to abnormal rate capability with cycle life. Such as, the specific capacities are $\left(741 \mathrm{~mA} \mathrm{~h} \mathrm{~g}^{-1}\right.$ and $141 \mathrm{~mA} \mathrm{~h} \mathrm{~g}^{-1}$ at $10 \mathrm{~A} \mathrm{~g}^{-1}$ and $50 \mathrm{~A} \mathrm{~g}^{-1}$, respectively over 1000 cycles) for $\mathrm{Fe}_{2} \mathrm{O}_{3} @ g r a p h e n e$ and $\left(980 \mathrm{~mA} \mathrm{~h} \mathrm{~g}{ }^{-1}\right.$ and $168 \mathrm{~mA} \mathrm{~h} \mathrm{~g}^{-1}$ at $10 \mathrm{~A} \mathrm{~g}^{-1}$ and $100 \mathrm{~A} \mathrm{~g}^{-1}$, respectively after 1000 cycles) for $\mathrm{CuO} @ g r a p h e n e$, makes them promising anode materials in commercial flexible LIBs.
Highly conductive and flexible graphene/modified mesoporous anatase $\mathrm{TiO}_{2}$ composite anodes are synthesized by twostep vacuum filtration, the down layer consists of a bare graphene layer obtained by the first filtration, then the top layer deposited as a composite layer. ${ }^{98}$ Numerous macropores in this film and mesopores in $\mathrm{TiO}_{2}$ facilitate longitudinal diffusion of the electrolyte and graphene layers provide high electrical conductivity for the hybrid anodes. Thus, the hybrid anode exhibits a better cycling performance $\left(155 \mathrm{~mA} \mathrm{~h} \mathrm{~g}^{-1}\right.$ at $1 \mathrm{C}$ after 200 cycles and $\sim 94 \mathrm{~mA} \mathrm{~h} \mathrm{~g}^{-1}$ at a high rate of $5 \mathrm{C}$ even after 3500 cycles), and excellent rate performance ( $76 \mathrm{~mA} \mathrm{~h} \mathrm{~g}^{-1}$ at $\left.20 \mathrm{C}\right)$. Layered structured graphene/porous $\mathrm{ZnCo}_{2} \mathrm{O}_{4}$ nanosheets composite films are prepared by vacuum filtration followed by heating at $600{ }^{\circ} \mathrm{C}$ for $2 \mathrm{~h}$, which has been suggested as flexible anodes for high-performance LIBs. ${ }^{99}$ The porous structure of active nanosheets facilitates fast Li-ion transfer rate and reducing diffusion path, and graphene sheets provide high conductivity for electrodes. As a result, after 1000 cycles, a high specific capacity of $791 \mathrm{~mA} \mathrm{~h} \mathrm{~g}^{-1}$ was achieved at a high rate of $1 \mathrm{~A} \mathrm{~g}^{-1}$, and superior rate performance $\left(322 \mathrm{~mA} \mathrm{~h} \mathrm{~g}^{-1}\right.$ even at $8 \mathrm{~A} \mathrm{~g}^{-1}$ ). 3D layered $\mathrm{SnO}_{2}$ quantum dots/graphene frameworks as flexible anodes are fabricated via using a combination of hydrothermal method, freeze-drying, and calcination at $300{ }^{\circ} \mathrm{C}$ for $2 \mathrm{~h}$ in Ar atmosphere. ${ }^{100}$ This 3D unique design with plenty of macropores as well as high specific surface area promotes fast ion/electrons transfer rate, and more active sites for $\mathrm{Li}$ binding, which leads to a high reversible capacity $\left(1300 \mathrm{~mA} \mathrm{~h} \mathrm{~g}^{-1}\right.$ at $\left.100 \mathrm{~mA} \mathrm{~g}^{-1}\right)$, high rate capability with ultralong cycle life ( $200 \mathrm{~mA} \mathrm{~h} \mathrm{~g}^{-1}$ at a high rate of $10 \mathrm{~A} \mathrm{~g}^{-1}$ even after 5000 cycles), that is far superior than previously mentioned $\mathrm{SnO}_{2}$ based electrode. Porous $\mathrm{Mn}_{3} \mathrm{O}_{4}$ nanorods/rGO hybrid paper as flexible anodes have been produced by simple filtration, and subsequent thermal reduction at $400{ }^{\circ} \mathrm{C}$ for $2 \mathrm{~h} .{ }^{101} \mathrm{In}$ this as formed 3D structures, active materials placed between flexible rGO layers, effectively buffer volume change of $\mathrm{Mn}_{3} \mathrm{O}_{4}$ NRs and prevent pulverization. Moreover, the porous structure of composite film facilitates fast Li-ion diffusion and increases the wettability of electrolytes. Consequently, after 100 cycles, the capacity stabilized at $573 \mathrm{~mA} \mathrm{~h}^{-1}$ at the rate of $100 \mathrm{~mA} \mathrm{~g}^{-1}$ as well as exhibits a good rate performance $\left(196 \mathrm{~mA} \mathrm{~h} \mathrm{~g}^{-1}\right.$ at 
$2000 \mathrm{~mA} \mathrm{~g}^{-1}$ ). Ultralong MnO@C/rGO as 3D hierarchical highperformance anode materials for flexible LIBs are fabricated by vacuum-assisted layer-by-layer assembly of polydopamine coated $\mathrm{MnO}_{2} \mathrm{NWs}$ and $\mathrm{GO}$, then thermal reduction at $700{ }^{\circ} \mathrm{C}$ for 2 h. $^{102}$ In this 3D architecture, coaxial MnO@C NWs multidimensionally interconnected with rGO sheets and formed continuous conductive path and open channels for $\mathrm{Li}^{+} / \mathrm{e}^{-}$ transport results high reversible capacity $\left(920 \mathrm{~mA} \mathrm{~h} \mathrm{~g}{ }^{-1}\right.$ at $0.2 \mathrm{~A} \mathrm{~g}^{-1}$ ), long term cycling duration (719 $\mathrm{mA} \mathrm{h} \mathrm{g}^{-1}$ after 800 cycles at $\left.2 \mathrm{~A} \mathrm{~g}^{-1}\right)$, and superior rate performance $\left(396 \mathrm{~mA} \mathrm{~h} \mathrm{~g}^{-1}\right.$ at $\left.10 \mathrm{~A} \mathrm{~g}^{-1}\right)$. A freestanding mesoporous $\mathrm{Li}_{4} \mathrm{Ti}_{5} \mathrm{O}_{12} / \mathrm{rGO}$ nanocomposites membrane as high rate flexible anodes for LIBs has been fabricated through using a combination of hydrothermal treatment, then vacuum filtration followed by thermal annealing at $600{ }^{\circ} \mathrm{C}$ for $2 \mathrm{~h} .{ }^{103}$ The excellent rate performance of this composite anode can be attributed to the improved $\mathrm{Li}^{+}$transfer through the mesoporous pathways, and high electrical conductivity of rGO sheets. So, the anode shows a good rate performance (135.4 $\mathrm{mA} \mathrm{h} \mathrm{g}^{-1}$ at $7000 \mathrm{~mA} \mathrm{~g}^{-1}$ ) and retained 93.9\% capacity at $1750 \mathrm{~mA} \mathrm{~g}^{-1}$ after 500 cycles. Freestanding and flexible $\mathrm{Mn}_{2} \mathrm{P}_{2} \mathrm{O}_{7}$-carbon@rGO hybrid films are prepared as high-performance anodes for LIBs. First, $\mathrm{Mn}^{2+}$ was absorbed by bacteria, then mixing with GO and subsequent vacuum filtration followed by thermal treatment at $700{ }^{\circ} \mathrm{C}$ for $2 \mathrm{~h}$ to obtained micro-yolk-shell $\mathrm{Mn}_{2} \mathrm{P}_{2} \mathrm{O}_{7}$-carbon@rGO hybrid papers. ${ }^{104}$ The framework consists of the graphitized bacterial carbon with rGO not only prevents the agglomeration of $\mathrm{Mn}_{2} \mathrm{P}_{2} \mathrm{O}_{7}$ but also provides sufficient space for buffer the volume changes of $\mathrm{Mn}_{2} \mathrm{P}_{2} \mathrm{O}_{7}$ during cycling which leads to high reversible capacity ( $880 \mathrm{~mA} \mathrm{~h} \mathrm{~g}^{-1}$ at $100 \mathrm{~mA} \mathrm{~g}^{-1}$ ), and excellent rate performance with long cycle life $\left(400 \mathrm{~mA} \mathrm{~h} \mathrm{~g}^{-1}\right.$ at $5000 \mathrm{~mA} \mathrm{~g}^{-1}$ over 2000 cycles). Core-shell $\mathrm{Fe}_{7} \mathrm{~S}_{8} @ \mathrm{C}$ NPs encapsulated within threedimensional graphene composites as flexible high-performance anodes for LIBs are synthesized by excessive metal ion spatially confined Ostwald ripening and vitamin $\mathrm{C}$ induced assembly, afterward calcination with Se powder at $600{ }^{\circ} \mathrm{C}$ for $2 \mathrm{~h}$, using metal-organic framework/3D graphene as precursor. ${ }^{105}$ This anode delivered a high reversible capacity (884.1 $\mathrm{mA} \mathrm{h} \mathrm{g}^{-1}$ at $0.1 \mathrm{~A} \mathrm{~g}^{-1}$ after 120 cycles), and superior cycling durability $\left(815.2 \mathrm{~mA} \mathrm{~h} \mathrm{~g}^{-1}\right.$ after 250 cycles at $1 \mathrm{~A} \mathrm{~g}^{-1}$ ). 3D freestanding cathodes composed of graphene/ $/ \mathrm{LiFePO}_{4}$ nanostructures are produced via solvent evaporation technique, ${ }^{106}$ which retained $165.3 \mathrm{~mA} \mathrm{~h} \mathrm{~g}^{-1}$ after 50 cycles at $0.1 \mathrm{C}$. Moreover, after 100 times of bending with a bending angle of $45^{\circ}$, the composite cathode shows only slight decay of discharge capacity, demonstrated its high mechanical stability. Freestanding flexible $\mathrm{MoO}_{3}$ nanobelts/graphene composite cathodes were fabricated by applying two-step ultra-fast microwave hydrothermal treatment followed by vacuum filtration, ${ }^{107}$ which exhibits a high initial discharge capacity ( $291 \mathrm{~mA} \mathrm{~h} \mathrm{~g}^{-1}$ at $100 \mathrm{~mA} \mathrm{~g}^{-1}$ ), and after

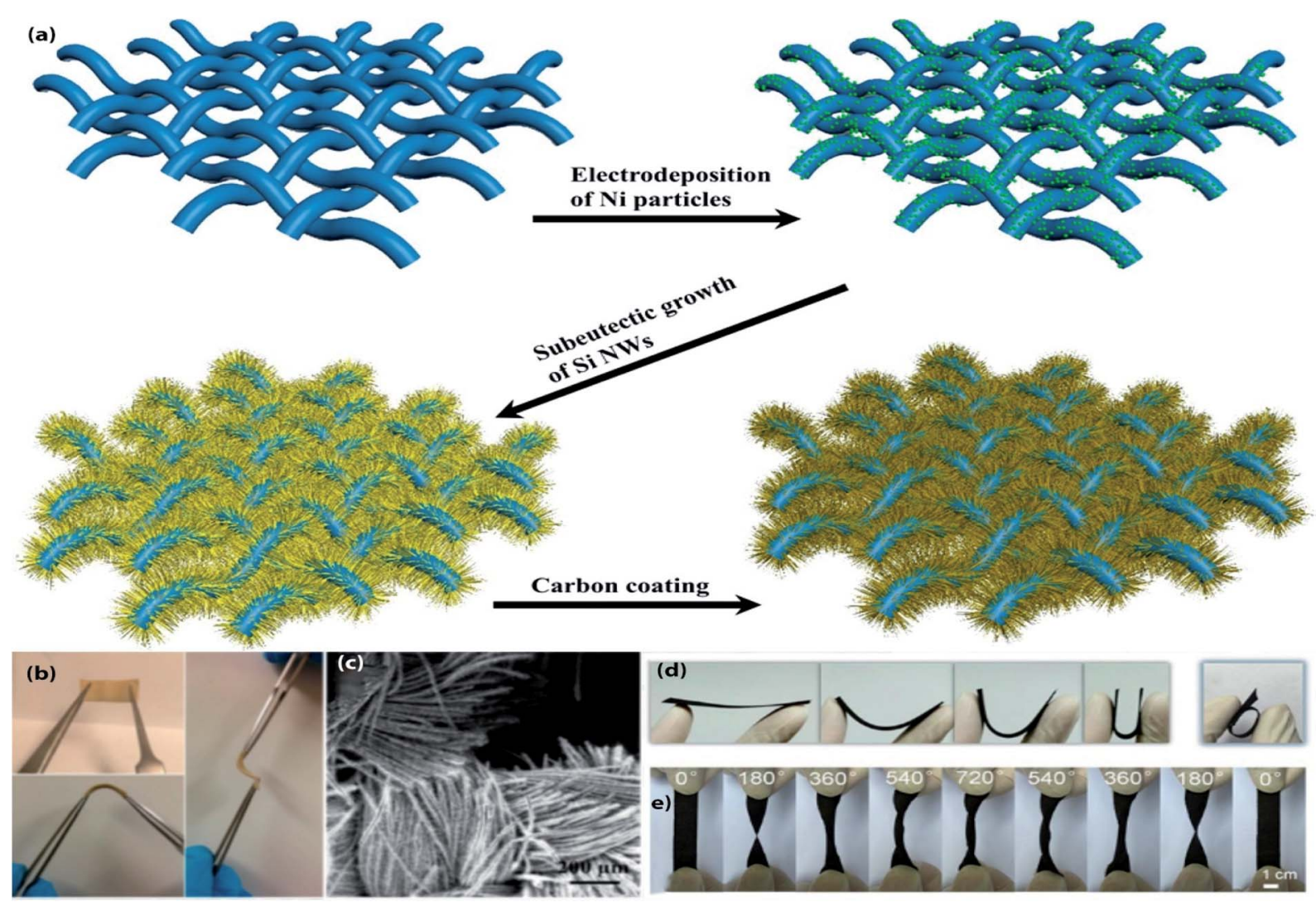

Fig. 4 (a) Schematic Illustration of the growth of carbon-coated Si NWs on flexible carbon cloth substrate. (b) Digital image of the c-Si NWs/ carbon cloth electrode, (c) representative SEM image of the c-Si NWs/carbon cloth electrode. (a-d) Reprinted from ref. 111. (d and e) Photographs of the flexible $\mathrm{CF}\left(\mathrm{SnO}_{2}-\mathrm{NS} @ \mathrm{AC}\right.$ electrode during the folding, the rolling, and twisting tests. (d and e) Reproduce with permission, ${ }^{124}$ copyright 2018, Elsevier. 
100 cycles, maintained $172 \mathrm{~mA} \mathrm{~h} \mathrm{~g}^{-1}$ at $100 \mathrm{~mA} \mathrm{~g}^{-1}$ that is superior to that of bare $\mathrm{MoO}_{3}$ based electrodes.

\subsection{Carbon cloth/fabric/textile (CFT)-supported electrodes}

3D CFT has been proposed as promising substrates for constructing flexible electrodes due to high electrical conductivity, good corrosion resistance, excellent mechanical flexibility, lightweight and commercial availability. ${ }^{108-110}$ Depositing, coating, or direct growing high capacity active materials on CFT conductive substrates have been found to be an effective route for fabricating the flexible electrodes. A variety of CFT based flexible electrodes (Fig. 4 and Table 4 ) have been extensively studied in flexible LIBs. This section will comprehensively present the recent developments in this field. Self-supported carbon-coated Si NWs in situ grown on carbon fabric (CF) via a nickel-catalyzed one-pot atmospheric pressure CVD process with a mass of $1.2-2.5 \mathrm{mg} \mathrm{cm}^{-2}$, which has been proposed as flexible anodes for LIBs. ${ }^{111} 1 \mathrm{D}$ NWs and CF formed a porous architecture, accommodate the huge volume change as well as increasing electrolyte infiltration. Moreover, an additional carbon layer on Si NWs helps to prevent further oxidation of active NWs by confining active NWs interior of the carbon layer results a high reversible specific capacity $\left(3362 \mathrm{~mA} \mathrm{~h} \mathrm{~g}^{-1}\right.$ at $100 \mathrm{~mA} \mathrm{~g}^{-1}$ after 100 cycles), better cycling stability (2061 $\mathrm{mA} \mathrm{h} \mathrm{g}^{-1}$ after 500 cycles even at a high current density of $\left.1 \mathrm{~A} \mathrm{~g}^{-1}\right)$, and superior rate performance $\left(1500 \mathrm{~mA} \mathrm{~h} \mathrm{~g}{ }^{-1}\right.$ at $5 \mathrm{~A} \mathrm{~g}^{-1}$ ), also the high areal capacity of $5 \mathrm{~mA} \mathrm{~h} \mathrm{~cm}{ }^{-2}$. 3D ordered macroporous $\mathrm{MoS}_{2} @ \mathrm{C} / \mathrm{CC}$ as high-performance flexible anodes are fabricated by dipping of $\mathrm{CC}$ in active materials precursor solution followed by calcination at $600{ }^{\circ} \mathrm{C}$ for $2 \mathrm{~h}$ in $\mathrm{Ar}$ steam. ${ }^{112}$ The high electrochemical performance of this anode can be attributed to the 3D interconnected ordered microporous nanostructure which not only facilitates large specific active surface area but also promotes the $\mathrm{Li}^{+}$diffusion rate as well as effectively buffers the volume change. As a result, this hybrid anode delivered a high areal capacity $\left(3.428 \mathrm{~mA} \mathrm{~h} \mathrm{~cm}{ }^{-2}\right.$ at 0.1 $\mathrm{mA} \mathrm{cm}^{-2}$ ), rapid charge-discharge performance (1.361 $\mathrm{mA} \mathrm{h} \mathrm{cm}^{-2}$ at $\left.5 \mathrm{~mA} \mathrm{~cm}{ }^{-2}\right)$, and excellent capacity retention $\left(2.471 \mathrm{~mA} \mathrm{~h} \mathrm{~cm}^{-2}\right.$ after 100 cycles at $\left.0.5 \mathrm{~mA} \mathrm{~cm}{ }^{-2}\right)$. Moreover, after 300 bending cycles, the anode can maintain its structural integrity and initial morphology. To attain a more favorable cycle life with areal capacity, another $\mathrm{MoS}_{2}$ contained, hierarchical $\mathrm{Fe}_{2} \mathrm{O}_{3}$ @carbon fabric (CF) decorated with $\mathrm{MoS}_{2}$ nanosheets as composite anodes for flexible ultrahigh areal capacity LIBs have been synthesized by using a combination of electrospinning, and subsequent calcination followed by hydrothermal treatment. ${ }^{113}$ The enhanced electrochemical performance can be ascribed to the synergistic effect between $\mathrm{Fe}_{2} \mathrm{O}_{3} @ \mathrm{CF}$ and $\mathrm{MoS}_{2}$ NSs. Consequently, the anode exhibits outstanding rate capability ( $304 \mathrm{~mA} \mathrm{~h} \mathrm{~g}^{-1}$ at $5 \mathrm{~A} \mathrm{~g}^{-1}$ ), and better cycle life (938 $\mathrm{mA} \mathrm{h} \mathrm{g}^{-1}$ at $0.2 \mathrm{~A} \mathrm{~g}^{-1}$ after 300 cycles). A new 3D hierarchical sandwiched type amorphous carbon-coated-SnO ${ }_{2}$ nanosheets/CC as composite anodes for ultra-flexible LIBs are fabricated by a multiple-step process. ${ }^{114}$ First, $\mathrm{SnO}_{2}$ NSs were grown on CC substrate by hydrothermal reaction followed by calcination; afterward, coated with amorphous carbon via using another hydrothermal treatment and subsequent annealing, which did not show any observable changes even after 200 continuous bendings. In this system, $2 \mathrm{D} \mathrm{SnO}_{2}$ NSs with CC constructed a 3D porous architecture with plenty of void spaces, which is beneficial for enabling high active surface area and shortening the diffusion distance of $\mathrm{Li}^{+}$ion. In addition, the extra carbon layer formed a chemical bond with $\mathrm{SnO}_{2}$ NSs, reduce detachment and volume expansion induced stress. Consequently, the hybrid anode exhibits a high specific capacity (968.6 $\mathrm{mA} \mathrm{h} \mathrm{g}^{-1}$ at $85 \mathrm{~mA} \mathrm{~g}^{-1}$ after 100 cycles), and long cycle life (471.2 $\mathrm{mA} \mathrm{h} \mathrm{g}^{-1}$ over 1500 cycles at $900 \mathrm{~mA} \mathrm{~g}^{-1}$ ). Flexible freestanding and high-performance $\mathrm{TiO}_{2}$ nanocrystals/CC anodes for LIBs are prepared by oleic acid assisted drop-casting followed by heating at $450{ }^{\circ} \mathrm{C},{ }^{115}$ which can tolerate bending stress when the bending angle was $180^{\circ}$ even after 100 times of bending. Also, the small size of active material crystals can not only shorten the diffusion length of $\mathrm{Li}$ ions but also provide a high available active surface area for electrochemical reactions. So, the hybrid anode delivered a capacity of $\sim 150 \mathrm{~mA} \mathrm{~h} \mathrm{~g}^{-1}$ after 100 cycles at $500 \mathrm{~mA} \mathrm{~g}^{-1}$. A flexible pouch type half-cell was assembled using this anode, which can power a red LED even after 100 times of flexion. A flexible $\mathrm{TiO}_{2} @ \mathrm{TiN}$ NWs/CC composite anodes with high rate capability for LIBs are synthesized by a hydrothermal reaction followed by calcination at $800{ }^{\circ} \mathrm{C}$ under Ar flow then $5 \mathrm{~min}$ in $\mathrm{NH}_{3}$ gas, in which the thin TiN layer improve electronic conductivity and electrochemical performance than pristine $\mathrm{TiO}_{2}{ }^{116}$ As a result, the composite anode shows a high discharge capacity $\left(579 \mathrm{~mA} \mathrm{~h} \mathrm{~g}^{-1}\right.$ at $\left.335 \mathrm{~mA} \mathrm{~g}^{-1}\right)$, excellent rate performance $\left(136 \mathrm{~mA} \mathrm{~h} \mathrm{~g}^{-1}\right.$ at $\left.10.05 \mathrm{~A} \mathrm{~g}^{-1}\right)$, better cycling stability $\left(203 \mathrm{~mA} \mathrm{~h} \mathrm{~g}^{-1}\right.$ at $3350 \mathrm{~mA} \mathrm{~g}^{-1}$ after 650 cycles), which is far beyond than previously mentioned pristine $\mathrm{TiO}_{2}$ contained one. Another $\mathrm{TiO}_{2}$ contained, $\mathrm{TiO}_{2} @ \mathrm{Ge}$ core-shell nanorods arrays/CT hybrid anode for high-density flexible LIBs are fabricated by step-bystep processes; first, $\mathrm{TiO}_{2}$ nanorod arrays hydrothermally grown on CT, then coated with Ge layer using radio frequency magnetron sputtering technique followed by thermal treatment at $450{ }^{\circ} \mathrm{C} .{ }^{117}$ The 3D $\mathrm{TiO}_{2} @$ Ge nanostructure with numerous void spaces and loose texture of CT not only enhances the electrolyte penetration through the electrode with rapid ion diffusivity but also relaxing the volume expansion induced stress. In addition, carbon textile facilitates high electrical conductivity for electrochemical reactions. Consequently, the hybrid anode delivered a high discharge capacity (1603.7 $\mathrm{mA} \mathrm{h} \mathrm{g}^{-1}$ at $1 \mathrm{~A} \mathrm{~g}^{-1}$ ), outstanding cycle life with better rate performance (700.3 mA h g ${ }^{-1}$ at $5 \mathrm{~A} \mathrm{~g}^{-1}$ over 600 cycles), demonstrated favorable performance than that of the abovementioned $\mathrm{TiO}_{2}$ contained electrodes. $\mathrm{ZnCo}_{2} \mathrm{O}_{4}$-urchins/CF as a flexible anode for LIBs are prepared by a hydrothermal approach followed by heat treatment at $400{ }^{\circ} \mathrm{C} .{ }^{118}$ The anode demonstrated a high discharge capacity $\left(1310 \mathrm{~mA} \mathrm{~h} \mathrm{~g}^{-1}\right.$ at $180 \mathrm{~mA} \mathrm{~g}^{-1}$ and $1350 \mathrm{~mA} \mathrm{~h} \mathrm{~g}^{-1}$ even at a high current density of $\left.4.5 \mathrm{~A} \mathrm{~g}^{-1}\right)$, excellent cycle life (1180 $\mathrm{mA} \mathrm{h} \mathrm{g}^{-1}$ at $180 \mathrm{~mA} \mathrm{~g}^{-1}$ and $750 \mathrm{~mA} \mathrm{~h} \mathrm{~g}^{-1}$ at a high rate of $18 \mathrm{~A} \mathrm{~g}^{-1}$ over 100 cycles). Selfsupported flexible high-performance $\mathrm{Zn}_{2} \mathrm{GeO}_{4}$ nanorods/CC anodes are fabricated via simple hydrothermal treatment combined with thermal treatment at $450{ }^{\circ} \mathrm{C}$ for $2 \mathrm{~h}$ in $\mathrm{N}_{2}$ 
atmosphere, ${ }^{119}$ in which synergistic effect between active nanorods and CC ascribed to the excellent electrochemical performance of these hybrid anodes. So, the hybrid anode delivered a high discharge capacity $\left(1851.9 \mathrm{~mA} \mathrm{~h} \mathrm{~g}^{-1}\right.$ at $\left.200 \mathrm{~mA} \mathrm{~g}^{-1}\right)$, better rate capability $\left(847.5 \mathrm{~mA} \mathrm{~h} \mathrm{~g}^{-1}\right.$ at $2000 \mathrm{~mA} \mathrm{~g}^{-1}$ ), and the reversible capacity stabilized at $1302.3 \mathrm{~mA} \mathrm{~h} \mathrm{~g}^{-1}$ after 200 cycles at $200 \mathrm{~mA} \mathrm{~g}^{-1}$ rate. A flexible anode composed of mesoporous $\mathrm{NiCo}_{2} \mathrm{O}_{4}$ nanowire arrays uniformly grown on carbon textile by a simple surfactantassisted hydrothermal approach followed by short postannealing. ${ }^{120}$ In this architecture, loose texture and mesoporous $\mathrm{NiCo}_{2} \mathrm{O}_{4}$ NWAs provides short electrolyte and ion diffusion channels as well as accommodate the volume change during cycling results high discharge capacity $\left(1524 \mathrm{~mA} \mathrm{~h} \mathrm{~g}^{-1}\right.$ at $\left.0.2 \mathrm{~A} \mathrm{~g}^{-1}\right)$, good rate capability (778 $\mathrm{mA} \mathrm{h} \mathrm{g}^{-1}$ at $\left.2 \mathrm{~A} \mathrm{~g}^{-1}\right)$, and better cycle life ( $854 \mathrm{~mA} \mathrm{~h} \mathrm{~g}^{-1}$ after 100 cycles at $0.5 \mathrm{~A} \mathrm{~g}^{-1}$ ). A pre-lithiation approach has been applied to resolve the initial capacity fading of $\mathrm{NiCo}_{2} \mathrm{O}_{4}$ based electrodes, thus lithiated $\mathrm{NiCo}_{2} \mathrm{O}_{4} \mathrm{NWs} / \mathrm{CC}$ hybrid anodes for flexible LIBs are fabricated through a hydrothermal approach followed by calcination at $300{ }^{\circ} \mathrm{C}$ in the air for $3 \mathrm{~h}$, then applying pre-lithiation. ${ }^{\mathbf{1 2 1}}$ Therefore, the pre-lithiated anode maintained a discharge capacity of $1026 \mathrm{~mA} \mathrm{~h} \mathrm{~g}^{-1}$ in the $10^{\text {th }}$ cycle at a current density of $100 \mathrm{~mA} \mathrm{~g}^{-1}$. In addition, a flexible full cell was assembled using this anode with $\mathrm{V}_{2} \mathrm{O}_{5} / \mathrm{CC}$ cathode, the cell exhibited an energy density of $364.2 \mathrm{~W} \mathrm{~h} \mathrm{~kg}{ }^{-1}$ at a power density of $240 \mathrm{~W} \mathrm{~h} \mathrm{~kg}$ with no obvious capacity fading even after 200 folding cycles. A novel $\mathrm{Fe}_{2} \mathrm{~N}$ NPs/CT hybrid anode with high power density has been fabricated by hydrothermal reaction followed by calcination at $600{ }^{\circ} \mathrm{C}$ in $\mathrm{NH}_{3}$ gas for $1 \mathrm{~h}$, which has been suggested for high-performance flexible LIBs. ${ }^{122}$ The large surface area of $\mathrm{Fe}_{2} \mathrm{~N}$ NPs and lose texture with high conductivity of CT can facilitate high electron/ions transfer and accommodate the volume change of active particles during electrochemical reaction which leads to attaining high reversible capacity with better capacity retention at a high rate $\left(900 \mathrm{~mA} \mathrm{~h} \mathrm{~g}^{-1}\right.$ at $6000 \mathrm{~mA} \mathrm{~g}^{-1}$ and retained $76 \%\left(240 \mathrm{~mA} \mathrm{~h} \mathrm{~g}^{-1}\right)$ after 300 cycles $)$. Well-aligned binary lithium reactive zinc phosphide $\left(\mathrm{Zn}_{3} \mathrm{P}_{2}\right)$ nanowire arrays are grown on carbon fabric by a facile CVD method, which has been proposed as an advanced integrated anode for flexible LIBs. ${ }^{123}$ The hierarchical structure with sufficient void spaces between nanowire arrays is beneficial for more electrolyte penetration, shorten the diffusion length of $\mathrm{Li}^{+}$, and buffering the volume change during cycling results in high rate capability (400 $\mathrm{mA} \mathrm{h} \mathrm{g}^{-1}$ at $15 \mathrm{~A} \mathrm{~g}^{-1}$ ), and long cycle life (1000 $\mathrm{mA} \mathrm{h} \mathrm{g}^{-1}$ after 200 cycles at $400 \mathrm{~mA} \mathrm{~g}^{-1}$ ). In situ oxidized $\mathrm{CuO}$ nanosheets/ CC composite anodes for high-performance flexible LIBs are produced by a facile two-step method combining magnetron sputtering and solution immersion. ${ }^{124}$ In this hybrid system, carbon cloth provides a highly conductive and pliable scaffold with sufficient open void spaces for buffering the volume change. Also, 2D nanosheets shorten the diffusion distance of Li ions. Hence, the composite anode shows a high capacity with better retention $\left(711.2 \mathrm{~mA} \mathrm{~h} \mathrm{~g}^{-1}\right.$ at $500 \mathrm{~mA} \mathrm{~g}^{-1}$ and maintained $88 \%$ after 100 cycles), as well as high rate capability (448.9 $\mathrm{mA} \mathrm{h} \mathrm{g}^{-1}$ at $2000 \mathrm{~mA} \mathrm{~g}^{-1}$ ). To obtained hierarchical mesoporous $\mathrm{NiO}$ nanosheets/CC flexible anode materials for high-performance LIBs, a hydrothermal treatment afterward calcination process has been adopted, ${ }^{\mathbf{1 2 5}}$ in which mesoporous NiO NSs interconnected with each other and creates extra void spaces to infiltrate more electrolyte, shorten the diffusion path as well as relaxing the volume change. So, the hybrid anode exhibits a high discharge capacity (1156.5 $\mathrm{mA} \mathrm{h} \mathrm{g} \mathrm{g}^{-1}$ at $\left.100 \mathrm{~mA} \mathrm{~g}^{-1}\right)$, good rate performance $\left(298.4 \mathrm{~mA} \mathrm{~h} \mathrm{~g}^{-1}\right.$ at $\left.5000 \mathrm{~mA} \mathrm{~g}^{-1}\right)$, and better cycle life $\left(758.1 \mathrm{~mA} \mathrm{~h} \mathrm{~g}^{-1}\right.$ over 150 cycles at $700 \mathrm{~mA} \mathrm{~g}^{-1}$ ). A combination of hydrothermal treatment and subsequent $3 \mathrm{~h}$ of heat treatment in air at $500{ }^{\circ} \mathrm{C}$ has used to fabricate freestanding $\mathrm{Cr}_{2} \mathrm{O}_{3}$ nanosheets/CC flexible anodes. ${ }^{126}$ The large surface area with better contact of active material with electrolyte improves the rate of Li-ion diffusion. Consequently, the hybrid anode delivered a high discharge capacity with good retention $\left(1547.8 \mathrm{~mA} \mathrm{~h} \mathrm{~g}^{-1}\right.$ at $0.1 \mathrm{~A} \mathrm{~g}^{-1}$ and retained $917.3 \mathrm{~mA} \mathrm{~h} \mathrm{~g}^{-1}$ after 200 cycles), and also demonstrated a specific capacity of $414.2 \mathrm{~mA} \mathrm{~h} \mathrm{~g}^{-1}$ after 400 cycles at $800 \mathrm{~mA} \mathrm{~g}^{-1}$. A freestanding $\mathrm{Li}_{4} \mathrm{Ti}_{5} \mathrm{O}_{12}$ cuboid arrays/carbon fiber cloth composite has been proposed as a high rate of LIBs anode materials, which are synthesized through the hydrothermal method, and subsequent lithiation ensuing thermal treatment at $800{ }^{\circ}$ C. $^{\mathbf{1 2 7}}$ Subtle slits between nanocuboids improve the interlayer spacing and specific surface area as well as numerous micropores and mesopores of electrode synergistically improve the electrolyte penetration, $\mathrm{Li}^{+}$transfer rate and shorten the diffusion path results in remarkable rate performance (169.1 $\mathrm{mA} \mathrm{h} \mathrm{g}^{-1}$ at 50C), and superior electrochemical stability (2.2\% capacity loss at $10 \mathrm{C}$ after 1000 cycles). A flexible full cell was fabricated with using this anode and $\mathrm{LiNi}_{0.5} \mathrm{Mn}_{1.5} \mathrm{O}_{4} / \mathrm{Al}$ cathode, the cell delivered a reversible capacity of $109.1 \mathrm{~mA} \mathrm{~h} \mathrm{~g}^{-1}$ at $10 \mathrm{C}$ and maintained $100 \%$ capacity after 200 times of bending. $\mathrm{V}_{2} \mathrm{O}_{5}$ nanosheet arrays are grown on polydopamine decorated CC (mas loading of $\sim 2.1 \mathrm{mg} \mathrm{cm}^{-2}$ ) by solvothermal method then calcination at $350{ }^{\circ} \mathrm{C}$ for $2 \mathrm{~h}$ under air atmosphere, ${ }^{\mathbf{1 2 8}}$ which exhibits a high rate capability (120 $\mathrm{mA} \mathrm{h} \mathrm{g}^{-1}$ at $4500 \mathrm{~mA} \mathrm{~g}^{-1}$ ), and excellent cycle performance (140 $\mathrm{mA} \mathrm{h} \mathrm{g}^{-1}$ at $600 \mathrm{~mA} \mathrm{~g}^{-1}$ after 100 cycles). N-doped carboncoated $\mathrm{V}_{2} \mathrm{O}_{5}$ nanobelt arrays/CC (mass loading $1.2 \mathrm{mg} \mathrm{cm}^{-2}$ ) as high-performance flexible cathodes for LIBs has been fabricated via hydrothermal reaction after that thermal treatment. ${ }^{129}$ Additional N-doped carbon layer provides high conductivity and protects from direct exposure of active materials in the electrolyte. Besides, the nanobelt arrays formed a porous structure and the elastic properties of nanobelt arrays facilitate high ion diffusion rate and reduce pulverization simultaneously. Therefore, the cathodes demonstrated high rate performance (135 $\mathrm{mA} \mathrm{h} \mathrm{g}^{-1}$ at $2940 \mathrm{~mA} \mathrm{~g}^{-1}$ ), and good cycling stability (215 $\mathrm{mA} \mathrm{h} \mathrm{g}^{-1}$ at $147 \mathrm{~mA} \mathrm{~g}^{-1}$ after 50 cycles), which exhibit high capacity at low mass loading than previously mentioned $\mathrm{V}_{2} \mathrm{O}_{5}$ contained one. $\mathrm{CoF}_{2}$ NPs hydrothermally grown on conductive CC, which has been proposed as a conversion reaction cathode for flexible LIBs, it can be intact when bending with $180^{\circ}$ angle. ${ }^{130}$ The composite cathode delivered a high capacity of $330 \mathrm{~mA} \mathrm{~h} \mathrm{~g}{ }^{-1}$ at $100 \mathrm{~mA} \mathrm{~g}^{-1}$ after 200 cycles, and after 1000 cycles, a stable capacity of $100 \mathrm{~mA} \mathrm{~h} \mathrm{~g}^{-1}$ at a current density of $1 \mathrm{~A} \mathrm{~g}^{-1}$. 


\subsection{Carbon coating/foam-supported electrodes}

2.5.1. Carbon coating-supported electrodes. In a carboncoated integrated system, carbon provides electrical and mechanical supports. Recently, the amorphous carbon coating process comes into the view due to suitable electrical conductivity and good mechanical stability. ${ }^{\mathbf{1 3 1 - 1 3 3}}$ Typically, thermal pyrolysis of carbon precursors on active materials is the widely applied technique to achieve carbon-coated integrated flexible electrodes (Fig. 5). Self-supporting flexible carbon micro scroll coated-Si@CNT (92\% Si content) anodes for LIBs are prepared by using a combination of ultrasonication, freeze-drying followed by calcination at $800{ }^{\circ} \mathrm{C}$ for $2 \mathrm{~h} .{ }^{134}$ In this architecture, surprising mass loading resolves the low active material loading issues. Moreover, high conductivity of carbon micro scroll and cage-like structure not only provided high conductivity but also prevent the pulverization of electrode as well as buffer the volume expansion of Si during the electrochemical reactions. Thus, the anode delivered a superior specific capacity (2700 $\mathrm{mA} \mathrm{h} \mathrm{g}^{-1}$ at $0.2 \mathrm{~A} \mathrm{~g}^{-1}$ ), long-term cycle life (above $2000 \mathrm{~mA} \mathrm{~h} \mathrm{~g}{ }^{-1}$ after 300 cycles at $0.2 \mathrm{~A} \mathrm{~g}^{-1}$ ), and commercial level areal capacity $\left(5.58 \mathrm{~mA} \mathrm{~h} \mathrm{~cm}^{-2}\right)$. Hence, this novel production route improves the areal capacity and cycle life for high-performance LIBs. An N-doped carbon-coated $/ \mathrm{Li}_{4} \mathrm{Ti}_{5} \mathrm{O}_{12}$ nanosheets self-standing films as high-performance LIB anodes are fabricated via a simple and scalable process including chemical lithiation, then thermal annealing followed by vacuum filtration. ${ }^{\mathbf{1 3 5}}$ Highly transfer pathways for electrons and ions are provided by $\mathrm{N}$-doped carbon and porous structures of nanosheets. So, the hybrid anode shows a capacity of $\left(170 \mathrm{~mA} \mathrm{~h} \mathrm{~g}^{-1}\right.$ at a current density of $\left.175 \mathrm{~mA} \mathrm{~g}^{-1}\right)$, superior rate

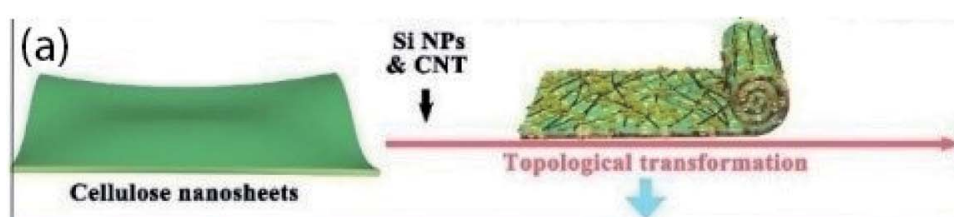

(b)

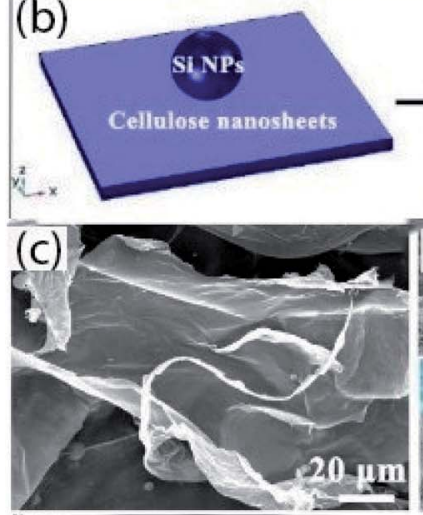

(f)
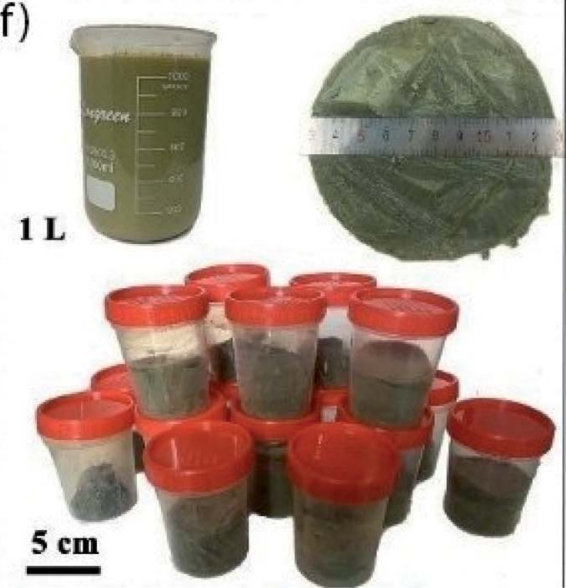
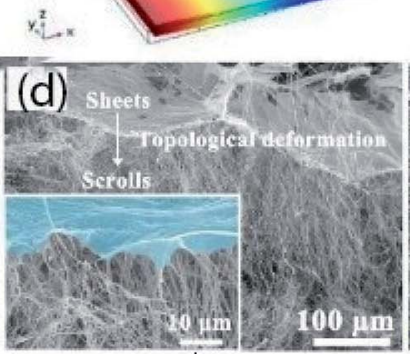

(i)

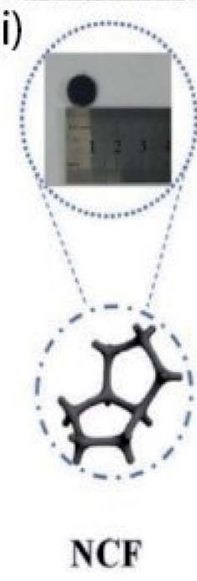

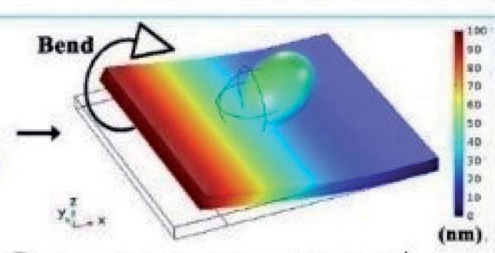

Si@CNT/Cellulose Microscrolls

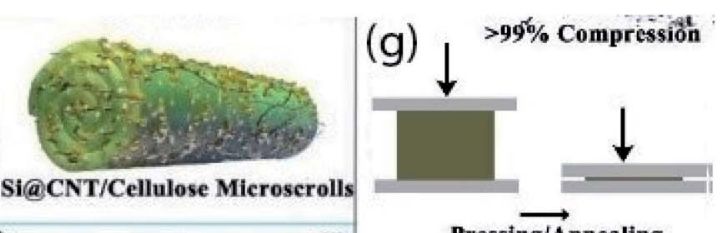

Pressing/Annealing

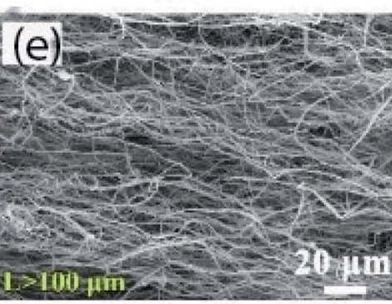

(h)
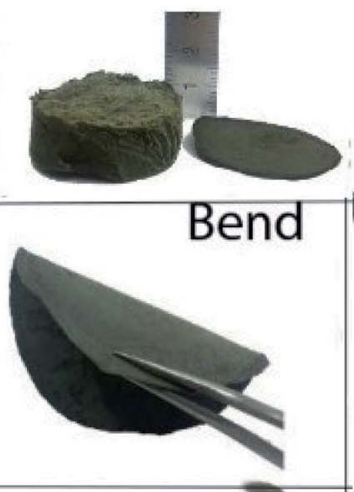

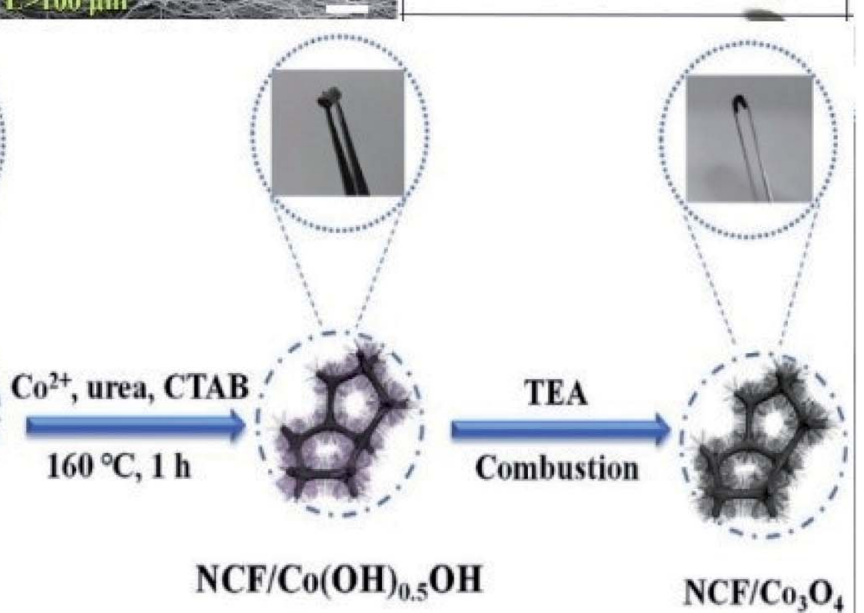

Fig. 5 (a) Schematic illustration of the preparation process for Si@CNT/C-microscrolls, (b) simulation modeling of the topological deformation process of one side of a cellulose nanosheet with one Si NP, (c-e) SEM images of cellulose nanosheets, the transition stage that simultaneously shows the sheet and scroll structure, and a Si@CNT/C-microscroll, (f) digital photographs of $1 \mathrm{~L}$ of a SiaCNT/cellulose mixed solution along with the amount of Si@CNT/cellulose aerogel produced per batch, (g) free-standing Si@CNT/C-microscroll electrode obtained by pressing and annealing the aerogel (>99\% compression), (h) bended state of Si@CNT/C-microscroll electrode. (a-h) Reprinted from ref. 134. (i) Schematic illustration of the synthesizing of binder-free $\mathrm{N}$-doped carbon foam $/ \mathrm{CO}_{3} \mathrm{O}_{4}$ electrode with photograph of flexible electrodes. (i) Reprinted from ref. 145. 
performance $(72 \%$ of theoretical capacity recovered at $17500 \mathrm{~mA} \mathrm{~g}^{-1}$ over 100 cycles), and good cycle life $\left(152 \mathrm{~mA} \mathrm{~h} \mathrm{~g}^{-1}\right.$ after 100 cycles at $1750 \mathrm{~mA} \mathrm{~g}^{-1}$ ). Flexible paperlike $\mathrm{Zn}_{2} \mathrm{GeO}_{4}$ nanofibers anchored with amorphous carbon composites are prepared via dissolution and recrystallization method, which has been proposed as flexible anode materials for advanced LIBs. ${ }^{136}$ The superior electrochemical and mechanical performance of this electrode can be attributed to the synergistic effect of the flexible intertwined network, strong $\mathrm{C}-\mathrm{O}-\mathrm{M}(\mathrm{M}=\mathrm{Zn}, \mathrm{Ge})$ bonds, and highly conductive carbon anchored in the nanofibers skeleton. So, the anode exhibits excellent rate capability ( $373 \mathrm{~mA} \mathrm{~h} \mathrm{~g}^{-1}$ at $12 \mathrm{~A} \mathrm{~g}^{-1}$ ), and ultralong cycle life $\left(\sim 820 \mathrm{~mA} \mathrm{~h} \mathrm{~g}^{-1}\right.$ over 2000 cycles at $\left.1 \mathrm{~A} \mathrm{~g}^{-1}\right) . \mathrm{N}$ doped carbon-coated $\mathrm{LiTi}_{2}\left(\mathrm{PO}_{4}\right)_{3}$ as high-performance anode materials are fabricated through one-pot carbonization incorporating the sol-gel method, which has been reported for high areal capacity flexible aqueous LIBs. ${ }^{137} \mathrm{~N}$-doped carbon coating provides high conductivity and helps to maintain structural integrity during electrochemical reactions and mechanical flexion. Thus, the anode exhibits a high capacity $\left(114 \mathrm{~mA} \mathrm{~h} \mathrm{~g}^{-1}\right.$ at $8 \mathrm{C}$ ), superior rate capability (64 $\mathrm{mA} \mathrm{h} \mathrm{g}^{-1}$ at 20C), and longterm cycling durability $\left(64.8 \mathrm{~mA} \mathrm{~h} \mathrm{~g}^{-1}\right.$ at $10 \mathrm{C}$ after 2000 cycles). A novel $\mathrm{ZnO}$ quantum dots (ZnO-QDs) anchored in amorphous carbon multilayered sheet (ZnO-QDs@CMS) composite anodes are fabricated via low-temperature thermal treatment using pre-prepared zinc glycolate complex as a precursor. ${ }^{138}$ In this hybrid electrode, a flexible amorphous carbon network is beneficial for ensuring high conductivity, mitigating volume expansion, suppressing the aggregation of active particles, and favored the formation of fast LiZn alloy, which contributed to the high electrochemical performance as well as long-time stability of flexible anode. Consequently, the anode delivered a high reversible capacity $\left(1015 \mathrm{~mA} \mathrm{~h} \mathrm{~g}^{-1}\right.$ at $50 \mathrm{~mA} \mathrm{~g}^{-1}$ after 80 cycles), and long-term cycling stability (565 $\mathrm{mA} \mathrm{h} \mathrm{g}^{-1}$ over 350 cycles at $1000 \mathrm{~mA} \mathrm{~g}^{-1}$ ). Free-standing $\mathrm{LiFePO}_{4} /$ carbon composite cathodes are prepared via a simple coating method by spreading out slurry onto a hydrophobic surface. ${ }^{139}$ The hybrid cathode shows a high initial capacity of $\sim 156 \mathrm{~mA} \mathrm{~h} \mathrm{~g}^{-1}$ at $0.1 \mathrm{C}$ and can be kept $\sim 133 \mathrm{~mA} \mathrm{~h} \mathrm{~g}^{-1}$ at $10 \mathrm{C}$ after 500 cycles.

2.5.2. Carbon foam-supported electrodes. Carbon foams have been explored in LIBs as lightweight, highly conductive and flexible scaffolds for constructing pliable electrode materials. ${ }^{\mathbf{1 4 0}}$ The porous structure of carbon foams is beneficial for containing active materials and rapid ion transportation. Several routes have been investigated such as template carbonization, bowing and carbonization, compression of exfoliated graphite, and assembly of graphene nanosheets, etc. for the preparation of carbon foams. ${ }^{\mathbf{1 4 1}}$ This section will briefly present the recent development of carbon foam-based electrode materials for flexible LIBs (Fig. 5).

The self-knitted alpha- $\mathrm{MnO}_{2}$ fabric/carbon foam composite as flexible anode materials for LIBs are produced via using a hydrothermal process and subsequent CVD process. ${ }^{142}$ The porous structure of $\mathrm{MnO}_{2}$ fabric with highly conductive carbon foam, which greatly improves the electrons/ion transportation for electrochemical reactions and also maintained structural integrity during flexion. Thus, the anode delivered a high discharge capacity ( $840 \mathrm{~mA} \mathrm{~h} \mathrm{~g} \mathrm{~g}^{-1}$ at $\left.0.1 \mathrm{~A} \mathrm{~g}^{-1}\right)$, excellent rate performance ( $86 \mathrm{~mA} \mathrm{~h} \mathrm{~g}^{-1}$ at $60 \mathrm{~A} \mathrm{~g}^{-1}$ ), and superior cycle life (450 $\mathrm{mA} \mathrm{h} \mathrm{g}^{-1}$ at $1200 \mathrm{~mA} \mathrm{~g}^{-1}$ after 1000 cycles). Moreover, a highly flexible was assembled by coupling this anode with LCO/Al cathode, the cell showed a high specific capacity of as high as $825 \mathrm{~mA} \mathrm{~h} \mathrm{~g}^{-1}$ at $200 \mathrm{~mA} \mathrm{~g}^{-1}$ and an impressive energy density of $2451 \mathrm{~W} \mathrm{~h} \mathrm{~kg}^{-1}$ at a power density of $4085 \mathrm{~W} \mathrm{~h} \mathrm{~kg}^{-1}$. Furthermore, a LED light still worked normally even when the battery bent, or rolled up continuously, demonstrated its promising potential use in highly flexible LIBs for foldable, stretchable, and wearable electronic devices. A binary metal sulfide, $\mathrm{NiCo}_{2} \mathrm{~S}_{4}$ nanotube arrays are directly grown on flexible 3D N-doped carbon foam through a facile surfactant-assisted hydrothermal process and the subsequent sulfurization treatment, which has been proposed as flexible anode materials for high-performance LIBs. ${ }^{\mathbf{1 4 3}}$ The superior electrochemical performance can be attributed to the unique material composition, integrated smart architecture by rationally designed hollow nanostructured, which facilitates fast electron/ion transfer, the large contact area with electrolyte as well as relaxing the strain-induced from lithiation/delithiation process. Consequently, the anode delivered a high reversible capacity and better capacity retention $\left(1721 \mathrm{~mA} \mathrm{~h} \mathrm{~g}^{-1}\right.$ at $500 \mathrm{~mA} \mathrm{~g}^{-1}$ and retained $1182 \mathrm{~mA} \mathrm{~h} \mathrm{~g}{ }^{-1}$ after 100 cycles). Freestanding and flexible LIBs anodes composed of $\mathrm{N}$-doped carbon foam/anatase $\mathrm{TiO}_{2}$ has been fabricated by using a combination of thermal pyrolysis, facile surface wetting, and subsequent hydrolysis process with a mass loading of as high as $5.31 \mathrm{mg} \mathrm{cm}^{-2}$, which is 2.5-4 times higher than that of other reported $\mathrm{TiO}_{2}$ based anodes. ${ }^{\mathbf{1 4 4}}$ High conductivity and mesoporous structure of carbon foam network, the low volume change of nanocrystalline $\mathrm{TiO}_{2}$, good adhesion between carbon foam and active material, and high cut-off voltage helps to achieve high capacity $\left(188 \mathrm{~mA} \mathrm{~h} \mathrm{~g}^{-1}\right.$ at $\left.200 \mathrm{~mA} \mathrm{~g}^{-1}\right)$, and good cycle life (149 $\mathrm{mA} \mathrm{h} \mathrm{g}^{-1}$ after 100 cycles at $1000 \mathrm{~mA} \mathrm{~g}^{-1}$ ). Freestanding and flexible N-doped carbon foam/

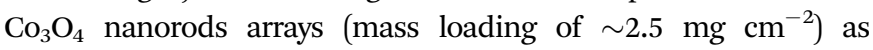
composite anodes are fabricated via using hydrothermal synthesis and unique triethylamine combustion in air method. ${ }^{145}$ The threedimensional framework and porous structure of the composite anode facilitate high ion/electron transfer rate, improve contact area between the electrolyte and active particles, and suppress the pulverization of the electrode. As a result, the free-standing anode delivered a high discharge capacity of $672 \mathrm{~mA} \mathrm{~h} \mathrm{~g}^{-1}$ at $0.1 \mathrm{~A} \mathrm{~g}^{-1}$, and excellent cycling stability $\left(576 \mathrm{~mA} \mathrm{~h} \mathrm{~g}^{-1}\right.$ after 300 cycles at $\left.1 \mathrm{~A} \mathrm{~g}^{-1}\right)$. So, this is an effective way to prepared flexible and binderfree carbon foam-based electrode materials for LIBs.

\subsection{Graphite-supported electrodes}

Graphite is one of the most widely used materials in the construction of LIB electrodes. Owing to high stability, stable electrochemical properties, good conductivity, impressive theoretical capacity, abundant in natural source, the yield capacity density can be closed to the theoretical specific capacity, and can be exhibit superior mechanical flexibility of graphite, results in graphite became an ideal anode active material as well as pliable conductive current collector/ 
(a)
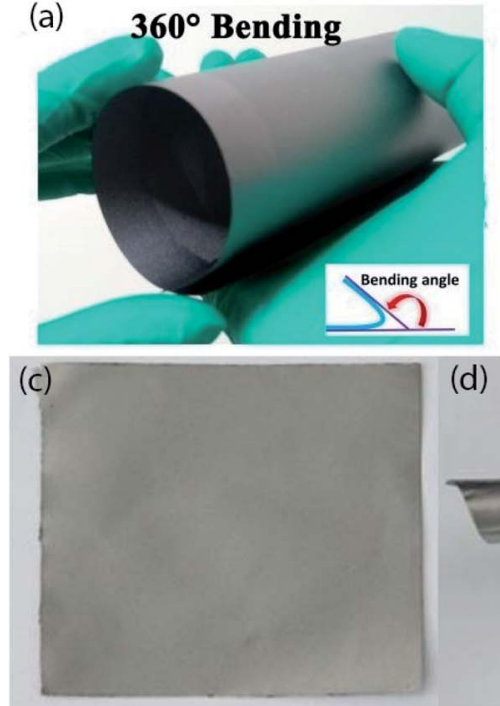

(b)

GF

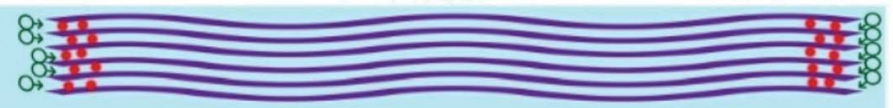

PGF

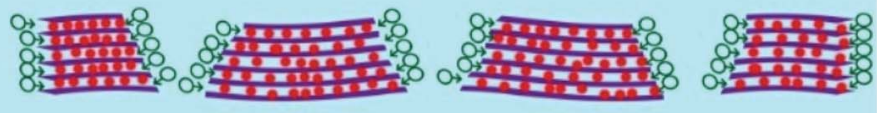

$\overline{\text { Graphene Sheet }}$ 
carbonaceous materials in flexible electrodes for FLIBs. This section will briefly summarize those factors and probable solutions for the future development are also provided.

2.7.1. For CNT-supported electrodes. CNT-based electrodes have some limitations due to (i) high cost, (ii) intricated preparation process, (iii) detachment of active materials, (iv) aggregation of CNT, (v) insufficient electrochemical performance and (vi) limited flexion. Therefore, insertion of active materials in hollow CNT skeleton will help to suppress the detachment of active materials, effectively accommodate the volume expansion of active materials, and generating the uniform SEI layer. In addition, heteroatom doping (i.e. nitrogen, boron) in CNT structure is another route to improving the conductivity and flexibility. Moreover, defect rich CNT for instance splitting optimized amount of carbon atoms from CNT structure helps to enhancing ion transfer rate. Furthermore, lowering the radius of CNTs improve the toughness while shortening the length decreased the voltage hysteresis and surface resistance, which can improve the capacity of electrodes. Additionally, heating at optimized temperature, ${ }^{22}$ and washed with $\mathrm{H}_{2} \mathrm{SO}_{4}$ prior ${ }^{152}$ of CNT films are significantly improve the electrochemical and mechanical performances. This discussion will help to developing CNT-based high-performance flexible electrodes for FLIBs.

2.7.2. ForCNFs-supported electrodes. CNFs-based electrodes suffer from some limitations such as (i) long synthesis process, (ii) poor interaction with active materials due to lacking of surface functional groups, (iii) low surface area causes poor conductivity and electrochemical performance. Therefore, introducing defects in CNFs structure such as heteroatom doping, etching and creating pores may help to improve flexibility and overall storage capacity. Additionally, embedding the active materials into the inner holes of CNFs are effectively reduce the fast capacity fading by suppressing the detachment and relaxing the volume changes of active materials. On the other hand, introducing CNT/graphene in CNFs based electrodes are significantly enhance the capacity and cycle stability. ${ }^{153,154}$ After all, it is necessary to the investigation of new CNFs structure with large surface areas and more functional groups to further the application of CNFs in flexible LIBs.

2.7.3. For graphene-supported electrodes. This type of electrodes is (i) costly, (ii) weak interfacial bonding active materials, (iii) restacking of graphene sheets, (iv) impeding in ion movement along vertical direction, (v) presence of large amount ( $\geq 10 \%$ ), (vi) unstable surface functional groups, (vii) insufficient in electrochemical and mechanical performances. Thus, using appropriate surfactants during electrode preparation helps to reduce the restacking of graphene sheets, complete abolishing of unstable surface functional groups can improve the coulombic efficiency. Moreover, pre-lithiation or pre-forming of artificial SEI on the electrode surface can mitigate the large irreversible capacity, though they are having not been yet available in industrial mass production. Furthermore, heteroatom doping in graphene skeleton also enhances the conductivity and active sites for Li storage. On the other side, combining CNT or CNFs in graphene-based electrodes, which effectively improves the capacity and cycle life of electrodes. ${ }^{\mathbf{1 5 5}}$ However, improvement of contact interaction, volumetric capacity, and mechanical strength for desirable flexion cycles are crucial for further applications of graphene in flexible electrodes for commercial LIBs.

2.7.4. For CFT-supported electrodes. CFT-based electrodes are facing some limitations as (i) complex synthesis procedure, (ii) low density, (iii) difficulty in installing desired amount of active materials, (iv) integration into wearable devices, (v) large mass (more than $10 \mathrm{mg} \mathrm{cm}^{-2}$ ) compared with copper foil (around $0.7 \mathrm{mg} \mathrm{cm}^{-2}$ ), (vi) low rate performance, (vii) poor adhesion with active materials. Owing to the high cost of the CVD technique, other promising coating procedures, for instance, screen printing, dip coating, and spinning should be used in industrial positions to large-scale manufacturing. Optimizing the number of carbon fibers in CFT textures may help to reducing the mass of CFT substrates and increasing in rate performance. Moreover, functionalizing the carbon fibers in CFT textures will increase the adhesion strength with active materials via generating chemical bonding. After all, exploring a novel strategy that includes scalability is more important for the multifarious applications and the commercialization of CFT based electrodes in flexible LIBs.

2.7.5. For carbon coating/foam-supported electrodes. Due to (i) more electrolyte consumption, (ii) low electrical conductivity, (iii) inhibition of ion transfer rate, (iv) limiting the flexibility, (v) poor volumetric and specific capacity, (vi) thickening the electrodes, the carbon coating/foam-based electrodes are not well accepted. Investigating novel production route, optimizing the carbon content, purifying the carbon parts, heteroatom doping, and introducing pores in carbon skeletons will help to sustaining the further development in this field.

2.7.6. For graphite-supported electrodes. These types of electrodes have some shortcomings as: (i) insufficient capacity in grams, (ii) easy to collapse layered structured after several subsequent cycles, (iii) lower purity and occurring more parasitic reactions, (iv) seriously limiting the deformability, (v) shortening the batteries life. Usually, binder is required, when graphite films are used as current collector/substrate. Therefore, new fabrication strategy and structural modification may solve the deformability related issues and integration of high capacitance active materials without binder can improve the capacity of electrodes. One the other hand, low-cost, environmental benignant and natural abundance advantages can support retaining its usefulness in the fabrication of flexible electrodes for LIBs.

\subsection{Possible solutions for improving the mechanical sustainability of CM skeletons}

In case of pliable electrodes, mechanical flexibility is the most crucial factor. To date, a lot of experimental works have been conducted to improve flexibility of electrodes without compromising energy density and capacity. Still this is a dilemma, how to achieve desirable flexion cycle without any lost in overall electrochemical performances of pliable electrodes? Limited flexion of conductive CMs, and detachment of active materials during flexion have been addressed as most responsible factors for this difficulty. In binder-free flexible electrode systems, CMs are mainly provide the mechanical support of deformable electrodes. Thus, it is important to enhance the mechanical properties of CM skeletons. In this section we will provide 
a brief understanding on how to improve the mechanical sustainability of pliable electrodes under long-term deformability.

Doping with appropriate hetero-atoms is a widely known strategy to improve mechanical and electrical performances of CMs. For instance, Khavrus et al. produced Boron-doped SWCNT by a post thermal diffusion method, ${ }^{156}$ Liu et al. reported N-doped CNT arrays, ${ }^{157}$ Yue et al. ${ }^{158}$ and Selvakumar et al. ${ }^{159}$ reported $\mathrm{N}$-doped porous graphene films, Cao et al. ${ }^{160}$ reported a highly elastic $\mathrm{N}$-doped carbon foam current collector that was synthesized via thermal pyrolysis of polyurethane foam. In addition, Zou et al. ${ }^{161}$ have reported boron and nitrogen co-doped holey graphene films, which possess improved electrical and mechanical performances than pristine graphene films. Therefore, doping with heteroatom will improve the mechanical performance of CMs supported flexible electrodes.

Guo et al. ${ }^{162}$ and Xiong et al. ${ }^{163}$ have been synthesized highly flexible and porous graphene films with enhanced mechanical performance. In addition, Liu and co-workers ${ }^{164}$ have proposed a porous carbon film composed by CNT as a current collector for supercapacitor that exhibited high flexibility and ion diffusivity. On the other side, 3D porous networks of CMs have also attracted huge research attentions due to their long-term morphological structures, low electrical resistance rising, and better structural integrity under outer mechanical stress. For example, Ummethala et al. ${ }^{165}$ and Lee et al. ${ }^{166}$ have proposed a 3D interconnected and porous CNT foam type materials with significantly enhanced mechanical flexibility. Graphene based 3D interconnected porous nanostructures also possess higher mechanical performance. ${ }^{167}$ Ren et al. ${ }^{168}$ synthesized CNT and graphene contained 3D interconnected hybrid foam for LIBs application and they demonstrated that this hybrid materialbased electrode shows only negligible amount of resistance increasing after several times of flexion. Further, Tang et al. ${ }^{140}$ have fabricated 3D interconnected and extremely flexible carbon foams with high conductivity $\left(177 \mathrm{~S} \mathrm{~cm}^{-1}\right)$, and porosity (99.6\%). Thus, formation of porous and 3D interconnected network by CMs also increases the mechanical properties and will be sustained after long-term flexion.

In case of CNFs, doping is also widely studied strategy for the improving in mechanical and electrical properties. ${ }^{169,170}$ On the other hand, porosity engineering plays an important role to enhancing mechanical performance of CNFs by mitigating the outer stress. ${ }^{79}$ Individual CNT and graphene sheets prone to aggregation with less mechanical flexibility. In a review article, Zhang et al. ${ }^{171}$ summarized that CNT fibers exhibited intrinsic mechanical flexibility and electrical conductivity. Cheng et al. ${ }^{172}$ also summarized the properties of graphene fibers and they conclude that graphene fibers (GFs) have excellent mechanical and electrical performances though GFs still require massive improvement.

Cheng et al. ${ }^{173}$ reported CNT-graphene hybrid fiber-based textile for the supercapacitor applications, which exhibited excellent flexibility. Liu et al. ${ }^{174}$ also prepared CNT-graphene hybrid fibers based stretchable $(200 \%)$ textiles. Hence, CNT and graphene fibers can be the better alternatives of conventional carbon fiber for the fabrication of CFT with high flexibility and electrochemical performance.

Jin et al. ${ }^{175}$ and Meng et al. ${ }^{176}$ synthesized poly(3,4ethylenedioxythiophene) (PEDOT) coated CNT and graphene composite materials. Both of them exhibited excellent flexibility, while maintaining structural integrity and electrical conductivity after several times of flexion. Besides, this electrically conducting polymers (ECP) coating can be acted as protecting the CMs from the aggregation or detachment and reduce the overall resistance. As a result, coating with ECPs is an excellent route to improve flexibility without significant changes in resistance. On the other hand, as a binder ECPs are better than non-conducting polymers because of they can simultaneously enhance the flexibility and electrical conductivity of overall electrodes.

\section{Metal mesh/fabric, nanowire, and foam/foil-supported flexible electrodes}

\subsection{Metal mesh/fabric-supported electrodes}

Owing to low cost, high electrical conductivity, large surface area, favorable mechanical sustainability under structural deformations, considerable thickness, and smaller or no capacity contribution of metal mesh/fabric based current collector, ${ }^{177}$ emerged as a promising alternative of carbon cloth for developing cost-effective and flexible but effective current collector/substrate for flexible LIBs (Fig. 7). 3D stainless steel fibril mat (SFM)-supported silicon anode materials for highperformance flexible LIBs have been fabricated through a simple method using radio frequency $(\mathrm{RF})$ magnetron sputtering technique. ${ }^{178}$ SFM created an interconnected mat-like configuration with open spaces between neighboring fibrils, results in fast ions and electrons transfer rate through the whole electrode. As a result, the anode delivered a high discharge capacity $\left(\sim 3000 \mathrm{~mA} \mathrm{~h} \mathrm{~g}{ }^{-1}\right.$ at $\left.300 \mathrm{~mA} \mathrm{~g}^{-1}\right)$, excellent capacity retention $\left(90 \%\right.$ capacity retention at $2000 \mathrm{~mA} \mathrm{~g}^{-1}$ after 200 cycles). Moreover, using this anode a flexible full cell was assembled, the cell lost a little capacity ( $86 \%$ capacity retention at $1000 \mathrm{~mA} \mathrm{~g}^{-1}$ ) even after 150 times of bending. A freestanding coaxial $\mathrm{MnO}_{2} / \mathrm{CNTs}$ nanocomposite membrane grown on stainless steel mesh (SSM) via a two-step process: first, CNTs were grown on SSM by CVD process, then $\mathrm{MnO}_{2}$ active particles are coated on CNTs surface by electrodeposition, which can be worked as a flexible anode material for high-performance LIBs. ${ }^{179}$ SSM enables additional conductivity and porous structure facilitates rapid ion movement rates. Thus, the hybrid anode exhibits a high capacity and better cycling stability $\left(2062 \mathrm{~mA} \mathrm{~h} \mathrm{~g}^{-1}\right.$ at $200 \mathrm{~mA} \mathrm{~g}^{-1}$ and retained $80 \%$ capacity retained after 260 cycles), good rate performance $\left(474 \mathrm{~mA} \mathrm{~h} \mathrm{~g}^{-1}\right.$ at $1600 \mathrm{~mA} \mathrm{~g}^{-1}$ ). Self-standing porous $\mathrm{LiCoO}_{2}$ nanosheet arrays/ $\mathrm{Au}$-coated stainless-steel 3D cathodes has been prepared by a facile hydrothermal lithiation process followed by quick calcination in the air using $\mathrm{Co}_{3} \mathrm{O}_{4}$ nanosheet arrays as the precursor. ${ }^{180} \mathrm{Au}-\mathrm{Co}-\mathrm{O}$ interface is formed during annealing, which is beneficial for enhancing adhesion strength between active material and substrate. Moreover, 3D configuration with 
(a)
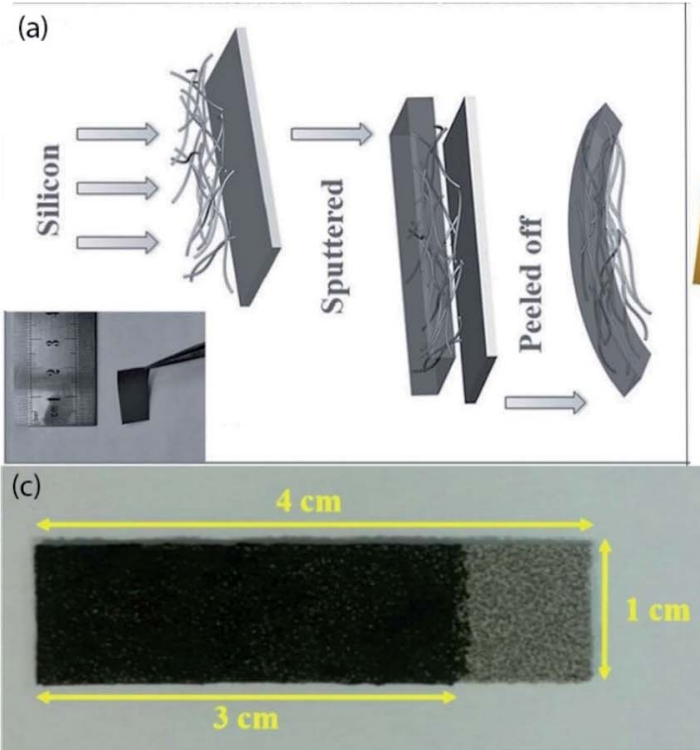

(b)

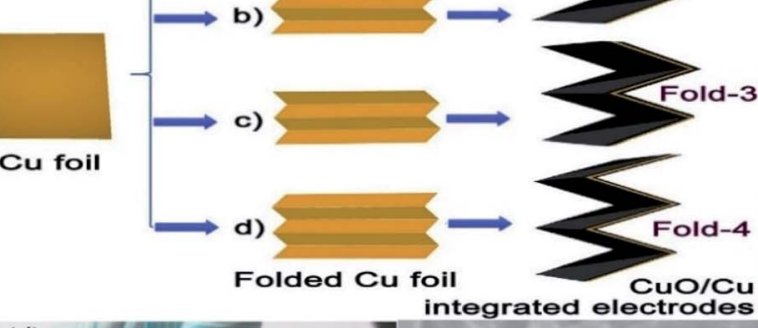

(d)

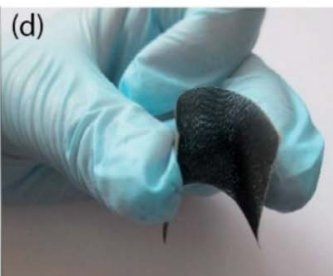

(e)

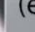

Fig. 7 (a) Schematic image of magnetron sputtering method to deposit silicon. Reprinted from ref. ${ }^{184}$. (b) Schematic illustration of fabrication procedures for four CuO/Cu integrated fold electrodes: One-fold, two folds, three folds and four folds. Reprinted from ref. ${ }^{193}$. (c) Optical image of a positive electrode using the 3D structured NiCr alloy metal foam of the bendable Li secondary battery. Reprinted from ref. ${ }^{191}$. (d) Photograph of as-prepared coaxial $\mathrm{MnO}_{2} / \mathrm{CNTs}$ nanocomposite freestanding membrane, (e) SEM image of the coaxial $\mathrm{MnO}_{2} / \mathrm{CNTS}$ nanocomposite freestanding membrane on SSM substrate anode after 200 cycles. (d and e) Reprinted from ref. ${ }^{179}$

the mesoporous structure of nanosheet facilitates electrolyte infiltration, relaxing volume expansion of LCO, and shortening the diffusion path of $\mathrm{Li}^{+}$ions. Consequently, the composite cathode demonstrated outstanding rate capability (104.6 $\mathrm{mA} \mathrm{h} \mathrm{g}^{-1}$ at $\left.10 \mathrm{C}\right)$, and long cycle life ( $81.8 \%$ of capacity retention after 1000 cycles at a current density of $0.1 \mathrm{C}$ ). Hence, these impressive results exhibited its potentiality in the comprising of high-performance flexible LIBs. 3D textile-based cathodes (mass loading of $2.5 \mathrm{mg} \mathrm{cm}{ }^{-2}$ ) are synthesized by combining $\mathrm{V}_{2} \mathrm{O}_{5}$ hollow multishelled structures (HoMSs) with conductive $\mathrm{Ni} /$ cotton fabric through a sequential templating approach for high-performance flexible LIBs. ${ }^{181} \mathrm{~V}_{2} \mathrm{O}_{5}$ HoMSs provides high surface-to-volume ratio and more active sites for $\mathrm{Li}^{+}$-ion storage and also effectively buffer the stress from volume changing during cycling. On the other side, metal fabric with a loose texture facilitates high electrical conductivity with a large amount of electrolyte infiltration simultaneously. Thus, the cathode retains a very high capacity of $224.2 \mathrm{~mA} \mathrm{~h} \mathrm{~g}^{-1}$ even after 500 subsequent cycles at a current density of $100 \mathrm{~mA} \mathrm{~g}^{-1}$. Moreover, under a large bending angle of $180^{\circ}$, the voltage remains barely changed after hundreds bending and folding cycles as well as no obvious resistance changes after 1000 bending cycles. Consequently, this unique investigation can be an open an extended avenue for the fabrication of flexible LIBs.

\subsection{Metal nanowires-supported electrodes}

Flexible current collectors have been fabricated by using metal nanowires (MNWs), enhances electrolyte penetrability and the diffusion kinetics of electron and ions, which led to improving rate performance. Owing to the high surface area, metallic electrical conductivity, and suitable mechanical ductility of metal nanowires (MNWs) have been extensively studied as flexible current collectors building element. ${ }^{182,183}$ Based on these useful properties, MNWs can be a potential alternative of carbon nanomaterials based on current collectors. Typically, filtration of MNWs contained dispersions has been used to fabricate flexible current collectors, later active materials are coated or deposited on as formed current collectors; or, onestep filtration of the dispersions of active materials and MNWs have also been used to fabricating MNWs-based flexible electrodes for LIBs. To date, several research groups have been extensively studied the MNWs based flexible electrodes in LIBs (Fig. 7). For example, a $\mathrm{Cu}$ NWs current collector sheets has been prepared by vacuum filtration, then $\mathrm{Si}$ active particles were deposited on $\mathrm{Cu}$ NWs current collector via radio frequency magnetron sputtering method, which can be act as a flexible anode for LIBs. ${ }^{184} \mathrm{Cu}$ NWs sheet served as a flexible and highly conductive current collector and also enhances the electron transport kinetics with providing the stability of the composite anodes. As a result, the hybrid anode delivered a high discharge capacity with good capacity retention $\left(3850 \mathrm{~mA} \mathrm{~h} \mathrm{~g}{ }^{-1}\right.$ at $0.84 \mathrm{~A} \mathrm{~g}^{-1}$ and retained $89.4 \%$ after 60 cycles), which is almost twice that of Si@Cu foil and Si@Ni-foam-based anodes. A composite anode composed of copper nanowires ( $\mathrm{Cu} \mathrm{NWs)/}$ MWCNT for fast charging/discharging LIBs are produced via simple filtration followed by sintered at $180{ }^{\circ} \mathrm{C}$ for $30 \mathrm{~min}$ in glycerol reducing conditions. ${ }^{185}$ The flexible anode with a mass ratio of $7: 1$ (Cu NWs : MWCNT) shows good electrochemical performance, at the rate of $5 \mathrm{C}$ the anode maintained $89.75 \%$ of capacity of $0.5 \mathrm{C}$ rate. Moreover, using this anode a flexible LIB retained more than $92.8 \%$ of its capacity after 1000 cycles under a continuous bending with a bending radius of $10 \mathrm{~mm}$. 
Furthermore, using this anode a constructed LIB can be $55.78 \%$ charged at a $5 \mathrm{C}$ rate only in $12 \mathrm{~min}$. Therefore, this is an effective route to comprise ultrafast charging flexible LIBs for next-generation advanced electronic devices. Binder-free, all inorganic nanowire bilayer $(\mathrm{Cu} / \mathrm{Ge})$ mesh as flexible anodes for high-performance LIBs has been fabricated by a step-by-step process; first, the dispersion of $\mathrm{Cu}$ NWs are drop cast on polytetrafluoroethylene (PTFE) mold, then drying, subsequently dispersion of Ge NWs drop cast on as obtained $\mathrm{Cu}$ NWs layer followed by calcination at $500{ }^{\circ} \mathrm{C}$ under $\mathrm{Ar} / \mathrm{H}_{2}$ atmosphere for 2 h. ${ }^{186}$ High conductivity with enormous open spaces between adjacent NWs is beneficial for rapid ion/electrons transfer. As a result, the hybrid anode exhibits a high specific capacity (1153 $\mathrm{mA} \mathrm{h} \mathrm{g}^{-1}$ at $0.1 \mathrm{~A} \mathrm{~g}^{-1}$ ), excellent rate capability (359 $\mathrm{mA} \mathrm{h} \mathrm{g}^{-1}$ at $20 \mathrm{~A} \mathrm{~g}^{-1}$ ), long-term cycling stability (1000 cycles and 1300 cycles when operated at $1 \mathrm{~A} \mathrm{~g}^{-1}$ and $10 \mathrm{~A} \mathrm{~g}^{-1}$ ),

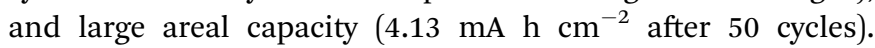
Moreover, the volumetric capacity of $\mathrm{Ge} / \mathrm{Cu}$ mesh anodes are 10 times enhanced than other Ge electrodes combined with graphene and CNFs.

\subsection{Metal foam/foil-supported electrodes}

Metal foams are usually explored as a $3 \mathrm{D}$ porous current collector or as flexible conductive scaffolds. Owing to unique porous architecture, active materials slurries can be embedded into the inner pore spaces led to suppress the volume expansions of active particles as well as curb the disengagement of active materials during the electrochemical reactions or mechanical deformation, offers the high surface area for redox reactions, shortening the diffusion path of $\mathrm{Li}^{+}$ion results in greatly improve the overall capacity of electrodes. ${ }^{187},{ }^{188}$ Besides, metal foams, metal foils are also investigated as a highly conductive and flexible current collectors for the building of pliable electrodes. ${ }^{189}$ Generally, coating or depositing of active materials onto the metal foam/foils have been employed for the preparation of pliable electrodes (Fig. 7). So far, various types of metal foam/foil based flexible electrodes have been explored by different research groups. This section will comprehensively introduce the recent development on metal foam/foil based pliable electrodes for LIBs. For instance, a 3D flexible $\mathrm{Cu}-\mathrm{Sn}$ current collectors has been synthesized by depositing metals on polyurethane (PU) foam followed by removal of PU by heat treatment. Afterward, as-obtained $\mathrm{Cu}-\mathrm{Sn}$ metal foams are calcined at $500{ }^{\circ} \mathrm{C}$ for $8 \mathrm{~h}$ under vacuum. Finally, LFP slurries are filled in the pore spaces of metal foam to yield flexible $\mathrm{LiFePO}_{4} / \mathrm{Cu}-\mathrm{Sn}$ cathodes for LIBs. ${ }^{190}$ In this system, 3D porous and conductive current collector facilitates high ion and electron transfer rates, and additional heat treatment is beneficial for resisting the rapid capacity fading. As a result, the hybrid cathodes delivered a superior capacity of above $400 \mathrm{~mA} \mathrm{~h} \mathrm{~g}$ after 50 cycles at a current density of $100 \mathrm{~mA} \mathrm{~g}{ }^{-1}$. Threedimensional NiCr-alloy metal foams are fabricated by the step-by-step process; first, Ni foams are produced by PU templating process, then NiCr alloy powder adsorbed on $\mathrm{Ni}$ foam followed by annealing to obtain NiCr-alloy foam. Finally, $\mathrm{LiFePO}_{4} / \mathrm{C}$ active material slurries deposited in the pores of foam and then reheated at $130{ }^{\circ} \mathrm{C}$ for $8 \mathrm{~h}$ under vacuum. ${ }^{191} \mathrm{High}$ electrochemical performance and mechanical pliability could be attributed to the $3 \mathrm{D}$ porous foam type conductive current collector using this flexible $\mathrm{LiFePO}_{4} / \mathrm{C} @ N i C r$ cathodes a pouch type battery exhibits a superior electrochemical performance (3.5 $\mathrm{mA} \mathrm{cm} \mathrm{cm}^{-2}$ at $0.2 \mathrm{C}$ ), good capacity retention ( $94 \%$ capacity retained after 50 cycles), and excellent mechanical performance (3.08 $\mathrm{mA} \mathrm{h} \mathrm{cm} \mathrm{cm}^{-2}$ capacity maintained even after 200 times bending at $0.2 \mathrm{C}$ with bending radii of 12.5 and $2.5 \mathrm{~mm}$ ). Threedimensional web-like anode materials are fabricated through numerous $\mathrm{Li}_{4} \mathrm{Ti}_{5} \mathrm{O}_{12}$ nanowires directly grown on $\mathrm{Ti}$ foil via a facile template-free route, which has been proposed as ultralong-life and high-rate anodes for high-performance flexible LIBs. ${ }^{192}$ In this 3D configuration, 1D nanowires significantly enhance the active sites for Li storage, shorten the transport length of electrons and ions, and helps to improve the contact area between active material and electrolyte. So, the anode shows a superior rate capability (103 $\mathrm{mA} \mathrm{h} \mathrm{g}^{-1}$ at $\left.80 \mathrm{C}\right)$, ultralong cycle life (153 $\mathrm{mA} \mathrm{h} \mathrm{g}^{-1}$ and $115 \mathrm{~mA} \mathrm{~h} \mathrm{~g}^{-1}$ after 5000 cycles at $2 \mathrm{C}$ and 20C, respectively), and only slight capacity decay in every single bending cycle. To produce high areal capacity anodes for flexible LIBs, $\mathrm{CuO}$ nanorods are grown on folded $\mathrm{Cu}$ foils through surface oxidation reaction. ${ }^{193}$ In this folding configuration, every fold adds one more $\mathrm{Cu}$ layer than the fold number. Such as one-fold and creates two Cu layers (fold-1), twofold and created three $\mathrm{Cu}$ layer (fold-2), and so on. This unique fabrication technique can not only enable the high adhesion between $\mathrm{CuO}$ NRs and $\mathrm{Cu}$ foils but also help to loads more CuO NRs. Consequently, $\mathrm{CuO}$ NRs/five-layers $\mathrm{Cu}$ foil (fold-4) achieved a outstanding areal capacity of $13.95 \mathrm{~mA} \mathrm{~h} \mathrm{~cm}^{-2}$. In addition, fold- 3 anodes maintained a high reversible areal capacity of $5.32 \mathrm{~mA} \mathrm{~cm}^{-2}$ after 100 cycles. On the other side, no observable cracks are found after 100 bending cycles in this integrated electrode systems. Thus, a flexible full cell comprised with a fold-3 anode and $\mathrm{LiMnSiO}_{4} / \mathrm{C}$ textile cathode, the cell exhibits an aerial capacity of $2.7 \mathrm{~mA} \mathrm{~h} \mathrm{~cm}^{-2}$ at a current density of 0.3 $\mathrm{mA} \mathrm{cm}{ }^{-2}$ with no significant capacity decay after 100 bending cycles. So, this unique fabrication technique can be an effective route to designing high areal capacity integrated anode materials with favorable deformability for LIBs.

\subsection{Possible solutions for developing metals-supported stable flexible electrodes}

As metallic current collectors prone to corrosion during longterm cycling, elevating the resistance, and crack formation in the stressed zone while repeatedly mechanical deformation leads to rapid structural failure. In order to overcome such shortcomings, researchers have provided several types of suggestions such as, coated with graphene, ${ }^{194-196}$ growing of CNTs on metallic current collectors ${ }^{197-199}$ surface modifying with conducting polymer, ${ }^{200}$ coated with carbon layers, ${ }^{201,202}$ surface modification ${ }^{203}$ In addition, Park et al. synthesized honey comb like 3D structured $\mathrm{Al}$ and $\mathrm{Cu}$ by using reactive-ion etching (RIE) process, which reduce the total mass of electrodes and improved the adhesion strength with active materials results in enhanced flexibility. ${ }^{\mathbf{2 0 4}}$ Metallic fibril mesh-like configuration is 
another approach to preparing free-standing electrodes, which generates $3 \mathrm{D}$ conductive pathways through the whole electrodes and reduce the mass of electrodes while improve the capacity and flexibility. ${ }^{178}$ Moreover, 3D fibrous current collectors have low value of tortuosity and controlled porosity results in sufficient electrolyte diffusion and enhanced volumetric capacity. ${ }^{205}$ On the other hand, 3D fibrous type current collectors generate more adhesion towards active materials, increase the surface area, and lowering the total mass of electrodes. So, based on those aspects, 3D fibrous type metallic current collectors are more promising than foam based current collectors. Besides, joint-to-joint welding of metal NWs will improve the mechanical integrity of conductive metals parts in flexible electrodes under outer deformation stress. ${ }^{206}$

In summary, coating with above-mentioned materials are the effective strategy to enhancing electrical, and mechanical properties of metallic current collectors. Also, protect from direct exposure in electrolyte solutions that prevent the corrosion of metal parts which leads to improving electrochemical stability. On the other side, surface modification or designing 3D hierarchical structure enhancing the adhesion strength with active materials also leads to enhancing cycling stability and overall capacity of electrodes. Therefore, (i) coated with conductive polymers/carbonaceous materials and active materials combining with optimized amount of binders on to the rough surface of 3D hierarchical metallic current collectors; or (ii) using the joint-to-joint welded structured metallic mesh/3D fibrous type current collectors for the preparation of flexible electrodes will help to sustaining the future metals supported pliable electrodes.

\section{Understanding of chemical and configurational stability}

Electrochemical performance and cycle life of FLIBs predominantly depends on the stability of electrodes integrity during electrochemical reactions and mechanical deformations. Metalbased current collectors are most popular due to their high conductivity, easy processability, low price, and commercial availability. ${ }^{\mathbf{1 0 2 0 7}}$ On the other side, over the past decade, carbonaceous materials are also extensively studied in deformable electrodes owing to their enough electrical conductivity, desirable electrochemical, and mechanical performances. $^{8}$ On contrary, high cost intricated synthesis procedures and lacking of industrial production routes of carbonaceous materials limiting their mass applications. However, with respect to carbonaceous materials, metal-based flexible electrodes suffer from various serious issues that generate instability of metal-supported flexible electrodes. Such as corrosion of metallic current collectors through oxidation/ reduction reactions, ${ }^{208,209}$ poor interfacial contact with active materials, ${ }^{16}$ high interfacial resistance, ${ }^{210} \mathrm{Al}$ and stainless steel based current collectors are completely decayed at voltages over 4.2-4.5 V vs. $\mathrm{Li}^{+} / \mathrm{Li}^{208,211,212}$ occupying huge segments of total masses of anodes and cathodes respectively without any contributing in capacity, fast detachment of active materials during deforming, accelerating crack formation under repeated mechanical flexion, and using a large amount of binder. In addition, Wang et al. reported that the contact angle of a graphite-CNT interface $\left(19^{\circ}\right)$ is smaller than graphite- $\mathrm{Cu}$ interface $\left(48^{\circ}\right)$ results in low adhesion between graphite and $\mathrm{Cu}$, which causes the fast detachment of graphite from $\mathrm{Cu}$ current collector. ${ }^{16}$ Cui et al. reported that with respect to pyrolytic graphite film, Al current collector rapidly contaminated in lithium bis(trifluoromethane sulfonyl)imide electrolyte containing system when temperature rises to $55^{\circ} \mathrm{C}$. Also, PGF based electrode possesses a greater degree of flexibility than that of Albased electrode. ${ }^{149}$ From the abovementioned discussion, we can assume that carbonaceous materials are highly reliable for the fabrication of pliable and stable electrodes for FLIBs.

\section{Techniques for mechanical deformation evaluation}

Flexibility is the crucial event for the implementation of pliable electrodes in deformable LIBs. Up to date, several methods have been proposed to evaluate the degree of flexibility and failure modes but still lacks available established evaluation method and standard degree of flexion limit for the measurement of the flexibility of pliable electrodes. However, in this part, we have tried to briefly highlight the key parameters and useful methods for the measurement of the flexibility of the pliable electrodes. For instance, end-to-end distance, bending angle, and bending radius are important parameters for the evaluation of the bending status of bendable electrodes. ${ }^{213}$ Firstly, end-to-end $(L)$ distance means that the distance between the two ends of flexible electrodes obtained by the bending of the electrodes. ${ }^{\mathbf{2 1 4}}$ Secondly, the bending angle $(\theta)$ expresses the rotating state of the moving end of an electrode. ${ }^{215}$ Though $L$ and $\theta$ provide the general understanding of bending conditions but in the case of long electrodes, it is hard to understand the actual bending status. Besides, these two parameters also failed to provide a general concept of the failure model of flexible electrodes. Bending radius $(R)$ has been proposed as another parameter to measure the actual bending status of flexible electrodes. ${ }^{\mathbf{2 1 6}}$ However, various techniques have been suggested to measure the actual $R$ of flexible devices such as the constant cylinder method, collapsing radius geometry process, and $X-Y-\theta$ method. In the constant cylinder method, flexible electrodes are manually wrapped around a cylinder with a known diameter then measure the $R$ of flexible electrodes. ${ }^{217}$ Nevertheless, the non-uniform stress distribution is observed due to manual handling. Also, this process is not appropriate for the measurement of perfect $R$ and failure strain of flexible electrodes for the continuous bending process. In the case of collapsing radius geometry measurement, testing devices are placed between the two parallel positioned squeezable plates. The $R$ was obtained as half of the two ends of testing devices. ${ }^{218}$ though this process can be applicable for the continuous process but non-uniform stress distribution and shape of the curved structure is not perfect cylindrical. Consequently, this method is not appropriate for the measurement of the real value 
of $R$. In the case of $X-Y-\theta$ method, the testing sample was initially placed horizontally in a testing device, the testing device consists with one fixed plate and one moving plate. During test process, moving end form an arc-shaped condition with fixed end of testing sample, where the speed and direction of moving end was controlled by rotary motorized actuators. ${ }^{219}$ In this process, $X$ refers to initial horizontal direction, and $\theta$ refers to the angle between $X$ and the tangent of the moving end. The bending angle is controlled between $0^{\circ}$ to $180^{\circ}$ and the smallest $R$ is obtained as less than $L_{0} / \pi$ ( $L_{0}$ defined the length between the two ends of testing sample). Thus, this process can be used for the measurement of $R$ due to the bending condition is controlled by an automated machine with uniform distribution of stress and variation speed of bending angle that can be

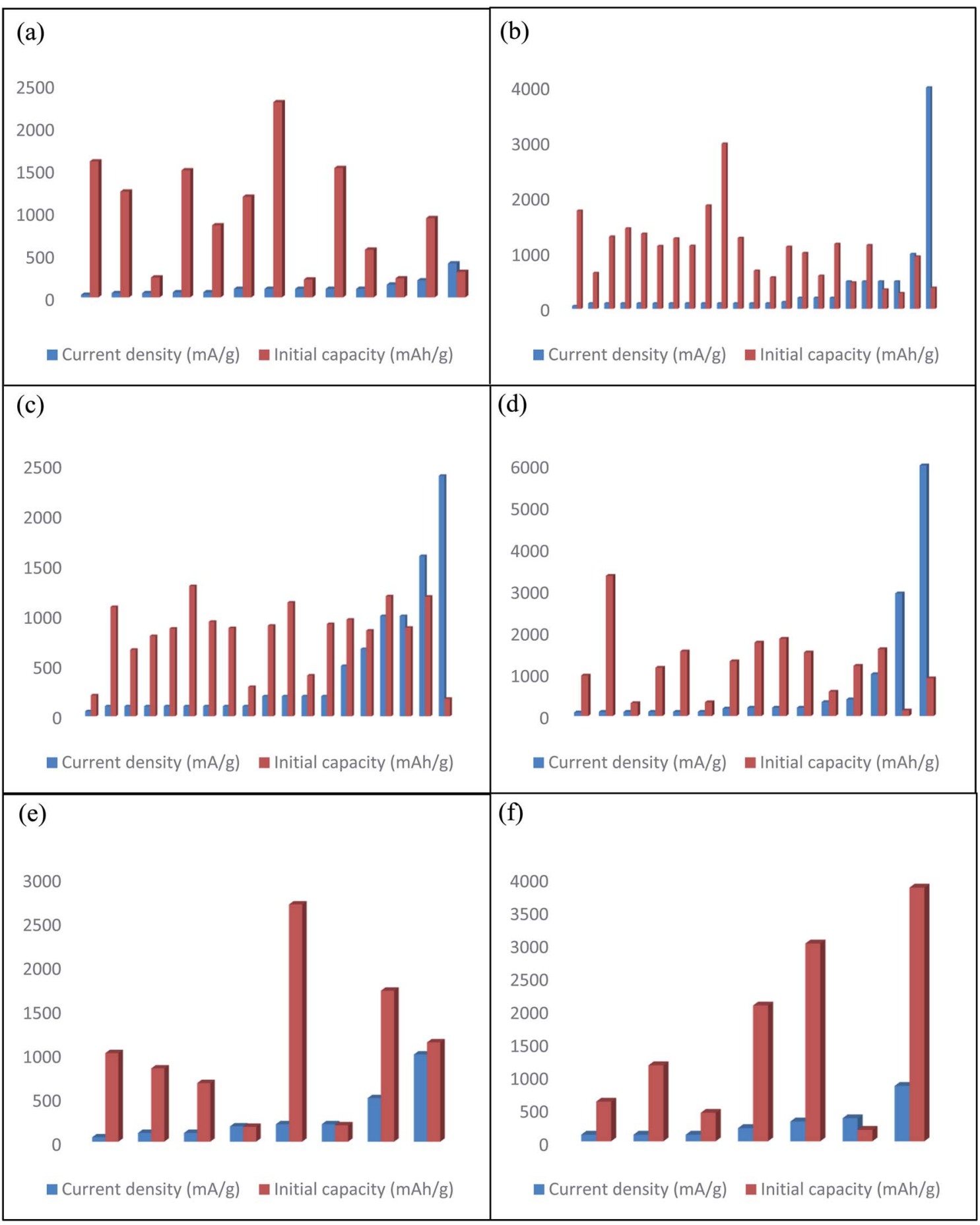

Fig. 8 Highest initial capacity at the certain current density of phene ${ }^{85-87,90-102,104,105,107}$ (d) CFT, ${ }^{111,113-120,122,123,125,126,129,130,134-136,138,142-145}$ ported ${ }^{178,179,181,184,190,192}$ flexible electrodes.

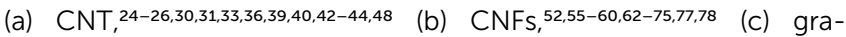
(e) carbon coating/foam, ${ }^{134-136,138,142-145}$ and (f) metals-sup- 
extended for the estimating $R$ of the flexible electrodes. On the other side, when the active materials distributed ununiformly on conductive supports/substrates then these aforementioned methods cannot predict the actual $R$. So, to calculate the actual bending radius of the non-homogeneously distributed active materials contained flexible electrodes, Island film method have been proposed. ${ }^{\mathbf{2 2 0 , 2 2 1}}$ Further, Stoney's formula suggested method to find out the films thickness and residual stress concerning bending radius. ${ }^{220,222}$

Therefore, from the abovementioned discussion, we can assume that determination of bending radius is more preferable than any other parameters to describe the bending state of the flexible electrodes. In addition, among various methods, $X-$ $Y-\theta$ method is highly recommended to calculate the bending

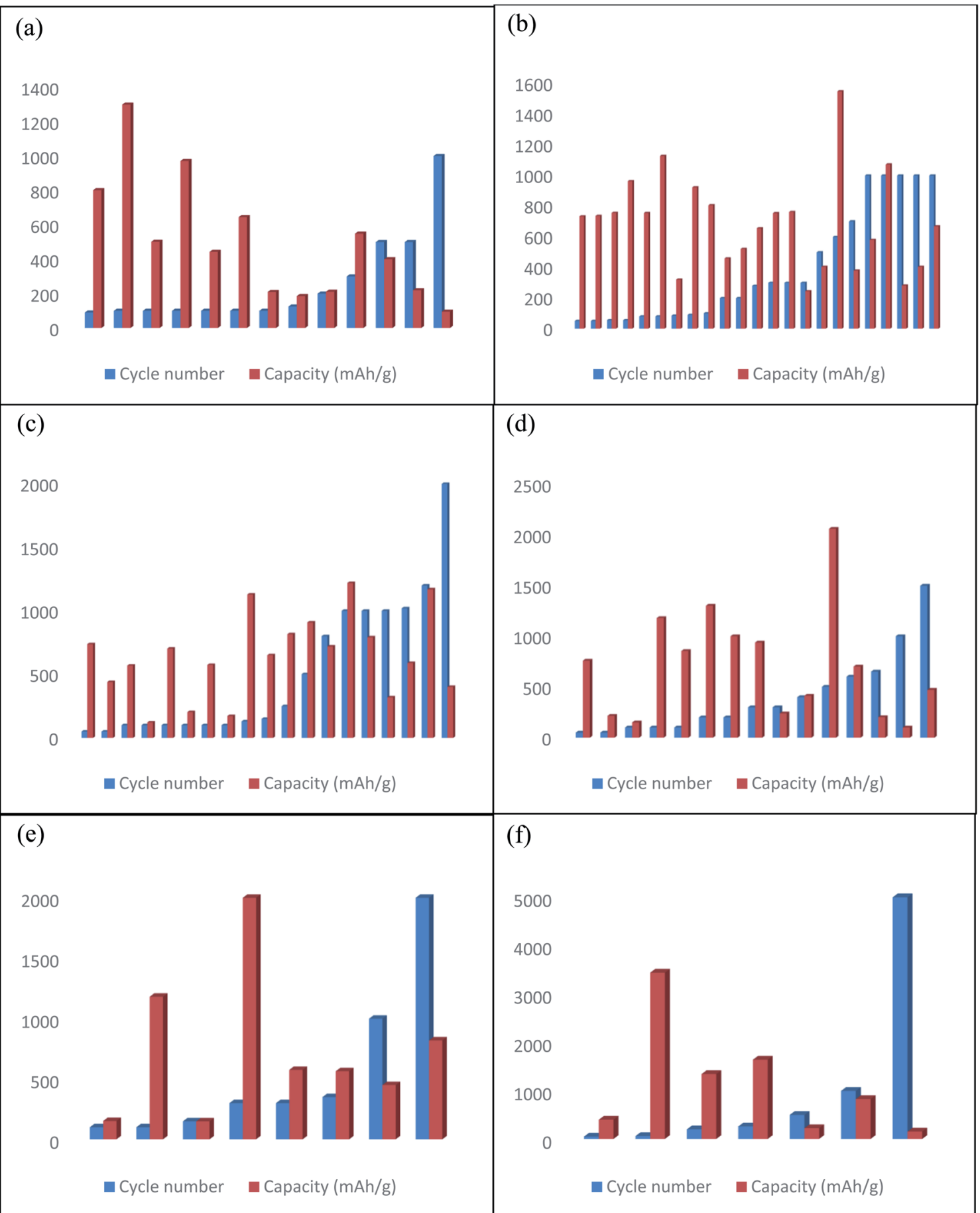

Fig. 9 Capacities after certain number of electrochemical cycles of (a) CNT, (b) CNFs, (c) graphene, (d) CFT, (e) carbon coating/foam, and (f) metals supported flexible electrodes (these data also collected from the same sources as presented in Fig. 8). 


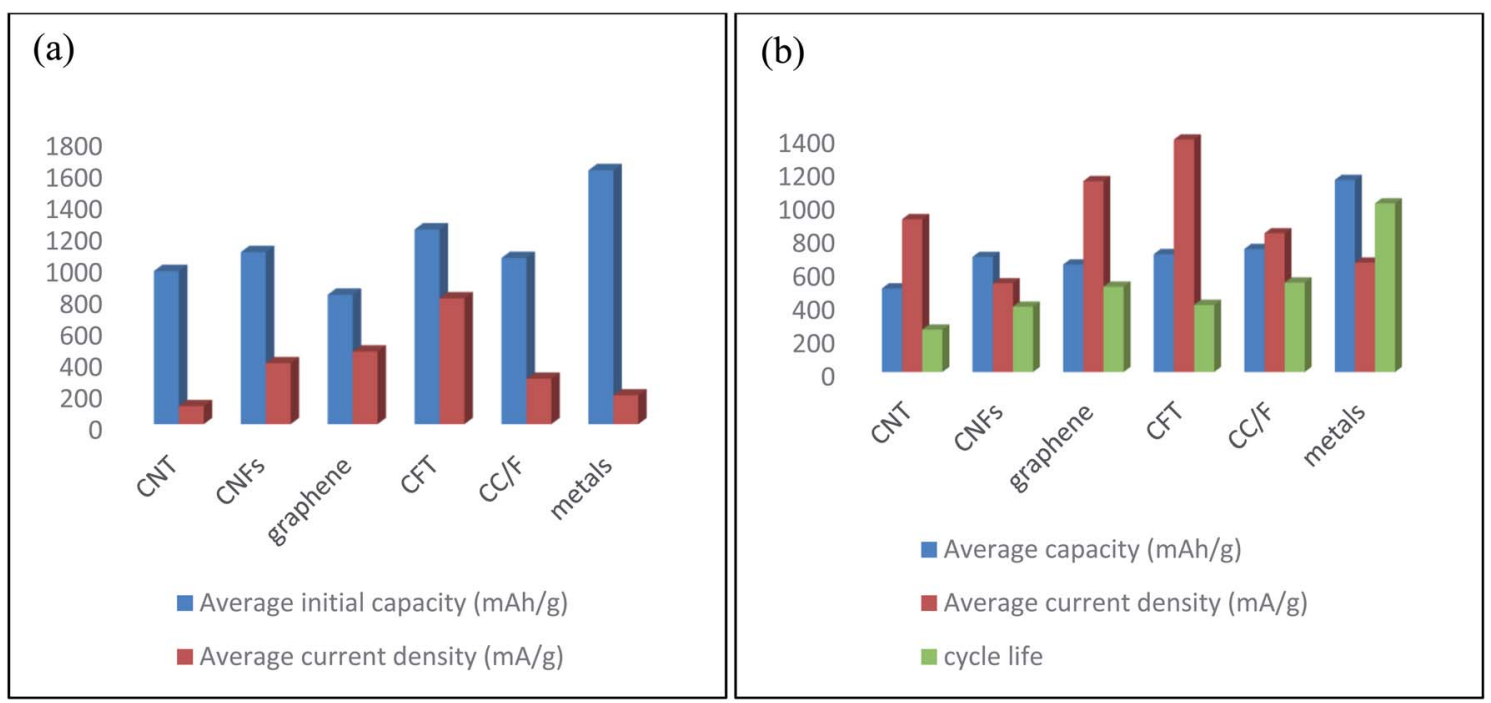

Fig. 10 (a) Average initial capacities at the average current densities, and (b) average capacities, average current densities, and average cycle life of all types of electrodes (these data also collected from the same sources as reported in Fig. 8).

radius. Further, island film and Stoney's theory should be used to attaining more realistic values of bending radius.

\section{Comparative study on electrochemical performances}

Applications of flexible electrodes in FLIBs are mainly dependent on their stability of electrochemical performance. Among various types of electrode materials CMs and metals-based electrodes exhibit greater performance due to their high electrical conductivity and low internal resistance. This part will provide a comparative understanding on their overall electrochemical behaviors based on our reported works in CMs and metals-supported flexible electrodes sections. Firstly, in Fig. 8 we have presented the initial capacities of CMs and metalsbased electrodes, and in Fig. 10a we systematically estimate the average initial capacities at the average initial current densities by using simple mathematical average calculation method. Moreover, Table 4 contained all of the initial and final performances of every type of electrodes that are depicted in subsequent graphs. Thus, from Fig. 10a CMs such as CNT, CNFs, graphene, CFT, and carbon coating/foam-based electrodes exhibits the average initial capacities of 972.71, 1092.32, $825.55,1235.97$, and $1055.43 \mathrm{~mA} \mathrm{~h} \mathrm{~g}^{-1}$ at the average current density $155.38,390.13,464.21,802.66$, and $290.62 \mathrm{~mA} \mathrm{~g}^{-1}$ respectively while metal-based electrodes demonstrated an average initial capacity of $1610.25 \mathrm{~mA} \mathrm{~h} \mathrm{~g}{ }^{-1}$ at the average current density of $284.28 \mathrm{~mA} \mathrm{~g}^{-1}$. Owing to the higher electrical conductivity of metals than that of CMs, which stimulates greater average initial electrochemical performance?

In Fig. 9 we plotted the capacity $\left(\mathrm{mA} \mathrm{h} \mathrm{g}^{-1}\right) v s$. cycle life values of CMs and metals supported flexible electrodes. By the comparing between Fig. 8 and 9, we can assume that with the increase of electrochemical cycle number the capacity of all types' electrodes is gradually decreased mainly due to the thick
SEI formation, growth of $\mathrm{Li}$ dendrite, detachment of active materials, and structural decay of conductive supports of electrodes. In addition, from Fig. 10b the average capacity retention at the average current densities after average cycle life of CNT, CNFs, graphene, CFT, carbon coating/foam, and metals based electrodes are around 502.4, 689.65, 643.48, 705.80, 736.75, $1149.72 \mathrm{~mA} \mathrm{~h} \mathrm{~g}^{-1}$ at $915.38,533.6,1143,1391.8,831.25$, and $655.71 \mathrm{~mA} \mathrm{~g}^{-1}$ corresponding to $51.65,63.14,77.95,57.10,69.80$, and $71.4 \%$ of their average initial capacities after the average electrochemical cycles of $255,393,514,403.33,537$, and 1010 (taking only integral number) respectively, these average values are also calculated by simple mathematical average calculation method.

As far we know limited amount of investigations have been done based on metals in the field of flexible electrodes, consequently it is hard to deciding precise approximate average values of capacity and cycle life. For instance, from ref. ${ }^{192}$ without the largest value of cycle life (5000) the average cycle life drastically declined to only 345 , and from ref. ${ }^{179}$ without largest value of capacity ( $3441.9 \mathrm{~mA} \mathrm{~h} \mathrm{~g}{ }^{-1}$ ) the average capacity value declined to $767.8 \mathrm{~mA} \mathrm{~h} \mathrm{~g}^{-1}$ corresponding to $62 \%$ of average initial capacity of metals supported electrodes, indicating the severe cycle instability even though this value is larger than various CMs based electrodes.

On the other hand, metals demonstrated poor adhesion strength with active materials due to plane surface and no surface functionality results in fast detachment of active materials under structural deformation. Moreover, Liang et al. systematically revealed that, in a specific cell 3D hierarchical CMs based electrodes enhancing the capacity retention of up to 5 times and the cycle number is 200 than that of their metallic counterparts. ${ }^{205}$ Furthermore, even if metals show superior electrochemical performance under flat states it will drastically fall after several times of flexion.

In brief, CMs based electrodes have more superior factors than metals-based electrodes in terms of electrochemical 
Table 4 Initial and final performances of all types of electrodes

Initial performance (ref.) [capacity/current rate/cycle life]

\begin{tabular}{|c|c|c|c|c|c|}
\hline $\begin{array}{l}\text { CNT-supported } \\
\text { electrodes }\end{array}$ & $\begin{array}{l}\text { CNFs-supported } \\
\text { electrodes }\end{array}$ & $\begin{array}{l}\text { Graphene-supported } \\
\text { electrodes }\end{array}$ & $\begin{array}{l}\text { CFT-supported } \\
\text { electrodes }\end{array}$ & $\begin{array}{l}\text { CC/F-supported } \\
\text { electrodes }\end{array}$ & $\begin{array}{l}\text { Metals-supported } \\
\text { electrodes }\end{array}$ \\
\hline $1780 \mathrm{~mA} \mathrm{~h} \mathrm{~g}^{-1} /$ & $1780 \mathrm{~mA} \mathrm{~h} \mathrm{~g}^{-1} /$ & $1198 \mathrm{~mA} \mathrm{~h} \mathrm{~g}^{-1 /}$ & $3362 \mathrm{~mA} \mathrm{~h} \mathrm{~g}^{-1} /$ & $2700 \mathrm{~mA} \mathrm{~h} \mathrm{~g}^{-1} /$ & $3000 \mathrm{~mA} \mathrm{~h} \mathrm{~g}^{-1 /}$ \\
\hline$\left[1550 \mathrm{~mA} \mathrm{~h} \mathrm{~g}^{-1} /\right.$ & {$\left[1550 \mathrm{~mA} \mathrm{~h} \mathrm{~g}^{-1} /\right.$} & {$\left[1170 \mathrm{~mA} \mathrm{~h} \mathrm{~g}^{-1} /\right.$} & {$\left[2061 \mathrm{~mA} \mathrm{~h} \mathrm{~g}^{-1} /\right.$} & {$\left[2000 \mathrm{~mA} \mathrm{~h} \mathrm{~g}^{-1} /\right.$} & {$\left[1350 \mathrm{~mA} \mathrm{~h} \mathrm{~g}^{-1} /\right.$} \\
\hline $\left.500 \mathrm{~mA} \mathrm{~g}^{-1} / 600\right]$ & $\left.500 \mathrm{~mA} \mathrm{~g}^{-1} / 600\right]$ & $\left.1000 \mathrm{~mA} \mathrm{~g}^{-1} / 1200\right]$ & $1000 \mathrm{~mA} \mathrm{~g}^{-1 / 500]}$ & $\left.200 \mathrm{~mA} \mathrm{~g}^{-1} / 300\right]$ & $2000 \mathrm{~mA} \mathrm{~g}^{-1 / 200]}$ \\
\hline $654 \mathrm{~mA} \mathrm{~h} \mathrm{~g}^{-1} /$ & $654 \mathrm{~mA} \mathrm{~h} \mathrm{~g}^{-1} /$ & $175 \mathrm{~mA} \mathrm{~h} \mathrm{~g}^{-1 /}$ & $1761 \mathrm{~mA} \mathrm{~h} \mathrm{~g}^{-1 /}$ & $170 \mathrm{~mA} \mathrm{~h} \mathrm{~g}^{-1} /$ & $2062 \mathrm{~mA} \mathrm{~h} \mathrm{~g}^{-1 /}$ \\
\hline $\left.100 \mathrm{~mA} \mathrm{~g}^{-1} / 55\right]$ & $100 \mathrm{~mA} \mathrm{~g}^{-1 / 55]}$ & $\left.1600 \mathrm{~mA} \mathrm{~g}^{-1} / 1020\right]$ & $200 \mathrm{~mA} \mathrm{~g}^{-1 / 300]}$ & $\left.1750 \mathrm{~mA} \mathrm{~g}^{-1} / 100\right]$ & $\left.200 \mathrm{~mA} \mathrm{~g}^{-1} / 260\right]$ \\
\hline $287.4 \mathrm{~mA} \mathrm{~h} \mathrm{~g}^{-1} /$ & $287.4 \mathrm{~mA} \mathrm{~h} \mathrm{~g}^{-1} /$ & $1194 \mathrm{~mA} \mathrm{~h} \mathrm{~g}^{-1} /$ & $968.6 \mathrm{~mA} \mathrm{~h} \mathrm{~g}^{-1} /$ & $1137.5 \mathrm{~mA} \mathrm{~h} \mathrm{~g}^{-1} /$ & $601.8 \mathrm{~mA} \mathrm{~h} \mathrm{~g}^{-1} /$ \\
\hline $500 \mathrm{~mA} \mathrm{~g}^{-1}$ (ref. 56) & $500 \mathrm{~mA} \mathrm{~g}^{-1}$ (ref. 56) & $1600 \mathrm{~mA} \mathrm{~g}^{-1}$ (ref. 87) & $850 \mathrm{~mA} \mathrm{~g}^{-1}$ (ref. 114) & $1000 \mathrm{~mA} \mathrm{~g}^{-1}$ (ref. 136) & $100 \mathrm{~mA} \mathrm{~g}^{-1}$ (ref. 181) \\
\hline$\left[380.1 \mathrm{~mA} \mathrm{~h} \mathrm{~g}^{-1} /\right.$ & {$\left[380.1 \mathrm{~mA} \mathrm{~h} \mathrm{~g}^{-1} /\right.$} & {$\left[1220 \mathrm{~mA} \mathrm{~h} \mathrm{~g}^{-1} /\right.$} & {$\left[471.2 \mathrm{~mA} \mathrm{~h} \mathrm{~g}^{-1} /\right.$} & {$\left[820 \mathrm{~mA} \mathrm{~h} \mathrm{~g}^{-1 /}\right.$} & {$\left[224.2 \mathrm{~mA} \mathrm{~h} \mathrm{~g}^{-1 /}\right.$} \\
\hline $200 \mathrm{~mA} \mathrm{~g}^{-1 / 700]}$ & $200 \mathrm{~mA} \mathrm{~g}^{-1 / 700]}$ & $1600 \mathrm{~mA} \mathrm{~g}^{-1 / 1000]}$ & $\left.900 \mathrm{~mA} \mathrm{~g}^{-1} / 1500\right]$ & $\left.1000 \mathrm{~mA} \mathrm{~g}^{-1} / 2000\right]$ & $100 \mathrm{~mA} \mathrm{~g}^{-1 / 500]}$ \\
\hline $1313 \mathrm{~mA} \mathrm{~h} \mathrm{~g}^{-1 /}$ & $1313 / 100 \mathrm{~mA} \mathrm{~g}^{-1}$ (ref. & $1091 \mathrm{~mA} \mathrm{~h} \mathrm{~g}^{-1 /}$ & $310 \mathrm{~mA} \mathrm{~h} \mathrm{~g}^{-1} /$ & $1015 \mathrm{~mA} \mathrm{~h} \mathrm{~g}^{-1 /}$ & $3850 \mathrm{~mA} \mathrm{~h} \mathrm{~g}^{-1} /$ \\
\hline $100 \mathrm{~mA} \mathrm{~g}^{-1}$ (ref. 58) & $100 \mathrm{~mA} \mathrm{~g}^{-1}$ (ref. 58) & $200 \mathrm{~mA} \mathrm{~g}^{-1}$ (ref. 91) & $335 \mathrm{~mA} \mathrm{~g}^{-1}$ (ref. 116) & $100 \mathrm{~mA} \mathrm{~g}^{-1}$ (ref. 142) & $100 \mathrm{~mA} \mathrm{~g}^{-1}$ (ref. 186) \\
\hline$\left[1072 \mathrm{~mA} \mathrm{~h} \mathrm{~g}^{-1 /}\right.$ & {$\left[1072 \mathrm{~mA} \mathrm{~h} \mathrm{~g}^{-1 /}\right.$} & {$\left[650 \mathrm{~mA} \mathrm{~h} \mathrm{~g}^{-1} /\right.$} & {$\left[203 \mathrm{~mA} \mathrm{~h} \mathrm{~g}^{-1} /\right.$} & {$\left[450 \mathrm{~mA} \mathrm{~h} \mathrm{~g}^{-1} /\right.$} & {$\left[830 \mathrm{~mA} \mathrm{~h} \mathrm{~g}^{-1} /\right.$} \\
\hline $1000 \mathrm{~mA} \mathrm{~g}^{-1 / 1000]}$ & $\left.1000 \mathrm{~mA} \mathrm{~g}^{-1} / 1000\right]$ & $\left.200 \mathrm{~mA} \mathrm{~g}^{-1} / 150\right]$ & $\left.3350 \mathrm{~mA} \mathrm{~g}^{-1} / 650\right]$ & $\left.1200 \mathrm{~mA} \mathrm{~g}^{-1} / 1000\right]$ & $\left.1000 \mathrm{~mA} \mathrm{~g}^{-1} / 1000\right]$ \\
\hline $1363.6 \mathrm{~mA} \mathrm{~h} \mathrm{~g}^{-1} /$ & $1363.6 \mathrm{~mA} \mathrm{~h} \mathrm{~g}^{-1 /}$ & $854.3 \mathrm{~mA} \mathrm{~h} \mathrm{~g}^{-1} /$ & $1603 \mathrm{~mA} \mathrm{~h} \mathrm{~g}^{-1} /$ & $1721 \mathrm{~mA} \mathrm{~h} \mathrm{~g}^{-1 /}$ & $432 \mathrm{~mA} \mathrm{~h} \mathrm{~g}^{-1} /$ \\
\hline $100 \mathrm{~mA} \mathrm{~g}^{-1}$ (ref. 59) & $100 \mathrm{~mA} \mathrm{~g}^{-1}$ (ref. 59) & $670 \mathrm{~mA} \mathrm{~g}^{-1}$ (ref. 92) & $1000 \mathrm{~mA} \mathrm{~g}^{-1}$ (ref. 117) & $500 \mathrm{~mA} \mathrm{~g}^{-1}$ (ref. 143) & $100 \mathrm{~mA} \mathrm{~g}^{-1}$ (ref. 190) \\
\hline$\left[655 \mathrm{~mA} \mathrm{~h} \mathrm{~g}^{-1} /\right.$ & {$\left[655 \mathrm{~mA} \mathrm{~h} \mathrm{~g}^{-1} /\right.$} & {$\left[736.8 \mathrm{~mA} \mathrm{~h} \mathrm{~g}^{-1} /\right.$} & {$\left[700.3 \mathrm{~mA} \mathrm{~h} \mathrm{~g}^{-1} /\right.$} & {$\left[1182 \mathrm{~mA} \mathrm{~h} \mathrm{~g}^{-1 /}\right.$} & {$\left[400 \mathrm{~mA} \mathrm{~h} \mathrm{~g}^{-1} /\right.$} \\
\hline $\left.500 \mathrm{~mA} \mathrm{~g}^{-1} / 280\right]$ & $\left.500 \mathrm{~mA} \mathrm{~g}^{-1} / 280\right]$ & $67 \mathrm{~mA} \mathrm{~g}^{-1 / 50]}$ & $\left.5000 \mathrm{~mA} \mathrm{~g}^{-1} / 600\right]$ & $\left.500 \mathrm{~mA} \mathrm{~g}^{-1} / 100\right]$ & $\left.100 \mathrm{~mA} \mathrm{~g}^{-1} / 50\right]$ \\
\hline $1131 \mathrm{~mA} \mathrm{~h} \mathrm{~g}^{-1} /$ & $1131 \mathrm{~mA} \mathrm{~h} \mathrm{~g}^{-1 /}$ & $1135.2 \mathrm{~mA} \mathrm{~h} \mathrm{~g}^{-1} /$ & $1310 \mathrm{~mA} \mathrm{~h} \mathrm{~g}^{-1} /$ & $188 \mathrm{~mA} \mathrm{~h} \mathrm{~g} \mathrm{~g}^{-1} /$ & $350 \mathrm{~mA} \mathrm{~h} \mathrm{~g}^{-1 /}$ \\
\hline $123 \mathrm{~mA} \mathrm{~g}^{-1}$ (ref. 60) & $123 \mathrm{~mA} \mathrm{~g}^{-1}$ (ref. 60$)$ & $200 \mathrm{~mA} \mathrm{~g}^{-1}$ (ref. 93) & $180 \mathrm{~mA} \mathrm{~g}^{-1}$ (ref. 118) & $200 \mathrm{~mA} \mathrm{~g}^{-1}$ (ref. 144) & $173 \mathrm{~mA} \mathrm{~g}^{-1}$ (ref. 192) \\
\hline$\left[923 \mathrm{~mA} \mathrm{~h} \mathrm{~g}^{-1} /\right.$ & {$\left[923 \mathrm{~mA} \mathrm{~h} \mathrm{~g}^{-1} /\right.$} & {$\left[1129.2 \mathrm{~mA} \mathrm{~h} \mathrm{~g}^{-1} /\right.$} & {$\left[1180 \mathrm{~mA} \mathrm{~h} \mathrm{~g}^{-1} /\right.$} & {$\left[149 \mathrm{~mA} \mathrm{~h} \mathrm{~g}^{-1} /\right.$} & {$\left[153 \mathrm{~mA} \mathrm{~h} \mathrm{~g}^{-1} /\right.$} \\
\hline $\left.123 \mathrm{~mA} \mathrm{~g}^{-1} / 90\right]$ & $\left.123 \mathrm{~mA} \mathrm{~g}^{-1} / 90\right]$ & $\left.200 \mathrm{~mA} \mathrm{~g}^{-1} / 130\right]$ & $\left.180 \mathrm{~mA} \mathrm{~g}^{-1} / 100\right]$ & $\left.1000 \mathrm{~mA} \mathrm{~g}^{-1} / 149\right]$ & $\left.350 \mathrm{~mA} \mathrm{~g}^{-1} / 5000\right]$ \\
\hline $1145 \mathrm{~mA} \mathrm{~h} \mathrm{~g}^{-1 /}$ & $1145 \mathrm{~mA} \mathrm{~h} \mathrm{~g}^{-1 /}$ & $405 \mathrm{~mA} \mathrm{~h} \mathrm{~g}^{-1 /}$ & $1851.9 \mathrm{~mA} \mathrm{~h} \mathrm{~g}^{-1} /$ & $672 \mathrm{~mA} \mathrm{~h} \mathrm{~g}^{-1 /}$ & \\
\hline $100 \mathrm{~mA} \mathrm{~g}^{-1}$ (ref. 64) & $100 \mathrm{~mA} \mathrm{~g}^{-1}$ (ref. 64 ) & $100 \mathrm{~mA} \mathrm{~g}^{-1}$ (ref. 96) & $6000 \mathrm{~mA} \mathrm{~g}^{-1}$ (ref. 122) & & \\
\hline$\left[963 \mathrm{~mA} \mathrm{~h} \mathrm{~g}^{-1} /\right.$ & {$\left[963 \mathrm{~mA} \mathrm{~h} \mathrm{~g}^{-1} /\right.$} & {$\left[438.5 \mathrm{~mA} \mathrm{~h} \mathrm{~g}^{-1} /\right.$} & {$\left[240 \mathrm{~mA} \mathrm{~h} \mathrm{~g}^{-1 /}\right.$} & & \\
\hline $\left.100 \mathrm{~mA} \mathrm{~g}^{-1} / 55\right]$ & $\left.100 \mathrm{~mA} \mathrm{~g}^{-1} / 55\right]$ & $\left.100 \mathrm{~mA} \mathrm{~g}^{-1} / 50\right]$ & $6000 \mathrm{~mA} \mathrm{~g}^{-1 / 300]}$ & & \\
\hline $954 \mathrm{~mA} \mathrm{~h} \mathrm{~g}^{-1 /}$ & $954 \mathrm{~mA} \mathrm{~h} \mathrm{~g}^{-1 /}$ & $800 \mathrm{~mA} \mathrm{~h} \mathrm{~g}^{-1} /$ & $1200 \mathrm{~mA} \mathrm{~h} \mathrm{~g}^{-1 /}$ & & \\
\hline $1000 \mathrm{~mA} \mathrm{~g}^{-1}$ (ref. 65) & $1000 \mathrm{~mA} \mathrm{~g}^{-1}$ (ref. 65) & $100 \mathrm{~mA} \mathrm{~g}^{-1}$ (ref. 97) & $400 \mathrm{~mA} \mathrm{~g}^{-1}$ (ref. 123$)$ & & \\
\hline$\left[736 \mathrm{~mA} \mathrm{~h} \mathrm{~g}^{-1 /}\right.$ & {$\left[736 \mathrm{~mA} \mathrm{~h} \mathrm{~g}^{-1 /}\right.$} & {$\left[702 \mathrm{~mA} \mathrm{~h} \mathrm{~g}^{-1} /\right.$} & {$\left[1000 \mathrm{~mA} \mathrm{~h} \mathrm{~g}^{-1} /\right.$} & & \\
\hline $\left.50 \mathrm{~mA} \mathrm{~g}^{-1} / 50\right]$ & $50 \mathrm{~mA} \mathrm{~g}^{-1 / 50]}$ & $100 \mathrm{~mA} \mathrm{~g}^{-1 / 100]}$ & $\left.400 \mathrm{~mA} \mathrm{~g}^{-1} / 200\right]$ & & \\
\hline $1149.4 \mathrm{~mA} \mathrm{hg}^{-1 /}$ & $1149.4 \mathrm{~mA} \mathrm{~h} \mathrm{~g}^{-1 /}$ & $210 \mathrm{~mA} \mathrm{~h} \mathrm{~g}^{-1 /}$ & $1156.5 \mathrm{~mA} \mathrm{~h} \mathrm{~g}^{-1} /$ & & \\
\hline $100 \mathrm{~mA} \mathrm{~g}^{-1}$ (ref. 66) & $100 \mathrm{~mA} \mathrm{~g}^{-1}$ (ref. 66) & $50 \mathrm{~mA} \mathrm{~g}^{-1}$ (ref. 98) & $100 \mathrm{~mA} \mathrm{~g}^{-1}$ (ref. 125) & & \\
\hline$\left[805.8 \mathrm{~mA} \mathrm{~h} \mathrm{~g}^{-1} /\right.$ & {$\left[805.8 \mathrm{~mA} \mathrm{~h} \mathrm{~g}^{-1} /\right.$} & {$\left[203 \mathrm{~mA} \mathrm{~h} \mathrm{~g}^{-1} /\right.$} & {$\left[758.1 \mathrm{~mA} \mathrm{~h} \mathrm{~g}^{-1} /\right.$} & & \\
\hline $100 \mathrm{~mA} \mathrm{~g}^{-1 / 100]}$ & $100 \mathrm{~mA} \mathrm{~g}^{-1 / 100]}$ & $50 \mathrm{~mA} \mathrm{~g}^{-1 / 100]}$ & $700 \mathrm{~mA} \mathrm{~g}^{-1 / 50]}$ & & \\
\hline $1872 \mathrm{~mA} \mathrm{~h} \mathrm{~g}^{-1} /$ & $1872 \mathrm{~mA} \mathrm{~h} \mathrm{~g}^{-1} /$ & $874 \mathrm{~mA} \mathrm{~h} \mathrm{~g}^{-1} /$ & $1547.8 \mathrm{~mA} \mathrm{~h} \mathrm{~g}^{-1} /$ & & \\
\hline $100 \mathrm{~mA} \mathrm{~g}^{-1}$ (ref. 67) & $100 \mathrm{~mA} \mathrm{~g}^{-1}$ (ref. 67 ) & $100 \mathrm{~mA} \mathrm{~g}^{-1}$ (ref. 99) & $100 \mathrm{~mA} \mathrm{~g}^{-1}$ (ref. 126$)$ & & \\
\hline$\left[755 \mathrm{~mA} \mathrm{~h} \mathrm{~g}^{-1} /\right.$ & {$\left[755 \mathrm{~mA} \mathrm{~h} \mathrm{~g}^{-1 /}\right.$} & {$\left[791 \mathrm{~mA} \mathrm{~h} \mathrm{~g}^{-1} /\right.$} & {$\left[414.2 \mathrm{~mA} \mathrm{~h} \mathrm{~g}^{-1} /\right.$} & & \\
\hline $\left.100 \mathrm{~mA} \mathrm{~g}^{-1} / 80\right]$ & $\left.100 \mathrm{~mA} \mathrm{~g}^{-1} / 80\right]$ & $\left.1000 \mathrm{~mA} \mathrm{~g}^{-1} / 1000\right]$ & $\left.800 \mathrm{~mA} \mathrm{~g}^{-1} / 400\right]$ & & \\
\hline $481 \mathrm{~mA} \mathrm{~h} \mathrm{~g}^{-1 /}$ & $481 \mathrm{~mA} \mathrm{~h} \mathrm{~g}^{-1 /}$ & $1300 \mathrm{~mA} \mathrm{~h} \mathrm{~g} \mathrm{~g}^{-1} /$ & $135 \mathrm{~mA} \mathrm{~h} \mathrm{~g}^{-1 /}$ & & \\
\hline $500 \mathrm{~mA} \mathrm{~g}^{-1}$ (ref. 68$)$ & $500 \mathrm{~mA} \mathrm{~g}^{-1}$ (ref. 68$)$ & $100 \mathrm{~mA} \mathrm{~g}^{-1}$ (ref. 100) & $2940 \mathrm{~mA} \mathrm{~g}^{-1}$ (ref. 129) & & \\
\hline$\left[321 \mathrm{~mA} \mathrm{~h} \mathrm{~g}^{-1} /\right.$ & {$\left[321 \mathrm{~mA} \mathrm{~h} \mathrm{~g}^{-1 /}\right.$} & {$\left[320 \mathrm{~mA} \mathrm{~h} \mathrm{~g}^{-1} /\right.$} & {$\left[215 \mathrm{~mA} \mathrm{~h} \mathrm{~g}^{-1 /}\right.$} & & \\
\hline $\left.500 \mathrm{~mA} \mathrm{~g}^{-1} / 85\right]$ & $500 \mathrm{~mA} \mathrm{~g}^{-1 / 85]}$ & $\left.5000 \mathrm{~mA} \mathrm{~g}^{-1} / 1000\right]$ & $147 \mathrm{~mA} \mathrm{~g}^{-1 / 50]}$ & & \\
\hline $2987.7 \mathrm{~mA} \mathrm{~h} \mathrm{~g}^{-1} /$ & $2987.7 \mathrm{~mA} \mathrm{~h} \mathrm{~g}^{-1} /$ & $943 \mathrm{~mA} \mathrm{~h}^{-1 /}$ & $330 \mathrm{~mA} \mathrm{~h} \mathrm{~g}^{-1} /$ & & \\
\hline $100 \mathrm{~mA} \mathrm{~g}^{-1}$ (ref. 69) & $100 \mathrm{~mA} \mathrm{~g}^{-1}$ (ref. 69) & $100 \mathrm{~mA} \mathrm{~g}^{-1}$ (ref. 101) & $100 \mathrm{~mA} \mathrm{~g}^{-1}$ (ref. 130) & & \\
\hline$\left[1128 \mathrm{~mA} \mathrm{~h} \mathrm{~g}^{-1} /\right.$ & {$\left[1128 \mathrm{~mA} \mathrm{~h} \mathrm{~g}^{-1 /}\right.$} & {$\left[573 \mathrm{~mA} \mathrm{~h} \mathrm{~g}^{-1} /\right.$} & {$\left[100 \mathrm{~mA} \mathrm{~h} \mathrm{~g}^{-1} /\right.$} & & \\
\hline $\left.100 \mathrm{~mA} \mathrm{~g}^{-1} / 80\right]$ & $100 \mathrm{~mA} \mathrm{~g}^{-1 / 80]}$ & $100 \mathrm{~mA} \mathrm{~g}^{-1 / 100]}$ & $\left.1000 \mathrm{~mA} \mathrm{~g}^{-1} / 1000\right]$ & & \\
\hline
\end{tabular}


Table 4 (Contd.)

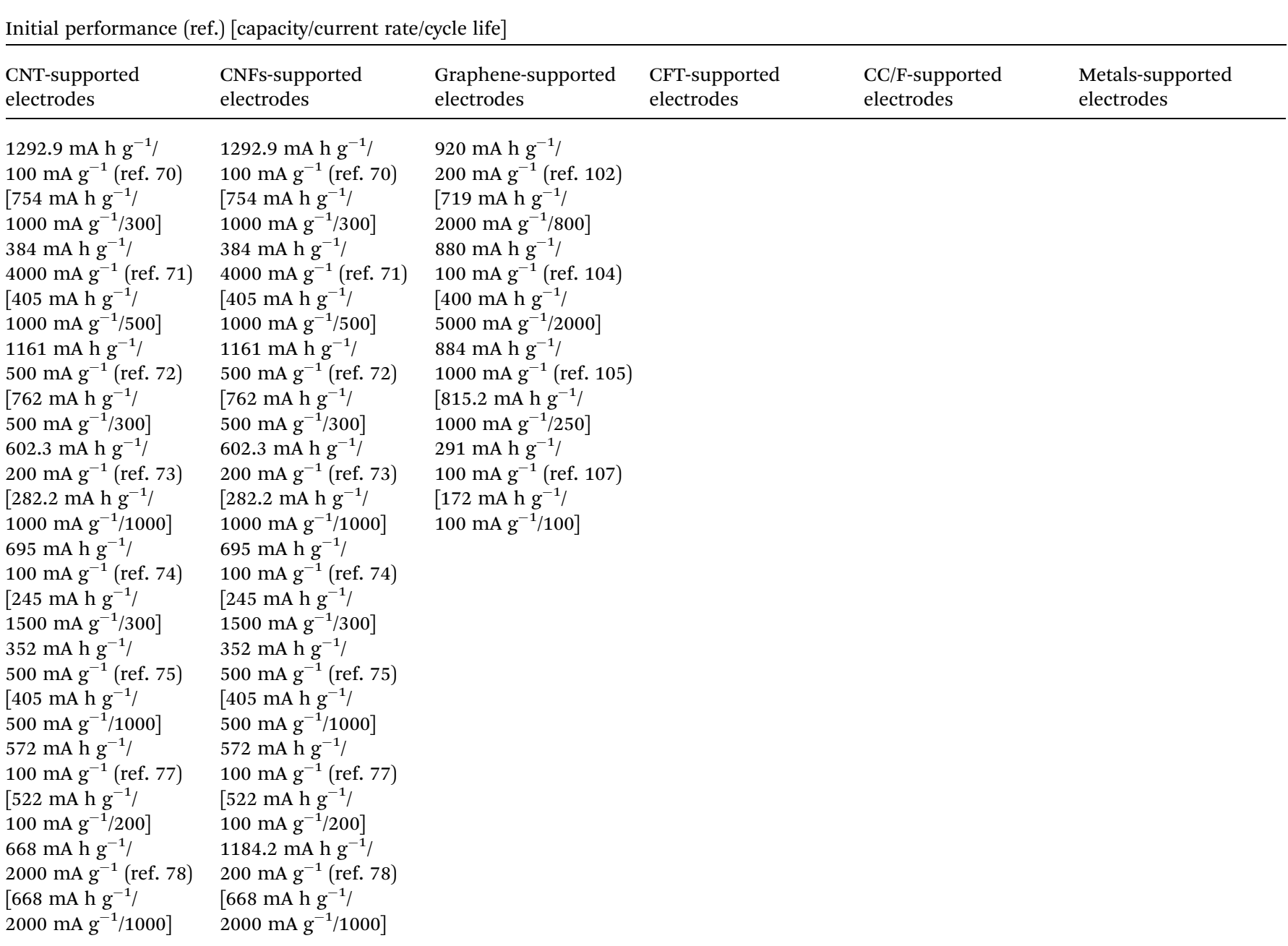

stability. These major advantageous factors are: (i) larger specific surface area, (ii) higher charge transfer rate for electrochemical reactions $\left(10^{8} \mathrm{~S} \mathrm{~m}^{-1}\right.$ of graphene while $10^{7} \mathrm{~S} \mathrm{~m}^{-1}$ of metals), ${ }^{223}$ (iii) better chemical stability that stimulate to wide potential window. These factors are crucial to improve the overall electrochemical performance of LIBs. Meanwhile, due to strong adhesion with active materials, CMs exhibit stable electrochemical performance under various structural deformation states. Therefore, CMs are more reliable to developing highly durable FLIBs for next-generation wearable electronic devices.

After all, from this discussion graphene-based electrodes exhibit superior electrochemical stability though various issues associated with integration of graphene in practical FLIBs applications. On the other hand, another CMs based electrodes also showed excellent electrochemical performances. Moreover, structural adaptation such as nanowire and mesh like configuration of metals will be the solution for the large mass, low surface area, and integrity of electrodes during deformation. Furthermore, controlling the pore size in metals foam-based electrodes will increase the specific surface area and electrolyte wettability. However, yet CMs and metals based flexible electrodes cannot meet the commercial demands in terms of electrochemical and mechanical performances, thus great research attentions required to implement those types of deformable electrodes in FLIBs.

\section{Conclusion and perspectives}

Based on recent investigations in Fig. 11, we have systematically presented the major issues associated with flexible electrodes. In addition, comparative understanding, and vital factors have been deeply discussed along with the applications of CMs and metal-based flexible electrodes for LIBs. The prominent obstacles about the electrodes are crack formation and detachment of active materials to realize desirable performance. Despite this, plenty of research has been carried out on CMs and metalbased flexible electrodes; their performances yet very poor than their rigid analogous.

Based on the above discussed experimental works, the binder-free flexible electrodes possess some excellent advantages:

(i) Firm interfacial contact between conductive parts and active materials which leads to the high charge transfer rate; 


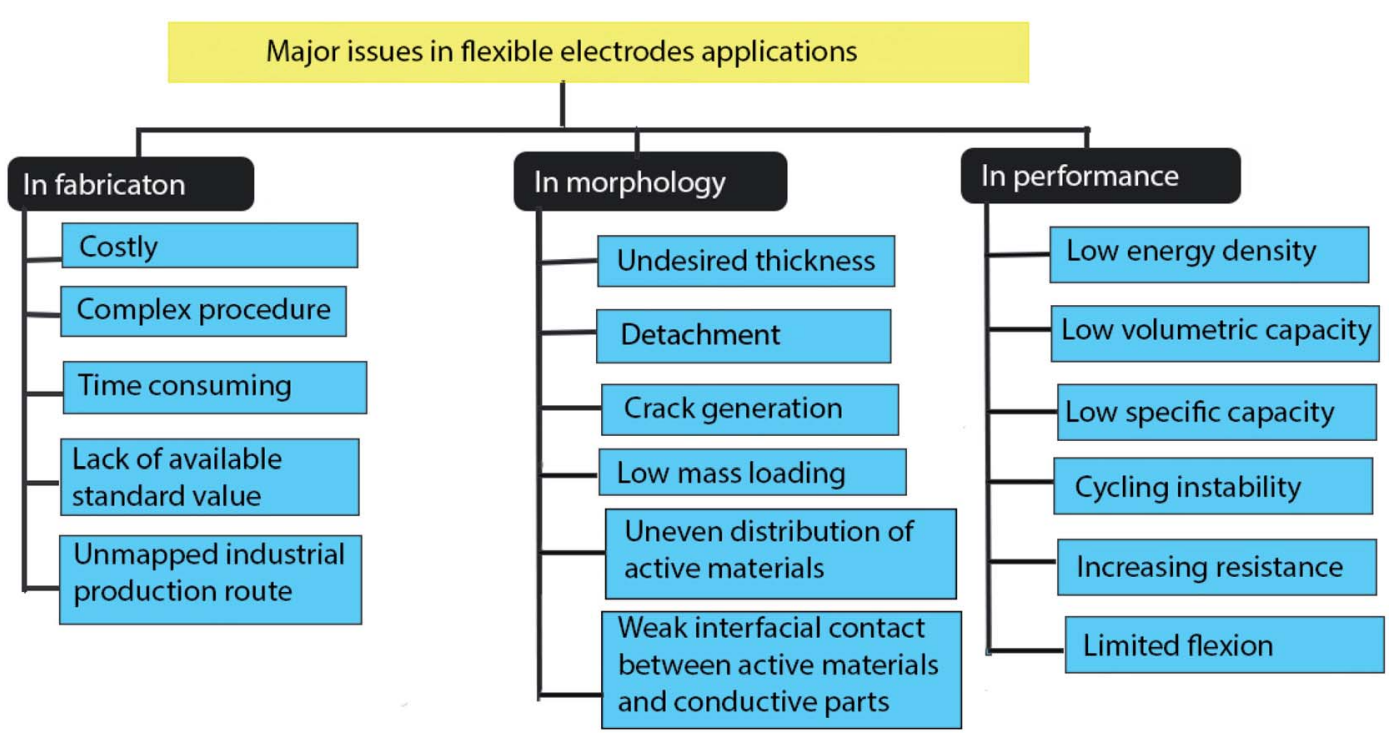

Fig. 11 Major issues associated with fabrication, structure, and performance of flexible electrodes.

(ii) Removal of inactive binders are beneficial for reducing overall mass and unwanted heat evolution;

(iii) High mass loading due to the direct bonding between active materials and conductive materials which can enhance the overall capacity of electrodes;

(iv) Capable to retain good mechanical integrity under outer stress due to the strong binding strength between active materials and conductive parts;

(v) Direct interaction between active materials and electrolytes results in proper utilization of active materials and outstanding electrochemical performance.

Metals have better electrical conductivity than carbonaceous materials but more readily undergo corrosion and increasing sheet resistance during long-term storage. Besides, concerning CMs based electrodes, metal-based electrodes possess fast cracking and delamination of active materials. Therefore, to improve the robustness of electrodes, various techniques such as modification of the current collectors and active materials have been suggested from the materials development period. For instance, nanosized and porous morphological alteration of active materials from the spherical shaped particles ensured the great adhesion of the electrode components during deformation. Furthermore, carbonaceous materials based free-standing electrodes come into the spotlight, due to the non-existence of the current collector to avoid the detachment of the active material and current collector, permitting outstanding electrochemical performance. Another main drawback is to attaining the high rate performances while elevated power and energy densities. Possible solutions are: using electrode components with a porous and large specific surface area that enables high ionic and electronic conductivity. Utilizing carbon nanomaterials with various forms that can generate a $3 \mathrm{D}$ interconnected porous network, allowing a high rate of electrons and ions transportation. Moreover, hybridizing active materials NPs with a 3D carbon network increase the charge storage capacity. ${ }^{224}$
For the future development, it is necessary to understand some major factors such as conductivity of conductive materials, interfacial strength between active materials and conductive parts, morphological stability of conductive materials etc. According to our findings, we provide seven major aspects to improve the mechanical and electrochemical performance of binder-free electrodes:

(i) Selecting lightweight and ultrahigh conductive materials as charge transferring medium;

(ii) High stress tolerance limit of conductive materials under various deformation, and good chemical stability in selected electrolyte and high current density is crucial for mechanical and electrochemical stability;

(iii) As active materials bind with conductive parts for the continuing electrochemical reactions. Thus, conductive materials should be 'deposition friendly' for the ease of active materials deposition. Also, tight interfacial strength is a critical factor to boost the electrochemical and mechanical performance;

(iv) Well organized or super aligned deposition of micro- or nano-structured active materials is recommended for the high mass loading, proper utilizing of active materials and good interfacial contact with conductive materials. High geometrical tortuosity of current collectors can impede the homogeneous growth of active materials. So, optimal tortuosity (equal to 1) value of current collectors is beneficial for uniform active materials growth;

(v) Perfect functionalization and heteroatom doping in CMs skeletons are crucial for improving their conductivity, bond strength with active materials and mechanical flexibility;

(vi) Mesh or nanowires like formation of metals is suitable for synthesizing free-standing and binder free flexible electrodes. On the other hand, porosity controlling in mesh/ nanowires or foam-based electrodes is another factor for the enhancing overall capacity; 
(vii) Coating the metals current collectors with various CMs or conductive polymers is another strategy to improve the electrochemical and mechanical performance while protecting them from corrosion.

In most cases, electrodes are not able to demonstrating stable electrochemical performance under continuous mechanical deformation. Peeling-off of active materials and crack formation are common issues that limiting the commercial uses of pliable electrodes. Hybridizing active materials with a 3D carbon network or using optimized amount of appropriate binder in metals-based electrodes may help to overcome this issue. From the analysis of electrochemical behavior, metals-based electrodes possess better initial electrochemical performance but severely lowering after several number of cycles. Meanwhile, CMs based electrodes exhibit more consistency in electrochemical performance due to the greater chemical stability and higher adhesion with active materials. On the other hand, with respect to CMs, large mass, fast crack generation, and possibility of corrosion hiders the further applications of metals in deformable electrodes. Structural modification such as nanowires and 3D mesh forms of metals may help to overcome some of these issues.

More importantly the good knowledge of the electrode/ electrolyte interfacial behavior under mechanical flexions contributes to better control of the electrochemical performance with mechanical deformability simultaneously. To date, many researchers have tried to predict mechanical characteristics, electrical conductivity with the energy storage capability of pliable electrodes via advanced computational simulationbased techniques that can help to find effective electrode materials for FLIBs. ${ }^{225}$ On the other side, morphology of active materials is affecting the storage capacity of electrodes such as rigid particles or nanosheets like structures of active materials cannot buffer the volume expansion during Li storing leads to delamination and crumbling of electrodes. Therefore, nanotube, or porous particle/nanosheets like formation of active materials can mitigate the self-volume expansion results in high storage capacity and long-term cycling stability.

In summary, owing to the intricate, costly, and timeconsuming production route of flexible electrode materials, yet flexible LIBs could not satisfy the commercial viability. However, the lacking of industrial assessment parameters to evaluate the variations of electrochemical performances under different flexion states are impeding their desirable advancement. Though many challenges are associated with carbonaceous materials and metals based flexible electrodes for LIBs, still they containing excellent potentiality in next-generation FLIBs. Finally, based on this review, the continuous advancement in energy and power densities while maintaining favorable mechanical properties of flexible electrodes for LIBs will unquestionably increase the wearable electronic devices in real life.

\section{Conflicts of interest}

There are no conflicts to declare.

\section{References}

1 A. Nathan, A. Ahnood, M. T. Cole, S. Lee, Y. Suzuki, P. Hiralal, et al., Flexible electronics: The next ubiquitous platform, Proc. IEEE, 2012, 100, 1486-1517, DOI: 10.1109/ JPROC.2012.2190168.

2 A. E. Ostfeld, A. M. Gaikwad, Y. Khan and A. C. Arias, Highperformance flexible energy storage and harvesting system for wearable electronics, Sci. Rep., 2016, 6, 1-10, DOI: 10.1038/srep26122.

3 Y. Khan, A. E. Ostfeld, C. M. Lochner, A. Pierre and A. C. Arias, Monitoring of Vital Signs with Flexible and Wearable Medical Devices, Adv. Mater., 2016, 28, 43734395, DOI: 10.1002/adma.201504366.

4 C. Pang, C. Lee and K. Y. Suh, Recent advances in flexible sensors for wearable and implantable devices, J. Appl. Polym. Sci., 2013, 130, 1429-1441, DOI: 10.1002/app.39461.

5 L. Zeng, L. Qiu and H. M. Cheng, Towards the practical use of flexible lithium ion batteries, Energy Storage Mater., 2019, 23, 434-438, DOI: 10.1016/j.ensm.2019.04.019.

6 G. Zhou, F. Li and H.-M. Cheng, Progress in flexible lithium batteries and future prospects, Energy Environ. Sci., 2014, 1307-1338, DOI: 10.1039/c3ee43182g.

7 X. Wang, X. Lu, B. Liu, D. Chen, Y. Tong and G. Shen, Flexible Energy-Storage Devices: Design Consideration and Recent Progress, Adv. Mater., 2014, 4763-4782, DOI: 10.1002/adma.201400910.

8 F. Yao, D. T. Pham and Y. H. Lee, Carbon-Based Materials for Lithium-Ion Batteries, ChemSusChem, 2015, 8, 22842311, DOI: $10.1002 /$ cssc.201403490.

9 M. Yamada, T. Watanabe, T. Gunji, J. Wu and F. Matsumoto, Review of the Design of Current Collectors for Improving the Battery Performance in Lithium-Ion and Post-Lithium-Ion Batteries, Electrochem, 2020, 1, 124-159, DOI: $10.3390 /$ electrochem1020011.

10 A. H. Whitehead and M. Schreiber, Current Collectors for Positive Electrodes of Lithium-Based Batteries, J. Electrochem. Soc., 2005, 152, A2105, DOI: 10.1149/ 1.2039587.

11 A. Mukhopadhyay and B. W. Sheldon, Deformation and stress in electrode materials for Li-ion batteries, Prog. Mater. Sci., 2014, 63, 58-116, DOI: 10.1016/ j.pmatsci.2014.02.001.

12 J. M. Reniers, G. Mulder and D. A. Howey, Review and Performance Comparison of Mechanical-Chemical Degradation Models for Lithium-Ion Batteries, J. Electrochem. Soc., 2019, 166, A3189-A3200, DOI: 10.1149/ 2.0281914jes.

13 H. Cha, J. Kim, Y. Lee, J. Cho and M. Park, Issues and Challenges Facing Flexible Lithium-Ion Batteries for Practical Application, Small, 2018, 14, 1-18, DOI: 10.1002/ smll.201702989.

14 D. Wang, C. Han, F. Mo, Q. Yang, Y. Zhao, Q. Li, et al., Energy density issues of flexible energy storage devices, Energy Storage Mater., 2020, 28, 264-292, DOI: 10.1016/ j.ensm.2020.03.006. 
15 E. Foreman, W. Zakri, M. Hossein Sanatimoghaddam, A. Modjtahedi, S. Pathak, A. G. Kashkooli, et al., A Review of Inactive Materials and Components of Flexible Lithium-Ion Batteries, Adv. Sustainable Syst., 2017, 1, 1700061, DOI: 10.1002/adsu.201700061.

16 K. Wang, S. Luo, Y. Wu, X. He, F. Zhao, J. Wang, et al., Super-aligned carbon nanotube films as current collectors for lightweight and flexible lithium ion batteries, $A d v$. Funct. Mater., 2013, 23, 846-853, DOI: 10.1002/ adfm.201202412.

17 M. Yousaf, H. T. H. Shi, Y. Wang, Y. Chen, Z. Ma, A. Cao, et al., Novel Pliable Electrodes for Flexible Electrochemical Energy Storage Devices: Recent Progress and Challenges, Adv. Energy Mater., 2016, 6, 1-23, DOI: 10.1002/aenm.201600490.

$18 \mathrm{Y}$. $\mathrm{Hu}$ and $\mathrm{X}$. Sun, Flexible rechargeable lithium ion batteries: Advances and challenges in materials and process technologies, J. Mater. Chem. A, 2014, 2, 1071210738, DOI: 10.1039/c4ta00716f.

19 N. Yao and V. Lordi, Young's modulus of single-walled carbon nanotubes, J. Appl. Phys., 1998, 84, 1939-1943, DOI: $10.1063 / 1.368323$.

20 K. T. Kashyap and R. G. Patil, On Young's modulus of multiwalled carbon nanotubes, Bull. Mater. Sci., 2008, 31, 185187, DOI: 10.1007/s12034-008-0032-2.

21 B. Q. Wei, R. Vajtai and P. M. Ajayan, Reliability and current carrying capacity of carbon nanotubes, Appl. Phys. Lett., 2001, 79, 1172-1174, DOI: 10.1063/1.1396632.

22 S. Yoon, S. Lee, S. Kim, K. W. Park, D. Cho and Y. Jeong, Carbon nanotube film anodes for flexible lithium ion batteries, J. Power Sources, 2015, 279, 495-501, DOI: 10.1016/j.jpowsour.2015.01.013.

23 S. Y. Chew, S. H. Ng, J. Wang, P. Novák, F. Krumeich, S. L. Chou, et al., Flexible free-standing carbon nanotube films for model lithium-ion batteries, Carbon, 2009, 47, 2976-2983, DOI: 10.1016/j.carbon.2009.06.045.

24 X. Li, J. Fu, Z. Pan, J. Su, J. Xu, B. Gao, et al., Peapod-like $\mathrm{V}_{2} \mathrm{O}_{3}$ nanorods encapsulated into carbon as binder-free and flexible electrodes in lithium-ion batteries, $J$. Power Sources, 2016, 331, 58-66, DOI: 10.1016/ j.jpowsour.2016.09.031.

25 Z. Ma, Y. Wang, Y. Yang, M. Yousaf, M. Zou, A. Cao, et al., Flexible hybrid carbon nanotube sponges embedded with $\mathrm{SnS}_{2}$ from tubular nanosheaths to nanosheets as freestanding anodes for lithium-ion batteries, RSC Adv., 2016, 6, 30098-30105, DOI: 10.1039/c6ra01143h.

26 P. Fan, H. Liu, L. Liao, J. Fu, Z. Wang, G. Lv, et al., Flexible and high capacity lithium-ion battery anode based on a carbon nanotube/electrodeposited nickel sulfide paperlike composite, $R S C A d v$., 2017, 7, 49739-49744, DOI: 10.1039/c7ra08239h.

27 S. Ahmad, D. Copic, C. George and M. De Volder, Hierarchical Assemblies of Carbon Nanotubes for Ultraflexible Li-Ion Batteries, Adv. Mater., 2016, 28, 67056710, DOI: 10.1002/adma.201600914.

28 J. Chen, A. I. Minett, Y. Liu, C. Lynam, P. Sherrell, C. Wang, et al., Direct growth of flexible carbon nanotube electrodes,
Adv. Mater., 2008, 20, 566-570, DOI: 10.1002/ adma.200701146.

29 Z. Pan, J. Ren, G. Guan, X. Fang, B. Wang, S. G. Doo, et al., Synthesizing Nitrogen-Doped Core-Sheath Carbon Nanotube Films for Flexible Lithium Ion Batteries, Adv. Energy Mater., 2016, 6, 1-6, DOI: 10.1002/aenm.201600271.

30 L. Wang, W. Guo, P. Lu, T. Zhang, F. Hou and J. Liang, A Flexible and Boron-Doped Carbon Nanotube Film for High-Performance Li Storage, Front. Chem., 2019, 7, 1-10, DOI: $10.3389 /$ fchem.2019.00832.

31 K. Yao, J. P. Zheng and Z. Liang, Binder-free freestanding flexible $\mathrm{Si}$ nanoparticle-multi-walled carbon nanotube composite paper anodes for high energy Li-ion batteries, J. Mater. Res., 2018, 33, 482-494, DOI: 10.1557/ jmr.2017.475.

32 J. Fu, H. Liu, L. Liao, P. Fan, Z. Wang, Y. Wu, et al., Ultrathin $\mathrm{Si} / \mathrm{CNTs}$ paper-like composite for flexible Li-Ion battery anode with high volumetric capacity, Front. Chem., 2018, 6, 1-9, DOI: 10.3389/fchem.2018.00624.

33 W. Guo, X. Yan, F. Hou, L. Wen, Y. Dai, D. Yang, et al., Flexible and free-standing $\mathrm{SiO}_{x} / \mathrm{CNT}$ composite films for high capacity and durable lithium ion batteries, Carbon, 2019, 152, 888-897, DOI: 10.1016/j.carbon.2019.06.088.

$34 \mathrm{X}$. He, Y. Wu, F. Zhao, J. Wang, K. Jiang and S. Fan, Enhanced rate capabilities of $\mathrm{Co}_{3} \mathrm{O}_{4}$ /carbon nanotube anodes for lithium ion battery applications, J. Mater. Chem. A, 2013, 1, 11121-11125, DOI: 10.1039/c3ta12608k.

35 S. J. Ee, H. Pang, U. Mani, Q. Yan, S. L. Ting and P. Chen, An interwoven network of $\mathrm{MnO}_{2}$ nanowires and carbon nanotubes as the anode for bendable lithium-ion batteries, ChemPhysChem, 2014, 15, 2445-2449, DOI: 10.1002/cphc.201402010.

36 G. Zhou, D. W. Wang, P. X. Hou, W. Li, N. Li, C. Liu, et al., A nanosized $\mathrm{Fe}_{2} \mathrm{O}_{3}$ decorated single-walled carbon nanotube membrane as a high-performance flexible anode for lithium ion batteries, J. Mater. Chem., 2012, 22, 1794217946, DOI: 10.1039/c2jm32893c.

37 Y. Lu, Q. Zhao, L. Miao, Z. Tao, Z. Niu and J. Chen, Flexible and Free-Standing Organic/Carbon Nanotubes Hybrid Films as Cathode for Rechargeable Lithium-Ion Batteries, J. Phys. Chem. C, 2017, 121, 14498-14506, DOI: 10.1021/ acs.jpcc.7b04341.

38 A. Abnavi, M. S. Faramarzi, A. Abdollahi, R. Ramzani, S. Ghasemi and Z. Sanaee, $\mathrm{SnO}_{2} @ a-S i$ core-shell nanowires on free-standing CNT paper as a thin and flexible Li-ion battery anode with high areal capacity, Nanotechnology, 2017, 28, 255404.

39 T. Xiang, S. Tao, W. Xu, Q. Fang, C. Wu, D. Liu, et al., Stable 1T-MoSe $\mathrm{H}_{2}$ and Carbon Nanotube Hybridized Flexible Film: Binder-Free and High-Performance Li-Ion Anode, ACS Nano, 2017, 11, 6483-6491, DOI: 10.1021/acsnano.7b03329.

40 I. Elizabeth, B. P. Singh and S. Gopukumar, Electrochemical performance of $\mathrm{Sb}_{2} \mathrm{~S}_{3} / \mathrm{CNT}$ free-standing flexible anode for Li-ion batteries, J. Mater. Sci., 2019, 54, 7110-7118, DOI: 10.1007/s10853-018-03275-w.

41 Y. Luo, K. Wang, S. Luo, F. Zhao, H. Wu, K. Jiang, et al., Three-Dimensional Carbon Nanotube/Transition-Metal 
Oxide Sponges as Composite Electrodes with Enhanced Electrochemical Performance, ACS Appl. Nano Mater., 2018, 1, 2997-3005, DOI: 10.1021/acsanm.8b00606.

42 M. Zou, Z. Ma, Q. Wang, Y. Yang, S. Wu, L. Yang, et al., Coaxial $\mathrm{TiO}_{2}$-carbon nanotube sponges as compressible anodes for lithium-ion batteries, J. Mater. Chem. A, 2016, 4, 7398-7405, DOI: 10.1039/c6ta01071g.

43 Q. Fan, L. Lei, G. Yin and Y. Sun, Self-weaving CNT-LiNbO nanoplate-polypyrrole hybrid as a flexible anode for Li-ion batteries, Chem. Commun., 2014, 50, 2370-2373, DOI: 10.1039/c3cc48367c.

44 D. Kong, X. Li, Y. Zhang, X. Hai, B. Wang, X. Qiu, Q. Song, Q.-H. Yanga and L. Zhia, Encapsulating V2O5 into Carbon Nanotube Enables Flexible High- Performance Lithium Ion Batteries, J. Mater. Chem. C, 2015, 3, 10715-10722, DOI: 10.1039/C5EE03345D.

45 X. Fang, C. Shen, M. Ge, J. Rong, Y. Liu, A. Zhang, et al., High-power lithium ion batteries based on flexible and light-weight cathode of $\mathrm{LiNi}_{0.5} \mathrm{Mn}_{1.5} \mathrm{O}_{4} /$ carbon nanotube film, Nano Energy, 2015, 12, 43-51, DOI: 10.1016/ j.nanoen.2014.11.052.

46 K. Amin, Q. Meng, A. Ahmad, M. Cheng, M. Zhang, L. Mao, et al., A Carbonyl Compound-Based Flexible Cathode with Superior Rate Performance and Cyclic Stability for Flexible Lithium-Ion Batteries, Adv. Mater., 2018, 30, 1-8, DOI: 10.1002/adma.201703868.

47 P. Yang, X. Xi, T. Huang, Q. Zhong, B. Jiang, R. Liu, et al., An acid-assisted vacuum filtration approach towards flexible PDI/SWCNT cathodes for highly stable organic lithium ion batteries, Electrochim. Acta, 2020, 338, 135771, DOI: 10.1016/j.electacta.2020.135771.

48 C. An, C. Li, H. Tang, T. Liu and Z. Tang, Binder-free flexible $\mathrm{Li}_{2} \mathrm{ZnTi}_{3} \mathrm{O}_{8} @ M W C N T s$ stereoscopic network as lightweight and superior rate performance anode for lithium-ion batteries, J. Alloys Compd., 2020, 816, 152580, DOI: 10.1016/j.jallcom.2019.152580.

49 N. Hedin, V. Sobolev, L. Zhang, Z. Zhu and H. Fong, Electrical properties of electrospun carbon nanofibers, $J$. Mater. Sci., 2011, 46, 6453-6456, DOI: 10.1007/s10853-0115725-z.

50 M. H. Al-Saleh and U. Sundararaj, Review of the mechanical properties of carbon nanofiber/polymer composites, Composites, Part A, 2011, 42, 2126-2142, DOI: 10.1016/ j.compositesa.2011.08.005.

51 S. Y. Gu, Q. L. Wu and J. Ren, Preparation and surface structures of carbon nanofibers produced from electrospun PAN precursors, Xinxing Tan Cailiao, 2008, 23, 171-175, DOI: 10.1016/s1872-5805(08)60021-9.

52 W. Li, M. Li, M. Wang, L. Zeng and Y. Yu, Electrospinning with partially carbonization in air: Highly porous carbon nanofibers optimized for high-performance flexible lithium-ion batteries, Nano Energy, 2015, 13, 693-701, DOI: 10.1016/j.nanoen.2015.03.027.

53 W. Li, Z. Yang, J. Cheng, X. Zhong, L. Gu and Y. Yu, Germanium nanoparticles encapsulated in flexible carbon nanofibers as self-supported electrodes for high performance lithium-ion batteries, Nanoscale, 2014, 6, 4532-4537, DOI: 10.1039/c4nr00140k.

54 S. J. Kim, M. C. Kim, S. B. Han, G. H. Lee, H. S. Choe, D. H. Kwak, et al., 3D flexible $\mathrm{Si}$ based-composite (Si@Si $\mathrm{N}_{3}$ )/CNF electrode with enhanced cyclability and high rate capability for lithium-ion batteries, Nano Energy, 2016, 27, 545-553, DOI: 10.1016/j.nanoen.2016.08.012.

55 B. N. Joshi, S. An, Y. Il Kim, E. P. Samuel, K. Y. Song, I. W. Seong, et al., Flexible freestanding $\mathrm{Fe}_{2} \mathrm{O}_{3}-\mathrm{SnO}_{x^{-}}$ carbon nanofiber composites for Li ion battery anodes, $J$. Alloys Compd., 2017, 700, 259-266, DOI: 10.1016/ j.jallcom.2017.01.057.

56 Y. Jiang, S. Chen, D. Mu, Z. Zhao, C. Li, Z. Ding, et al., Flexible $\mathrm{TiO}_{2} / \mathrm{SiO}_{2} / \mathrm{C}$ film anodes for lithium-ion batteries, ChemSusChem, 2018, 11, DOI: 10.1002/cssc.201800560.

57 F. Zhang, Y. Tang, Y. Yang, X. Zhang and C. Lee, In situ assembly of three-dimensional $\mathrm{MoS}_{2}$ nanoleaves/carbon nano fiber composites derived from bacterial cellulose as flexible and binder-free anodes for enhanced lithium-ion batteries, Electrochim. Acta, 2016, 211, 404-410, DOI: 10.1016/j.electacta.2016.05.181.

58 Z. Wang, M. Liu, G. Wei, P. Han, X. Zhao and J. Liu, A Hierarchical self-supported $\mathrm{C} @ \mathrm{TiO}_{2}-\mathrm{MoS}_{2}$ core-shell nanofiber mats as flexible anode for advanced lithium ion batteries, Appl. Surf. Sci., 2017, 423, 375-382, DOI: 10.1016/j.apsusc.2017.06.129.

59 X. Zhao, Y. Du, L. Jin, Y. Yang, S. Wu, W. Li, et al., Membranes of MnO Beading in Carbon Nanofibers as Flexible Anodes for High-Performance Lithium-Ion Batteries, Sci. Rep., 2015, 5, 1-11, DOI: 10.1038/srep14146.

60 E. Samuel, H. S. Jo, B. Joshi, S. An, H. G. Park, Y. Il Kim, et al., Decoration of MnO Nanocrystals on Flexible Freestanding Carbon Nanofibers for Lithium Ion Battery Anodes, Electrochim. Acta, 2017, 231, 582-589, DOI: 10.1016/j.electacta.2017.02.077.

61 W. Li, M. Li, Z. Yang, J. Xu, X. Zhong, J. Wang, et al., CarbonCoated Germanium Nanowires on Carbon Nanofibers as Self-Supported Electrodes for Flexible Lithium-Ion Batteries, Small, 2015, 11, 2762-2767, DOI: 10.1002/ smll.201403533.

62 M. Dirican, O. Yildiz, Y. Lu, X. Fang, H. Jiang, H. Kizil, et al., Flexible binder-free silicon/silica/carbon nanofiber composites as anode for lithium-ion batteries, Electrochim. Acta, 2015, 169, 52-60, DOI: 10.1016/ j.electacta.2015.04.035.

63 J. Wang, W. L. Song, Z. Wang, L. Z. Fan and Y. Zhang, Facile fabrication of binder-free metallic tin nanoparticle/carbon nanofiber hybrid electrodes for lithium-ion batteries, Electrochim. Acta, 2015, 153, 468-475, DOI: 10.1016/ j.electacta.2014.12.026.

64 B. N. Joshi, S. An, H. S. Jo, K. Y. Song, H. G. Park, S. Hwang, et al., Flexible, Freestanding, and Binder-free $\mathrm{SnO}_{x}-\mathrm{ZnO} /$ Carbon Nanofiber Composites for Lithium Ion Battery Anodes, ACS Appl. Mater. Interfaces, 2016, 8, 9446-9453, DOI: 10.1021/acsami.6b01093.

65 Y. E. Miao, Y. Huang, L. Zhang, W. Fan, F. Lai and T. Liu, Electrospun porous carbon nanofiber@ MoS2 core/sheath 
fiber membranes as highly flexible and binder-free anodes for lithium-ion batteries, Nanoscale, 2015, 7, 11093-11101, DOI: $10.1039 /$ C5NR02711J.

66 L. Zhang, Y. Huang, Y. Zhang, H. Gu, W. Fan and T. Liu, Flexible Electrospun Carbon Nanofiber@NiS Core/Sheath Hybrid Membranes as Binder-Free Anodes for Highly Reversible Lithium Storage, Adv. Mater. Interfaces, 2016, 3, 1-10, DOI: 10.1002/admi.201500467.

67 Y. Wan, Z. Yang, G. Xiong, R. Guo, Z. Liu and H. Luo, Anchoring $\mathrm{Fe}_{3} \mathrm{O}_{4}$ nanoparticles on three-dimensional carbon nanofibers toward flexible high-performance anodes for lithium-ion batteries, J. Power Sources, 2015, 294, 414-419, DOI: 10.1016/j.jpowsour.2015.06.057.

68 J. Lee, C. Jo, B. Park, W. Hwang, H. I. Lee, S. Yoon, et al., Simple fabrication of flexible electrodes with high metaloxide content: electrospun reduced tungsten oxide/carbon nano fibers for lithium ion battery applications, Nanoscale, 2014, 6, 10147-10155, DOI: 10.1039/ C4NR01033G.

69 Y. Liu, J. Jiang, Y. Yuan and Q. Jiang, Vertically Aligned $\mathrm{NiCo}_{2} \mathrm{O}_{4}$ Nanosheet-Encapsulated Carbon Fibers as a SelfSupported Electrode for Superior $\mathrm{Li}^{+}$Storage Performance, Nanomaterials, 2019, 9(9), 1336, DOI: 10.3390/ nano9091336.

70 L. Xia, S. Wang, G. Liu, L. Ding, D. Li and H. Wang, Flexible $\mathrm{SnO}_{2} / \mathrm{N}$-Doped Carbon Nanofiber Films as Integrated Electrodes for Lithium-Ion Batteries with Superior Rate Capacity and Long Cycle Life, Small, 2016, 853-859, DOI: 10.1002/smll.201503315.

71 J. Xia, Y. Yuan, H. Yan, J. Liu, Y. Zhang, L. Liu, et al., Electrospun SnSe/C nanofibers as binder-free anode for lithium - ion and sodium-ion batteries, J. Power Sources, 2019, 227559, DOI: 10.1016/j.jpowsour.2019.227559.

72 Q. Wu, R. Zhao, X. Zhang, W. Li, R. Xu, G. Diao, et al., Synthesis of flexible $\mathrm{Fe}_{3} \mathrm{O}_{4} / \mathrm{C}$ nanofibers with buffering volume expansion performance and their application in lithium-ion batteries, J. Power Sources, 2017, 359, 7-16, DOI: 10.1016/j.jpowsour.2017.05.020.

$73 \mathrm{~J}$. Zhu, L. Chen, Z. Xu and B. Lu, Electrospinning preparation of ultra-long aligned nanofibers thin films for high performance fully flexible lithium-ion batteries, Nano Energy, 2015, 12, 339-346, DOI: 10.1016/ j.nanoen.2014.10.026.

74 F. Zhao, X. Zhao, B. Peng, F. Gan, M. Yao, W. Tan, et al., Polyimide-derived carbon nanofiber membranes as anodes for high-performance flexible lithium ion batteries, Chin. Chem. Lett., 2018, 29, 1692-1697, DOI: 10.1016/j.cclet.2017.12.015.

75 L. Li, P. Liu, K. Zhu, J. Wang, G. Tai and J. Liu, Flexible and robust $\mathrm{N}$-doped carbon nanofiber film encapsulating uniformly silica nanoparticles: Free-standing long-life and low-cost electrodes for $\mathrm{Li}^{-}$and Na-Ion batteries, Electrochim. Acta, 2017, 235, 79-87, DOI: 10.1016/ j.electacta.2017.03.071.

76 A. A. Aboalhassan, J. Yan, Y. Zhao, K. Dong, X. Wang, J. Yu, et al., Self-Assembled Porous-Silica within N-Doped Carbon Nanofibers as Ultra-flexible Anodes for Soft Lithium
Batteries, iScience, 2019, 16, 122-132, DOI: 10.1016/ j.isci.2019.05.023.

77 L. Guo, H. Sun, C. Qin, W. Li, F. Wang, W. Song, et al., Flexible $\mathrm{Fe}_{3} \mathrm{O}_{4}$ nanoparticles/N-doped carbon nanofibers hybrid film as binder-free anode materials for lithium-ion batteries, Appl. Surf. Sci., 2018, DOI: 10.1016/ j.apsusc.2018.08.001.

78 H. Chen, J. He, Y. Li, S. Luo, L. Sun, X. Ren, et al., Hierarchical $\mathrm{CuO}_{x}-\mathrm{Co}_{3} \mathrm{O}_{4}$ heterostructure nanowires decorated on $3 \mathrm{D}$ porous nitrogen-doped carbon nanofibers as flexible and free-standing anodes for highperformance lithium-ion batteries, J. Mater. Chem. A, 2019, 7, 7691-7700, DOI: 10.1039/c9ta00275h.

79 W. Zhang, W. Shen, Y. Weng, R. Lv, F. Kang and Z. H. Huang, Steam Selective Etching: A Strategy to Effectively Enhance the Flexibility and Suppress the Volume Change of Carbonized Paper-Supported Electrodes, ACS Nano, 2019, 13, 5731-5741, DOI: 10.1021/ acsnano.9b01173.

80 J. Ortiz Balbuena, P. Tutor De Ureta, E. Rivera Ruiz and S. Mellor Pita, Electric Field Effect in Atomically Thin Carbon Films, Science, 2016, 146, 93-94, DOI: 10.1016/ j.medcli.2015.04.005.

81 M. D. Stoller, S. Park, Y. Zhu, J. An and R. S. Ruoff, Graphene-Based Ultracapacitors, J. Am. Chem. Soc., 2008, 32, 13620-13626, DOI: 10.1021/acs.langmuir.6b03602.

82 C. Lee, X. Wei, J. W. Kysar and J. Hone, Measurement of the elastic properties and intrinsic strength of monolayer graphene, Science, 2008, 321, 385-388, DOI: 10.1126/ science.1157996.

83 D. G. Papageorgiou, I. A. Kinloch and R. J. Young, Mechanical properties of graphene and graphene-based nanocomposites, Prog. Mater. Sci., 2017, 90, 75-127, DOI: 10.1016/j.pmatsci.2017.07.004.

84 X. Zhao, C. M. Hayner, M. C. Kung and H. H. Kung, Flexible holey graphene paper electrodes with enhanced rate capability for energy storage applications, ACS Nano, 2011, 5, 8739-8749, DOI: 10.1021/nn202710s.

85 Y. Ma, R. Younesi, R. Pan, C. Liu, J. Zhu and B. Wei, Constraining Si Particles within Graphene Foam Monolith: Interfacial Modification for High-Performance $\mathrm{Li}+$ Storage and Flexible Integrated Configuration, Adv. Funct. Mater., 2016, 1-10, DOI: 10.1002/adfm.201602324.

86 L. David, R. Bhandavat, U. Barrera and G. Singh, Silicon oxycarbide glass-graphene composite paper electrode for long-cycle lithium-ion batteries, Nat. Commun., 2016, 7, 110, DOI: $10.1038 /$ ncomms10998.

87 R. Mo, D. Rooney, K. Sun and H. Y. Yang, 3D nitrogendoped graphene foam with encapsulated germanium/ nitrogen-doped graphene yolk-shell nanoarchitecture for high-performance flexible Li-ion battery, Nat. Commun., 2017, 7, 1-9, DOI: 10.1038/ncomms13949.

88 X. Zhang, J. Zhou, X. Chen and H. Song, Pliable EmbeddedType Paper Electrode of Hollow Metal Oxide@Porous Graphene with Abnormal but Superior Rate Capability for Li-Ion Storage, ACS Appl. Energy Mater., 2017, 48-55, DOI: 10.1021/acsaem.7b00087. 
89 F. Liu, S. Song, D. Xue and H. Zhang, Folded structured graphene paper for high performance electrode materials, Adv. Mater., 2012, 24, 1089-1094, DOI: 10.1002/ adma.201104691.

90 H. Zhang, S. Jing, Y. Hu, H. Jiang and C. Li, A flexible freestanding $\mathrm{Si} / \mathrm{rGO}$ hybrid film anode for stable Li-ion batteries, J. Power Sources, 2016, 307, 214-219, DOI: 10.1016/j.jpowsour.2015.12.107.

91 Y. Liu, W. Wang, L. Gu, Y. Wang, Y. Ying and Y. Mao, Flexible $\mathrm{CuO}$ nanosheets/reduced-graphene oxide composite paper: binder-free anode for high performance lithium-ion batteries, ACS Appl. Mater. Interfaces, 2013, 9850-9855, DOI: 10.1021/am403136e.

92 T. Jiang, F. Bu, X. Feng, I. Shakir, G. Hao and Y. Xu, Porous $\mathrm{Fe}_{2} \mathrm{O}_{3} \quad$ Nanoframeworks Encapsulated within ThreeDimensional Graphene as High- Performance Flexible Anode for Lithium-Ion Battery, ACS Nano, 2017, 51405147, DOI: 10.1021/acsnano.7b02198.

93 T. Hu, X. Sun, H. Sun, M. Yu, F. Lu, C. Liu, et al., Flexible free-standing graphene- $\mathrm{TiO}_{2}$ hybrid paper for use as lithium ion battery anode materials, Carbon, 2012, 51, 322-326, DOI: 10.1016/j.carbon.2012.08.059.

94 Q. Ru, Z. Wang, S. Cheng, P. Liu, X. Hou, S. Su, et al., Self Assembled Rice Ball-Like $\mathrm{ZnCo}_{2} \mathrm{O}_{4}$ Inlaid on $\mathrm{rGO}$ as Flexible Anodes with High Lithium Storage Capability and Superior Cycling Stability, Energy Technol., 2018, 6, 18991903, DOI: 10.1002/ente.201700983.

95 J. Liang, Y. Zhao, L. Guo and L. Li, Flexible free-standing graphene $/ \mathrm{SnO}_{2}$ nanocomposites paper for Li-ion battery, ACS Appl. Mater. Interfaces, 2012, 4, 5742-5748, DOI: 10.1021/am301962d.

96 J. G. Wang, D. Jin, R. Zhou, X. Li, X. R. Liu, C. Shen, et al., Highly Flexible Graphene/ $\mathrm{Mn}_{3} \mathrm{O}_{4}$ Nanocomposite Membrane as Advanced Anodes for Li-Ion Batteries, ACS Nano, 2016, 10, 6227-6234, DOI: 10.1021/acsnano.6b02319.

97 X. Chen, H. Tang, Z. Huang, J. Zhou, X. Ren and K. Huang, Flexible Bismuth Selenide/Graphene composite paper for lithium-ion batteries, Ceram. Int., 2016, 1, DOI: 10.1016/ j.ceramint.2016.10.110.

98 H. Luo, C. Xu, B. Wang, F. Jin, L. Wang, T. Liu, et al., Highly conductive graphene-modified $\mathrm{TiO}_{2}$ hierarchical film electrode for flexible Li-ion battery anode, Electrochim. Acta, 2019, 313, 10-19, DOI: 10.1016/ j.electacta.2019.05.018.

99 H. Cao, X. Zhou, W. Deng, Z. Ma, Y. Liu and Z. Liu, Layer structured graphene/porous $\mathrm{ZnCo}_{2} \mathrm{O}_{4}$ composite film for high performance flexible lithium-ion batteries, Chem. Eng. J., 2018, 343, 654-661, DOI: 10.1016/j.cej.2018.03.001.

100 L. Gao, G. Wu, J. Ma, T. Jiang, B. Chang, Y. Huang and S. Han, $\mathrm{SnO}_{2}$ Quantum Dots@Graphene Frameworks as a High-Performance Flexible Anode Electrode for Lithium-Ion Batteries, ACS Appl. Mater. Interfaces, 2020, 12982-12989, DOI: 10.1021/acsami.9b22679.

101 S. K. Park, C. Y. Seong, S. Yoo and Y. Piao, Porous $\mathrm{Mn}_{3} \mathrm{O}_{4}$ nanorod/reduced graphene oxide hybrid paper as a flexible and binder-free anode material for lithium ion battery, Energy, 2016, 99, 266-273, DOI: 10.1016/ j.energy.2016.01.061.

102 G. Zhong, J. Yu, P. Zhuang, M. Jin, Y. Fu and X. Ma, Ultralong MnO@C nanowires with internal voids anchored between graphene as a robust high performance anode for flexible Li-Ion battery, Electrochim. Acta, 2019, 296, 276-282, DOI: 10.1016/ j.electacta.2018.09.199.

103 K. Zhu, H. Gao and G. Hu, A flexible mesoporous $\mathrm{Li}_{4} \mathrm{Ti}_{5} \mathrm{O}_{12}$ rGO nanocomposite film as free-standing anode for high rate lithium ion batteries, J. Power Sources, 2018, 375, 5967, DOI: 10.1016/j.jpowsour.2017.11.053.

104 Y. Yang, B. Wang, J. Zhu, J. Zhou, Z. Xu, L. Fan, et al., Bacteria Absorption-Based $\mathrm{Mn}_{2} \mathrm{P}_{2} \mathrm{O}_{7}$-Carbon@Reduced Graphene Oxides for High-Performance Lithium-Ion Battery Anodes, ACS Nano, 2016, 10, 5516-5524, DOI: 10.1021/acsnano.6b02036.

105 T. Jiang, F. Bu, B. Liu, G. Hao and Y. Xu, Fe $\mathrm{Se}_{8} @ \mathrm{C}$ coreshell nanoparticles encapsulated within a threedimensional graphene composite as a high-performance flexible anode for lithium-ion batteries, New J. Chem., 2017, 41, 5121-5124, DOI: 10.1039/c7nj01166k.

106 Y. H. Ding, H. M. Ren, Y. Y. Huang, F. H. Chang and P. Zhang, Three-dimensional graphene/LiFePO nanostructures as cathode materials for flexible lithiumion batteries, Mater. Res. Bull., 2013, 8-11, DOI: 10.1016/ j.materresbull.2013.05.118.

107 L. Noerochim, J. Z. Wang, D. Wexler, Z. Chao and H. K. Liu, Rapid synthesis of free-standing $\mathrm{MoO}_{3} /$ Graphene films by the microwave hydrothermal method as cathode for bendable lithium batteries, J. Power Sources, 2013, 228, 198-205, DOI: 10.1016/j.jpowsour.2012.11.113.

108 F. Coeuret, E. O. Vilar and E. B. Cavalcanti, Carbon fibre cloth as an electrode material: Electrical conductivity and mass transfer, J. Appl. Electrochem., 2002, 32, 1175-1182, DOI: 10.1023/A:1021236210511.

109 Y. Zhou, F. Pervin, S. Jeelani and P. K. Mallick, Improvement in mechanical properties of carbon fabricepoxy composite using carbon nanofibers, J. Mater. Process. Technol., 2008, 198, 445-453, DOI: 10.1016/ j.jmatprotec.2007.07.028.

110 B. Shivamurthy, K. Murthy and S. Anandhan, Tribology and Mechanical Properties of Carbon Fabric/MWCNT/Epoxy Composites, Adv. Tribol., 2018, 1508145, DOI: 10.1155/ 2018/1508145.

111 X. Wang, G. Li, M. H. Seo, G. Lui, F. M. Hassan and K. Feng, Carbon-Coated Silicon Nanowires on Carbon Fabric as SelfSupported Electrodes for Flexible Lithium-Ion Batteries, ACS Appl. Mater. Interfaces, 2017, 9551-9558, DOI: 10.1021/acsami.6b12080.

112 Z. Deng, H. Jiang, Y. Hu, Y. Liu, L. Zhang, H. Liu, et al., 3D Ordered Macroporous $\mathrm{MoS}_{2}$ @C Nanostructure for Flexible Li-Ion Batteries, Adv. Mater., 2017, 29, DOI: 10.1002/ adma.201603020.

113 X. Huang, X. Cai, D. Xu, W. Chen, S. Wang, W. Zhou, et al., Hierarchical $\mathrm{Fe}_{2} \mathrm{O}_{3} @ \mathrm{CNF}$ fabric decorated with $\mathrm{MoS}_{2}$ nanosheets as a robust anode for flexible lithium-ion 
batteries exhibiting ultrahigh areal capacity, J. Mater. Chem. A, 2018, 6, 16890-16899, DOI: 10.1039/c8ta04341h.

114 X. Min, B. Sun, S. Chen, M. Fang, X. Wu, Y. Liu, et al., A textile-based $\mathrm{SnO}_{2}$ ultra-flexible electrode for lithium-ion batteries, Energy Storage Mater., 2019, 16, 597-606, DOI: 10.1016/j.ensm.2018.08.002.

115 R. Tjandra, G. Li, X. Wang, J. Yan, M. Li and A. Yu, Flexible high performance lithium ion battery electrode based on a free-standing $\mathrm{TiO}_{2}$ nanocrystals/carbon cloth composite, RSC Adv., 2016, 6, 35479-35485, DOI: 10.1039/c6ra03262a.

116 M. S. Balogun, C. Li, Y. Zeng, M. Yu, Q. Wu, M. Wu, et al., Titanium dioxide@titanium nitride nanowires on carbon cloth with remarkable rate capability for flexible lithiumion batteries, J. Power Sources, 2014, 272, 946-953, DOI: 10.1016/j.jpowsour.2014.09.034.

117 S. Fang, L. Shen, P. Nie, G. Xu, L. Yang and H. Zheng, Titanium Dioxide/Germanium Core-Shell Nanorod Arrays Grown on Carbon Textiles as Flexible Electrodes for High Density Lithium-Ion Batteries, Part. Part. Syst. Charact., 2015, 364-372, DOI: 10.1002/ppsc.201400153.

118 B. Liu, X. Wang, B. Liu, Q. Wang, D. Tan, W. Song, et al., Advanced rechargeable lithium-ion batteries based on bendable $\mathrm{ZnCo}_{2} \mathrm{O}_{4}$-urchins-on-carbon-fibers electrodes, Nano Res., 2013, 6, 525-534, DOI: 10.1007/s12274-0130329-3.

119 T. T. Yu, H. L. Liu, M. Huang, J. H. Zhang, D. Q. Su, Z. H. Tang, et al., $\mathrm{Zn}_{2} \mathrm{GeO}_{4}$ nanorods grown on carbon cloth as high performance flexible lithium-ion battery anodes, RSC Adv., 2017, 7, 51807-51813, DOI: 10.1039/ c7ra09273c.

120 L. Shen, Q. Che, H. Li and X. Zhang, Mesoporous $\mathrm{NiCo}_{2} \mathrm{O}_{4}$ nanowire arrays grown on carbon textiles as binder-free flexible electrodes for energy storage, Adv. Funct. Mater., 2014, 24, 2630-2637, DOI: 10.1002/adfm.201303138.

121 J. M. Son, S. Oh, S. H. Bae, S. Nam and I. K. Oh, A Pair of $\mathrm{NiCO}_{2} \mathrm{O}_{4}$ and $\mathrm{V}_{2} \mathrm{O}_{5}$ Nanowires Directly Grown on Carbon Fabric for Highly Bendable Lithium-Ion Batteries, Adv. Energy Mater., 2019, 9, 1-10, DOI: 10.1002/ aenm.201900477.

122 M. S. Balogun, M. Yu, Y. Huang, C. Li, P. Fang, Y. Liu, et al., Binder-free $\mathrm{Fe}_{2} \mathrm{~N}$ nanoparticles on carbon textile with high power density as novel anode for high-performance flexible lithium ion batteries, Nano Energy, 2015, 11, 348-355, DOI: 10.1016/j.nanoen.2014.11.019.

$123 \mathrm{~W} . \mathrm{Li}, \mathrm{L} . \mathrm{Gan}, \mathrm{K} . \mathrm{Guo}, \mathrm{L} . \mathrm{Ke}, \mathrm{Y}$. Wei, H. Li, et al., Selfsupported $\mathrm{Zn}_{3} \mathrm{P}_{2}$ nanowire arrays grafted on carbon fabrics as an advanced integrated anode for flexible lithium ion batteries, Nanoscale, 2016, 8, 8666-8672, DOI: 10.1039/c5nr08467a.

124 S. Cheng, T. Shi, X. Tao, Y. Zhong, Y. Huang, J. Li, et al., In situ oxidized copper-based hybrid film on carbon cloth as flexible anode for high performance lithium-ion batteries, Electrochim. Acta, 2016, 212, 492-499, DOI: 10.1016/ j.electacta.2016.07.058.

125 H. Long, T. Shi, H. Hu, S. Jiang, S. Xi and Z. Tang, Growth of hierarchal mesoporous $\mathrm{NiO}$ nanosheets on carbon cloth as binder-free anodes for high-performance flexible lithium- ion batteries, Sci. Rep., 2014, 4, 1-9, DOI: 10.1038/ srep07413.

126 D. Guo, M. Yang, L. Zhang, Y. Li, J. Wang, G. Liu, et al., $\mathrm{Cr}_{2} \mathrm{O}_{3}$ nanosheet/carbon cloth anode with strong interaction and fast charge transfer for pseudocapacitive energy storage in lithium-ion batteries, RSC Adv., 2019, 9, 33446-33453, DOI: 10.1039/c9ra07465a.

127 C. Wang, X. Wang, C. Lin and X. S. Zhao, Lithium Titanate Cuboid Arrays Grown on Carbon Fiber Cloth for High-Rate Flexible Lithium-Ion Batteries, Small, 2019, 1902183, DOI: 10.1002/smll.201902183.

128 K. Ma, X. Liu, Q. Cheng, P. Saha, H. Jiang and C. Li, Flexible textile electrode with high areal capacity from hierarchical $\mathrm{V}_{2} \mathrm{O}_{5}$ nanosheet arrays, J. Power Sources, 2017, 357, 71-76, DOI: 10.1016/j.jpowsour.2017.04.105.

129 L. Wu, Y. Zhang, B. Li, P. Wang, L. Fan and N. Zhang, N doped carbon coated $\mathrm{V}_{2} \mathrm{O}_{5}$ nanobelt arrays performance cathodes for lithium ion batteries, RSC Adv., 2018, 65406543, DOI: $10.1039 / \mathrm{c} 7 \mathrm{ra} 13633 \mathrm{a}$.

130 Q. Zhang, Y. Tong, X. Chen, A. Pan, Z. Cai, S. Liu, et al., $\mathrm{CoF}_{2}$ nanoparticles grown on carbon fiber cloth as conversion reaction cathode for lithium-ion batteries, J. Alloys Compd., 2019, 805, 539-544, DOI: 10.1016/ j.jallcom.2019.07.034.

131 X. Shi, T. W. Liskiewicz, B. D. Beake, J. Chen and C. Wang, Tribological performance of graphite-like carbon films with varied thickness, Tribol. Int., 2020, 149, 1-11, DOI: 10.1016/ j.triboint.2019.01.045.

132 M. Kot, Ł. Major, J. M. Lackner, K. Chronowska-Przywara, M. Janusz and W. Rakowski, Mechanical and Tribological Properties of Carbon-Based Graded Coatings, J. Nanomater., 2016, DOI: 10.1155/2016/8306345.

133 M. Molenda, M. Świtosławski, M. Drozdek, B. Dudek and R. Dziembaj, Morphology and electrical conductivity of carbon nanocoatings prepared from pyrolysed polymers, J. Nanomater., 2014, 103418, DOI: 10.1155/2014/103418.

134 H. Wang, J. Fu, C. Wang, J. Wang, A. Yang, C. Li, Q. Sun, Y. Cui and H. Li, Environ. Sci., 2019, 848-858, DOI: 10.1039/C9EE02615K.

135 N. Li, G. Zhou, F. Li, L. Wen and H. Cheng, A Self-Standing and Flexible Electrode of $\mathrm{Li}_{4} \mathrm{Ti}_{5} \mathrm{O}_{12}$ Nanosheets with a $\mathrm{N}$ Doped Carbon Coating for High Rate Lithium Ion Batteries, Adv. Funct. Mater., 2013, 1-7, DOI: 10.1002/ adfm.201300495.

136 C. Fan, X. Wu, H. Wang, X. Li and K. Wang, Flexible paper electrode constructed of $\mathrm{Zn}_{2} \mathrm{GeO}_{4}$ nanofibers anchored with amorphous carbon for advanced lithium ion batteries, J. Mater. Chem. A, 2016, 2055-2059, DOI: 10.1039/C5TA08779A.

137 G.-M. Weng, L.-Y. S. Tam and Y.-C. Lu, High-performance $\mathrm{LiTi}_{2}\left(\mathrm{PO}_{4}\right)_{3}$ anode for high-areal-capacity flexible aqueous lithium-ion batteries, J. Mater. Chem. A, 2017, 1176411771, DOI: 10.1039/C7TA00482F.

138 J. F. S. Fernando, C. Zhang, K. L. Firestein, J. Y. Nerkar and D. V. Golberg, ZnO Quantum Dots Anchored in Multilayered and Flexible Amorphous Carbon Sheets for High Performance and Stable Lithium Ion Batteries, $J$. 
Mater. Chem. A, 2019, 8460-8471, DOI: 10.1039/ C8TA12511B.

139 X. Liu, W. Qi, T. Zou, D. Fan, S. Guo and Y. Zhao, Flexible current collector - free $\mathrm{LiFePO}_{4} /$ carbon composite film for high-performance lithium-ion batteries, Ionics, 2019, 25, 939-947, DOI: 10.1007/s11581-019-02869-x.

140 Y. Tang, D. Li, D. Ao, S. Li and X. Zu, Ultralight, highly flexible and conductive carbon foams for high performance electromagnetic shielding application, $J$. Mater. Sci.: Mater. Electron., 2018, 29, 13643-13652, DOI: 10.1007/s10854-018-9493-2.

141 M. Inagaki, J. Qiu and Q. Guo, Review Carbon foam: Preparation and application., Carbon, 2015, 87, 128-152, DOI: 10.1016/j.carbon.2015.02.021.

142 X. Shen, T. Qian, J. Zhou, N. Xu, T. Yang and C. Yan, Highly Flexible Full Lithium Batteries with Self-Knitted $\alpha-\mathrm{MnO}_{2}$ Fabric Foam, ACS Appl. Mater. Interfaces, 2015, 2529825305, DOI: 10.1021/acsami.5b07145.

$143 \mathrm{X} . \mathrm{Wu}, \mathrm{S}$. Li, B. Wang, J. Liu and M. Yu, $\mathrm{NiCo}_{2} \mathrm{~S}_{4}$ nanotube arrays grown on flexible nitrogen-doped carbon foams as three- dimensional binder-free integrated anodes for high-performance lithium-ion batteries, Phys. Chem. Chem. Phys., 2016, 4505-4512, DOI: 10.1039/C5CP07541F.

144 S. Chu, Y. Zhong, R. Cai, Z. Zhang and S. Wei, Mesoporous and Nanostructured $\mathrm{TiO}_{2}$ layer with Ultra-High Loading on Nitrogen-Doped Carbon Foams as Flexible and FreeStanding Electrodes for Lithium-Ion Batteries, Small, 2016, 1-11, DOI: 10.1002/smll.201602179.

145 R. Huang, Y. Li, Y. Song and L. Wang, Facial preparation of $\mathrm{N}$-doped carbon foam supporting $\mathrm{Co}_{3} \mathrm{O}_{4}$ nanorod arrays as free-standing lithium-ion batteries ' anode, J. Alloys Compd., 2019, 152839, DOI: 10.1016/j.jallcom.2019.152839.

146 X. Hai, W. Lang, L. Jin and X. Zhang, Mechanical, electrical, thermal performances and structure characteristics of flexible graphite sheets, J. Mater. Sci., 2010, 2449-2455, DOI: $10.1007 / \mathrm{s} 10853-010-4216-\mathrm{y}$.

147 Q. Guo, L. Liu and J. Shi, Synthesis and electrochemical properties of artificial graphite as an anode for highperformance lithium-ion batteries, Carbon, 2013, 64, 553556, DOI: 10.1016/j.carbon.2013.07.089.

148 C. Ma, C. Ma, J. Wang, H. Wang and J. Shi, Exfoliated graphite as a flexible and conductive support for Si-based Li-ion battery anodes, Carbon, 2014, 72, 38-46, DOI: 10.1016/j.carbon.2014.01.027.

149 P. Han, B. Zhang, C. Huang, L. Gu, H. Li and G. Cui, Anticorrosive flexible pyrolytic polyimide graphite film as a cathode current collector in lithium bis(trifluoromethane sulfonyl)imide electrolyte, Electrochem. Commun., 2014, 44, 70-73, DOI: 10.1016/ j.elecom.2014.05.001.

150 S. D. Kim, K. Rana and J. H. Ahn, Additive-Free Synthesis of $\mathrm{Li}_{4} \mathrm{Ti}_{5} \mathrm{O}_{12}$ Nanowire Arrays on Freestanding Ultrathin Graphite as a Hybrid Anode for Flexible Lithium Ion Battery, J. Mater. Chem. A, 2016, 19197-19206, DOI: 10.1039/C6TA09059A.

151 G. Xu, P. Han, X. Wang, X. Zhou, X. Han and D. Lu, A HighEnergy 5 V-Class Flexible Lithium-Ion Battery Endowed by
Laser-Drilled Flexible Integrated Graphite Film, ACS Appl. Mater. Interfaces, 2020, 9468-9477, DOI: 10.1021/ acsami.9b22358.

152 N. Yitzhack, M. Auinat, N. Sezin and Y. Ein-Eli, Carbon nanotube tissue as anode current collector for flexible Liion batteries - Understanding the controlling parameters influencing the electrochemical performance, APL Mater., 2018, 6, 111102, DOI: 10.1063/1.5052224.

153 F. U. Geo, X. He, Y. Hu, R. Chen, Z. Shen and K. Wu, Foldable Uniform $\mathrm{GeO}_{\mathrm{x}} / \mathrm{ZnO} / \mathrm{C}$ Composite Nanofibers as a High-capacity Anode Material for Flexible Lithium Ion Batteries, Chem. Eng. J., 2018, 1020-1029, DOI: 10.1016/ j.cej.2018.10.163.

154 Q. Zhao, J. Liu, X. Li, Z. Xia, Q. Zhang, M. Zhou, et al., Graphene oxide-induced synthesis of button-shaped amorphous $\mathrm{Fe}_{2} \mathrm{O}_{3} / \mathrm{rGO} / \mathrm{CNFs}$ films as flexible anode for high-performance lithium-ion batteries, Chem. Eng. J., 2019, 369, 215-222, DOI: 10.1016/j.cej.2019.03.076.

155 S. Li, Y. Zhao, Z. Liu, L. Yang, J. Zhang and M. Wang, Flexible Graphene-Wrapped Carbon Nanotube/ Graphene@ $\mathrm{MnO}_{2}$ 3D Multilevel Porous Film for HighPerformance Lithium-Ion Batteries, Small, 2018, 1801007, DOI: $10.1002 /$ smll.201801007.

156 Y. Liu, V. Khavrus, T. Lehmann, H. L. Yang, L. Stepien, M. Greifzu, et al., Boron-Doped Single-Walled Carbon Nanotubes with Enhanced Thermoelectric Power Factor for Flexible Thermoelectric Devices, ACS Appl. Energy Mater., 2020, 3, 2556-2564, DOI: 10.1021/acsaem.9b02243.

157 L. Liu, X. Zhang, F. Yan, B. Geng, C. Zhu and Y. Chen, Selfsupported N-doped CNT arrays for flexible Zn-air batteries, J. Mater. Chem. A, 2020, 8, 18162-18172, DOI: 10.1039/ d0ta05510g.

158 S. Yue, H. Tong, Z. Gao, W. Bai, L. Lu, J. Wang, et al., Fabrication of flexible nanoporous nitrogen-doped graphene film for high-performance supercapacitors, $J$. Solid State Electrochem., 2017, 21, 1653-1663, DOI: 10.1007/s10008-017-3538-y.

159 D. Selvakumar, A. Alsalme, A. Alswieleh and R. Jayavel, Freestanding flexible nitrogen doped-reduced graphene oxide film as an efficient electrode material for solid-state supercapacitors, J. Alloys Compd., 2017, 723, 995-1000, DOI: 10.1016/j.jallcom.2017.06.333.

160 Z. Cao, J. Zhang, Y. Ding, Y. Li, M. Shi, H. Yue, et al., In situ synthesis of flexible elastic N-doped carbon foam as a carbon current collector and interlayer for highperformance lithium sulfur batteries, J. Mater. Chem. A, 2016, 4, 8636-8644, DOI: 10.1039/c6ta01855f.

161 X. Zou, D. Wu, Y. Mu, L. Xing, W. Zhang, Z. Gao, et al., Boron and nitrogen Co-doped holey graphene aerogels with rich B-N motifs for flexible supercapacitors, Carbon, 2020, 159, 94-101, DOI: 10.1016/j.carbon.2019.12.018.

162 T. Guo, C. Li, Y. Wang, Y. Wang, J. Yue and X.-Z. Tang, A highly flexible and porous graphene-based hybrid film with superior, Appl. Phys. A, 2020, 126, 776, DOI: 10.1007/ s00339-020-03965-w.

163 Z. Xiong, C. Liao, W. Han and X. Wang, Mechanically Tough Large-Area Hierarchical Porous Graphene Films 
for High-Performance Flexible Supercapacitor Applications, Adv. Mater., 2015, 27, 4469-4475, DOI: 10.1002/adma.201501983.

164 Y. Liu, G. Li, Y. Guo, Y. Ying and X. Peng, Flexible and Binder-Free Hierarchical Porous Carbon Film for Supercapacitor Electrodes Derived from MOFs/CNT, ACS Appl. Mater. Interfaces, 2017, 9, 14043-14050, DOI: 10.1021/acsami.7b03368.

165 R. Ummethala, M. Fritzsche, T. Jaumann, J. Balach, S. Oswald, R. Nowak, et al., Lightweight, free-standing 3D interconnected carbon nanotube foam as a flexible sulfur host for high performance lithium-sulfur battery cathodes, Energy Storage Mater., 2018, 10, 206-215, DOI: 10.1016/j.ensm.2017.04.004.

166 M. H. Lee, Y. H. Kang, J. Kim, Y. K. Lee and S. Y. Cho, Freely Shapable and 3D Porous Carbon Nanotube Foam Using Rapid Solvent Evaporation Method for Flexible Thermoelectric Power Generators, Adv. Energy Mater., 2019, 9, 1-9, DOI: 10.1002/aenm.201900914.

167 Z. Yang, S. Chabi, Y. Xia and Y. Zhu, Preparation of 3D graphene-based architectures and their applications in supercapacitors, Prog. Nat. Sci.: Mater. Int., 2015, 25, 554562, DOI: 10.1016/j.pnsc.2015.11.010.

168 J. Ren, R. P. Ren and Y. K. Lv, A flexible 3D graphene@CNT@MoS $\mathrm{MoS}_{2}$ hybrid foam anode for highperformance lithium-ion battery, Chem. Eng. J., 2018, 353, 419-424, DOI: 10.1016/j.cej.2018.07.139.

169 J. Tan, Y. Han, L. He, Y. Dong, X. Xu, D. Liu, et al., In situ nitrogen-doped mesoporous carbon nanofibers as flexible freestanding electrodes for high-performance supercapacitors, J. Mater. Chem. A, 2017, 5, 23620-23627, DOI: $10.1039 / \mathrm{c} 7 \mathrm{ta0} 024 \mathrm{a}$.

170 Y. Cheng, L. Huang, X. Xiao, B. Yao, L. Yuan, T. Li, et al., Flexible and cross-linked $\mathrm{N}$-doped carbon nanofiber network for high performance freestanding supercapacitor electrode, Nano Energy, 2015, 15, 66-74, DOI: 10.1016/j.nanoen.2015.04.007.

171 X. Zhang, W. Lu, G. Zhou and Q. Li, Understanding the Mechanical and Conductive Properties of Carbon Nanotube Fibers for Smart Electronics, Adv. Mater., 2020, 32, 1-21, DOI: 10.1002/adma.201902028.

172 H. Cheng, C. Hu, Y. Zhao and L. Qu, Graphene fiber: A new material platform for unique applications, NPG Asia Mater., 2014, 6, e113-13, DOI: 10.1038/am.2014.48.

173 H. Cheng, Z. Dong, C. Hu, Y. Zhao, Y. Hu, L. Qu, et al., Textile electrodes woven by carbon nanotube-graphene hybrid fibers for flexible electrochemical capacitors, Nanoscale, 2013, 5, 3428-3434, DOI: 10.1039/c3nr00320e.

174 K. Liu, Y. Yao, T. Lv, H. Li, N. Li, Z. Chen, et al., Textile-like electrodes of seamless graphene/nanotubes for wearable and stretchable supercapacitors, J. Power Sources, 2020, 446, 227355, DOI: 10.1016/j.jpowsour.2019.227355.

175 Z. H. Jin, Y. L. Liu, J. J. Chen, S. L. Cai, J. Q. Xu and W. H. Huang, Conductive Polymer-Coated Carbon Nanotubes to Construct Stretchable and Transparent Electrochemical Sensors, Anal. Chem., 2017, 89, 20322038, DOI: 10.1021/acs.analchem.6b04616.
176 Y. Meng, L. Jin, B. Cai and Z. Wang, Facile fabrication of flexible core-shell graphene/conducting polymer microfibers for fibriform supercapacitors, RSC Adv., 2017, 7, 38187-38192, DOI: 10.1039/c7ra06641d.

177 B. Long, L. Luo, H. Yang, M. Balogun and S. Song, Promoting Alternative Flexible Substrate for Electrode Materials to Achieve Enhanced Lithium Storage Properties, ChemistrySelect, 2018, 3, 6965-6971, DOI: 10.1002/slct.201801000.

178 S. Song, S. W. Kim, D. J. Lee, Y. Lee, K. Man and C. Kim, Flexible Binder-Free Metal Fibril Mat-Supported Silicon Anode for High-Performance Lithium-Ion Batteries, ACS Appl. Mater. Interfaces, 2014, 11544-11549, DOI: 10.1021/ am502221f.

179 Y. Wu, X. Li, Q. Xiao, G. Lei, Z. Li and J. Guan, The coaxial $\mathrm{MnO}_{2} / \mathrm{CNTs}$ nanocomposite freestanding membrane on SSM substrate as anode materials in high performance lithium ion batteries, J. Electroanal. Chem., 2019, 834, 161-166, DOI: 10.1016/j.jelechem.2019.01.001.

180 L. Xue, S. V. Savilov and V. V. Lunin, Self-Standing Porous $\mathrm{LiCoO}_{2}$ Nanosheet Arrays as 3D Cathodes for Flexible LiIon Batteries, Adv. Funct. Mater., 2018, 1705836, DOI: 10.1002/adfm.201705836.

181 Y. Zhu, M. Yang, Q. Huang, D. Wang, R. Yu and J. Wang, $\mathrm{V}_{2} \mathrm{O}_{5}$ Textile Cathodes with High Capacity and Stability for Flexible Lithium-Ion Batteries, Adv. Mater., 2020, 1906205, DOI: 10.1002/adma.201906205.

182 Z. Yin, S. K. Song, S. Cho, D. You, J. Yoo and S. T. Chang, Curved copper nanowires-based robust flexible transparent electrodes via all-solution approach, Nano Res., 2017, 2, 1-15, DOI: 10.1007/s12274-017-1523-5.

183 Z. Yin, C. Lee, S. Cho, J. Yoo and Y. Piao, Facile Synthesis of Oxidation-Resistant Copper Nanowires toward SolutionProcessable, Flexible, Foldable, and Free-Standing Electrodes, Small, 2014, 1-6, DOI: 10.1002/smll.201401276.

184 R. Lin, S. Zhang, Z. Du, H. Fang, Y. Ren and X. Wu, Copper nanowires based current collector for light-weight and flexible composite silicon anode with high stability and specific capacity, $R S C A d v ., 2015$, 5, 87090-87097, DOI: 10.1039/C5RA13568K.

185 Z. Yin, S. Cho, D. You, Y. Ahn, J. Yoo and Y. S. Kim, Copper nanowire/multi-walled carbon nanotube composites as allnanowire flexible electrode for fast-charging/discharging lithium-ion battery, Nano Res., 2018, 11, 769-779.

186 W. C. Chang, T. L. Kao, Y. Lin and H. Y. Tuan, Flexible All Inorganic Nanowire Bilayer Mesh as a High-Performance Lithium-Ion Battery Anode, J. Mater. Chem. A, 2017, 5, 22662-22671, DOI: 10.1039/C7TA07472G.

$187 \mathrm{H}$. Choe and D. C. Dunand, Mechanical properties of oxidation-resistant Ni-Cr foams, Mater. Sci. Eng., A, 2004, 384, 184-193, DOI: 10.1016/j.msea.2004.06.045.

188 B. H. Shin and M. Liu, Three-Dimensional Porous CopperTin Alloy Electrodes for Rechargeable Lithium Batteries, Adv. Funct. Mater., 2005, 582-586, DOI: 10.1002/ adfm.200305165.

189 B. Liao, Z. H. Zhong, P. Lu, M. P. Wang, P. Li and Y. C. Wu, Mechanical Behavior and Deformation Mechanism of 
Commercial Pure Titanium Foils, Mater. Sci. Eng., A, 2017, 435-442, DOI: 10.1016/j.msea.2017.09.080.

190 M. Yao, K. Okuno, T. Iwaki, T. Awazu and T. Sakai, Long cycle-life $\mathrm{LiFePO}_{4} / \mathrm{Cu}$-Sn lithium ion battery using foamtype three-dimensional current collector, J. Power Sources, 2010, 195, 2077-2081, DOI: 10.1016/ j.jpowsour.2009.10.014.

191 K. Y. Song and S. K. Joo, High electrochemical performance bendable $\mathrm{Li}$ secondary batteries based on a threedimensional metal foam-type current collector, Mater. Res. Bull., 2017, 94, 328-334, DOI: 10.1016/ j.materresbull.2017.06.026.

192 X. Wang, B. Liu, X. Hou, Q. Wang, W. Li and D. Chen, Ultralong-life and high-rate web-like $\mathrm{Li}_{4} \mathrm{Ti}_{5} \mathrm{O}_{12}$ anode for high-performance flexible lithium-ion batteries, Nano Res., 2014, 7, 1073-1082, DOI: 10.1007/s12274-014-0470-7.

193 Z. Zhang, M. Zhang, P. Lu, Q. Chen and H. Wang, CuO nanorods growth on folded $\mathrm{Cu}$ foil as integrated electrodes with high areal capacity for flexible Li-ion batteries, J. Alloys Compd., 2019, 809, 151823, DOI: 10.1016/j.jallcom.2019.151823.

194 S. Zhang, G. Chen, T. Qu, G. Fang, S. Bai, Y. Yan, et al., Simultaneously enhancing mechanical properties and electrical conductivity of aluminum by using graphene as the reinforcement, Mater. Lett., 2020, 265, 127440, DOI: 10.1016/j.matlet.2020.127440.

195 S. Y. Kim, Y. Il Song, J. H. Wee, C. H. Kim, B. W. Ahn, J. W. Lee, et al., Few-layer graphene coated current collector for safe and powerful lithium ion battery, Carbon, 2019, 153, 495-503, DOI: 10.1016/ j.carbon.2019.07.032.

196 C. Salvo, R. V. Mangalaraja, R. Udayabashkar, M. Lopez and C. Aguilar, Enhanced mechanical and electrical properties of novel graphene reinforced copper matrix composites, $J$. Alloys Compd., 2019, 777, 309-316, DOI: 10.1016/ j.jallcom.2018.10.357.

197 K. Z. Milowska, M. Burda, L. Wolanicka, P. D. Bristowe and K. K. K. Koziol, Carbon nanotube functionalization as a route to enhancing the electrical and mechanical properties of Cu-CNT composites, Nanoscale, 2019, 11, 145-157, DOI: 10.1039/c8nr07521b.

198 W. Choi, High Capacity and Excellent Stability of Multiwall Carbon Nanotubes Grown on Interface-Controlled BinderFree Lithium Ion Battery Anode Using Copper, ACS Nano, 2010, 4, 3440-3446.

199 K. Wang, Y. Wu, H. Wu, Y. Luo, D. Wang, K. Jiang, et al., Super-aligned carbon nanotube films with a thin metal coating as highly conductive and ultralight current collectors for lithium-ion batteries, J. Power Sources, 2017, 351, 160-168, DOI: 10.1016/j.jpowsour.2017.03.081.

200 D. Lepage, L. Savignac, M. Saulnier, S. Gervais and S. B. Schougaard, Modification of aluminum current collectors with a conductive polymer for application in lithium batteries, Electrochem. Commun., 2019, 102, 1-4, DOI: 10.1016/j.elecom.2019.03.009.

201 Y. Zhao, Z. Wu, F. Di Carlo, H. Li, B. Qian, Z. Feng, et al., Enhancing the electrical and mechanical properties of copper by introducing nanocarbon derived from polydopamine coating, J. Alloys Compd., 2019, 778, 288293, DOI: 10.1016/j.jallcom.2018.11.145.

202 S. W. Kang, H. M. Xie, W. Zhang, J. P. Zhang, Z. Ma and R. S. Wang, Improve the Overall Performances of Lithium Ion Batteries by a Facile Method of Modifying the Surface of $\mathrm{Cu}$ Current Collector with Carbon, Electrochim. Acta, 2015, 604-609, 176, DOI: 10.1016/j.electacta.2015.06.107.

203 J. Wu, Z. Zhu, H. Zhang, H. Fu, H. Li, A. Wang, et al., Improved electrochemical performance of the Silicon/ Graphite-Tin composite anode material by modifying the surface morphology of the $\mathrm{Cu}$ current collector, Electrochim. Acta, 2014, 146, 322-327, DOI: 10.1016/ j.electacta.2014.09.075.

204 M. Park, M. Noh, S. Lee, M. Ko, S. Chae and S. Sim, Flexible High-Energy Li-Ion Batteries with Fast-Charging Capability, Nano Lett., 2014, 4083-4089, DOI: 10.1021/nl501597s.

205 Y. Yue and H. Liang, 3D Current Collectors for Lithium-Ion Batteries: A Topical Review, Small Methods, 2018, 2, 1800056, DOI: 10.1002/smtd.201800056.

206 X. Chen, G. Xu, G. Zeng, H. Gu and H. Chen, Realizing Ultrahigh Mechanical Flexibility and $>15 \%$ Efficiency of Flexible Organic Solar Cells via a "Welding" Flexible Transparent Electrode, Adv. Mater., 2020, 1908478, DOI: 10.1002/adma.201908478.

207 C. Iwakura, Y. Fukumoto, H. Inoue, S. Ohashi, S. Kobayashi, H. Tada, et al., Electrochemical characterization of various metal foils as a current collector of positive electrode for rechargeable lithium batteries, J. Power Sources, 1997, 68, 301-303, DOI: 10.1016/S0378-7753(97)02538-X.

208 X. Zhang, B. Winget, M. Doeff, J. W. Evans and T. M. Devine, Corrosion of Aluminum Current Collectors in Lithium-Ion Batteries with Electrolytes Containing LiPF $_{6}$, J. Electrochem. Soc., 2005, 152, B448, DOI: 10.1149/ 1.2041867.

209 S. Dai, J. Chen, Y. Ren, Z. Liu, J. Chen, C. Li, et al., Electrochemical corrosion behavior of the copper current collector in the electrolyte of lithium-ion batteries, Int. J. Electrochem. Sci., 2017, 12, 10589-10598, DOI: 10.20964/ 2017.11.28.

210 H. Nara, D. Mukoyama, R. Shimizu, T. Momma and T. Osaka, Systematic analysis of interfacial resistance between the cathode layer and the current collector in lithium-ion batteries by electrochemical impedance spectroscopy, J. Power Sources, 2019, 409, 139-147, DOI: 10.1016/j.jpowsour.2018.09.014.

211 S. T. Myung, Y. Hitoshi and Y. K. Sun, Electrochemical behavior and passivation of current collectors in lithiumion batteries, J. Mater. Chem., 2011, 21, 9891-9911, DOI: 10.1039/c0jm04353b.

212 S. T. Myung, Y. Sasaki, S. Sakurada, Y. K. Sun and H. Yashiro, Electrochemical behavior of current collectors for lithium batteries in non-aqueous alkyl carbonate solution and surface analysis by ToF-SIMS, Electrochim. Acta, 2009, 55, 288-297, DOI: 10.1016/ j.electacta.2009.08.051. 
213 H. Li, Z. Tang, Z. Liu and C. Zhi, Evaluating Flexibility and Wearability of Flexible Energy Storage Devices, Joule, 2019, 3, 613-619, DOI: 10.1016/j.joule.2019.01.013.

214 J. Park, M. Park, G. Nam, J. S. Lee and J. Cho, All-solid-state cable-type flexible zinc-air battery, Adv. Mater., 2015, 27, 1396-1401, DOI: 10.1002/adma.201404639.

215 Y. Fu, X. Cai, H. Wu, Z. Lv, S. Hou, M. Peng, et al., Fiber supercapacitors utilizing pen ink for flexible/wearable energy storage, Adv. Mater., 2012, 24, 5713-5718, DOI: 10.1002/adma.201202930.

216 M. Ohsawa and N. Hashimoto, Bending reliability of flexible transparent electrode of gravure offset printed invisible silver-grid laminated with conductive polymer, Microelectron. Reliab., 2019, 98, 124-130, DOI: 10.1016/ j.microrel.2019.05.009.

217 H. Y. Jung, M. B. Karimi, M. G. Hahm, P. M. Ajayan and Y. J. Jung, Transparent, flexible supercapacitors from nano-engineered carbon films, Sci. Rep., 2012, 1-5, DOI: 10.1038/srep00773.

218 T. G. Yun, B. Hwang, D. Kim, S. Hyun, S. Min and J. Han, Polypyrrole, $\mathrm{MnO}_{2}$ Coated Textile Based FlexibleStretchable Supercapacitor with High Electrochemical and Mechanical Reliability, ACS Appl. Mater. Interfaces, 2015, 9228-9234, DOI: 10.1021/acsami.5b01745.
219 S. Grego and D. Temple, Development and evaluation of bend-testing techniques for flexible-display applications, J. Soc. Inf. Disp., 2005, 575-581, DOI: 10.1889/1.2001215.

220 L. Mao, Q. Meng, A. Ahmad and Z. Wei, Mechanical Analyses and Structural Design Requirements for Flexible Energy Storage Devices, Adv. Energy Mater., 2017, 1700535, DOI: 10.1002/aenm.201700535.

221 H. Wu, Q. Meng, Q. Yang, M. Zhang, K. Lu and Z. Wei, Large-Area Polyimide/SWCNT Nanocable Cathode for Flexible Lithium-Ion Batteries, Adv. Mater., 2015, 27, 6504-6510, DOI: 10.1002/adma.201502241.

222 M. Koo, K. I. Park, S. H. Lee, M. Suh, D. Y. Jeon, J. W. Choi, et al., Bendable inorganic thin-film battery for fully flexible electronic systems, Nano Lett., 2012, 12, 4810-4816, DOI: $10.1021 / \mathrm{nl} 302254 \mathrm{v}$.

223 W. D. Callister, Materials science and engineering: An introduction (2nd edition), Mater. Des., 1991, 12, 59, DOI: 10.1016/0261-3069(91)90101-9.

224 S. Xin, Y. G. Guo and L. J. Wan, Nanocarbon networks for advanced rechargeable lithium batteries, Acc. Chem. Res., 2012, 45, 1759-1769, DOI: 10.1021/ar300094m.

225 X. Wu, F. Kang, W. Duan and J. Li, Density functional theory calculations: A powerful tool to simulate and design high-performance energy storage and conversion materials, Prog. Nat. Sci.: Mater. Int., 2019, 29, 247-255, DOI: 10.1016/j.pnsc.2019.04.003. 